\title{
Use of Diagnosis Codes to Find Blood Transfusion Adverse Events in Electronic Health Records
}

\author{
Roselie A. Bright ${ }^{1}$; Susan J. Bright-Ponte ${ }^{2}$; Lee Anne Palmer ${ }^{2}$; Summer K. Rankin ${ }^{3}$; Sergey Blok ${ }^{3}$ \\ ${ }^{1}$ Office of the Commissioner, Food and Drug Administration (FDA), Silver Spring, MD, USA. \\ Corresponding author: Roselie.Bright@fda.hhs.gov, 240-429-3972. \\ ${ }^{2}$ Center for Veterinary Medicine, FDA, Rockville, MD, USA \\ ${ }^{3}$ Booz Allen Hamilton, McLean, VA, USA
}

\section{ABSTRACT}

Background: Electronic health records (EHRs) and big data tools offer the opportunity for surveillance of adverse events (patient harm associated with medical care). We chose the case of transfusion adverse events (TAEs) and potential TAEs (PTAEs) because 1.) real dates were obscured in the study data, and 2.) there was emerging recognition of new types during the study data period.

Objective: We aimed to use the structured data in electronic health records (EHRs) to find TAEs and PTAEs among adults.

Methods: We used 49,331 adult admissions involving critical care at a major teaching hospital, 20012012, in the MIMIC-III EHRs database. We formed a T (defined as packed red blood cells, platelets, or plasma) group of 21,443 admissions vs. 25,468 comparison (C) admissions. The ICD-9-CM diagnosis codes were compared for T vs. C, described, and tested with statistical tools.

Results: TAEs such as transfusion associated circulatory overload (TACO; 12 T cases; rate ratio (RR) 15.61; 95\% Cl 2.49 to 98) were found. There were also PTAEs similar to TAEs, such as fluid overload disorder (361 T admissions; RR 2.24; $95 \% \mathrm{Cl} 1.88$ to 2.65), similar to TACO. Some diagnoses could have been sequelae of TAEs, including nontraumatic compartment syndrome of abdomen (52 T cases; RR 6.76; $95 \% \mathrm{Cl} 3.40$ to 14.9 ) possibly being a consequence of TACO.

Conclusions: Surveillance for diagnosis codes that could be TAE sequelae or unrecognized TAE might be useful supplements to existing medical product adverse event programs.

\section{KEYWORDS}

Electronic health records; big data; patient harm; patient safety; public health; product surveillance, postmarketing; diagnosis codes; proof of concept study; critical care; blood transfusion; humans

\section{ACKNOWLEDGEMENTS}

We thank enthusiastic support by our FDA and Booz Allen Hamilton supervisors, Department of Health and Human Services innovation programs (Ignite Accelerator and Data Science CoLab), and Alistair Johnson, DPhil, of the MIMIC-III program, Massachusetts Institute of Technology. George Plopper, PhD, Booz Allen Hamilton, provided project and consultation support. Many FDA colleagues offered ideas and feedback regarding the selection of the case of blood transfusion and the final paper. All authors had access to the data. Drs. Bright, Bright-Ponte, and Palmer are responsible for the study topic, design, and 
medRxiv preprint doi: https://doi.org/10.1101/2020.12.30.20218610; this version posted January 4, 2021. The copyright holder for this preprint (which was not certified by peer review) is the author/funder, who has granted medRxiv a license to display the preprint in perpetuity.

This article is a US Government work. It is not subject to copyright under 17 USC 105 and is also made available for use under a CCO license.

interpretation. Drs. Rankin and Bright formed the study groups. Drs. Bright and Blok are responsible for data analysis.

Financial support: The research was done with FDA support and under contract HHSF223201510027B between FDA and Booz Allen Hamilton Inc.

Conflicts of interest: None of the authors have other relevant financial interests.

Disclaimer: The opinions are those of the authors and do not represent official policy of either the FDA or Booz Allen Hamilton.

\section{ABBREVIATIONS USED MORE THAN ONCE}

95\% LCL: $\quad$ normal approximate 95\% lower confidence limits

95\% UCL: $\quad$ normal approximate 95\% upper confidence limits

AE: $\quad$ adverse events

C: $\quad$ comparison group of admissions

EHRs: $\quad$ electronic health records

FDA: $\quad$ Food and Drug Administration

FET: $\quad$ Fisher's exact test

Gl: $\quad$ gastrointestinal

ICD9: International Statistical Classification of Diseases and Related Health Problems 9-CM

MIMIC-III: $\quad$ Medical Information Mart for Intensive Care III

NOS: $\quad$ Not otherwise specified

PTAE: $\quad$ potential transfusion adverse event

RD: $\quad$ rate difference

RR: $\quad$ rate ratio

T: $\quad$ group of transfusion admissions

TACO: $\quad$ transfusion associated circulatory overload

TAE: transfusion adverse event

TRALI: $\quad$ transfusion related acute lung injury 
medRxiv preprint doi: https://doi.org/10.1101/2020.12.30.20218610; this version posted January 4, 2021. The copyright holder for this preprint

(which was not certified by peer review) is the author/funder, who has granted medRxiv a license to display the preprint in perpetuity.

This article is a US Government work. It is not subject to copyright under 17 USC 105 and is also made available for use under a CCO license.

\section{INTRODUCTION}

FDA relies on spontaneous reports of patient harm (known as adverse events (AE)) from manufacturers, healthcare providers, and the general public to learn of AEs that may need regulatory action [1].

Published deficiencies of these reports [2-10] include varying representativeness of harm and problems. Now that electronic healthcare records (EHRs) are very common [11], we have an opportunity to leverage them as sources of AE information [4, 12-14].

Challenges to the automated use of diagnosis codes for surveillance include:

- ICD [International Classification of Diseases] codes may be "invalid, insensitive or non-specific" [15].

- EHRs are “...subject to access restrictions...” [2].

- “...[N]ot all events and outcomes are consistently captured ...” [13].

The most directly useful program would analyze EHRs $[1,6]$ in real time. The data available to us (critical care admissions) did not allow calendar time analyses, so we compared blood transfusion admissions (T) vs. comparison admissions $(C)$ because:

- An earlier version of the dataset showed a higher risk of near-term mortality for red blood cell transfusion patients, compared to non-transfused patients [16].

- During the time of the dataset, new transfusion AE (TAE) types, transfusion related acute lung injury (TRALI) and transfusion associated cardiac overload (TACO), were being recognized among transfusion experts and prompted new guidelines to reduce the use of blood transfusion [17].

- During the dataset time, far fewer reports were coming to FDA than would have been expected, considering the level of professional concern [18-20].

The focus of this study is on diagnosis codes in electronic health records (EHR) because it is a relatively available source of information in EHRs and are readily computable. Many studies have looked for predetermined unwelcome conditions; for example, emergency department visits due to opioid overdose [21], motor vehicle crash injury [22], and serious infections [23]. We studied the utility of this method in this setting so that we can compare the results to using another surveillance method with the same data.

The objective of this study was to observe the utility of diagnosis codes to find TAEs that could be further evaluated (outside this study's scope) with a formal analysis to demonstrate causality.

\section{METHODS}

We used EHRs for critical care admissions within an adult hospital, Beth Israel Deaconess Medical Center, Boston, MA. The Massachusetts Institute of Technology (MIT) worked with the hospital to process EHRs, including unstructured notes, from 2001 to 2012 into a privacy-protected dataset, Medical Information Mart for Intensive Care III (MIMIC-III) [24, 25], that is publicly available to those meeting human subjects research requirements. The research was designated not human subjects research by the FDA Institutional Review Board under Code of Federal Regulations Title 45 Part 46 [26]. 
medRxiv preprint doi: https://doi.org/10.1101/2020.12.30.20218610; this version posted January 4, 2021. The copyright holder for this preprint (which was not certified by peer review) is the author/funder, who has granted medRxiv a license to display the preprint in perpetuity. This article is a US Government work. It is not subject to copyright under 17 USC 105 and is also made available for use under a CCO license.

We removed admissions with patient age $<16$ years on the date of admission, as well as admissions without any notes, from the total of 58,976 admissions, resulting in 49,284 admissions.

The transfused group ( $\mathrm{T}$ ) of 21,443 admissions had at least one transfusion (red blood cells, platelets, or plasma) "input code" in the "Inputs" table or International Statistical Classification of Diseases and Related Health Problems (ICD) 9-CM Volume 3 procedure code in the "Procedures" table, listed in Appendix Table A1 (Codes for transfusion and exclusion groups). Among the remaining patients, we identified 2,373 admissions whose only indication of possible transfusion are the codes listed in Appendix Table A1 and excluded them from further study. The other 25,468 admissions formed the comparison (C) group.

We counted the numbers of admissions in T and C for all ICD9 diagnoses [27] that occurred at least as often in T as in C, using Python packages SciPy Stats [28] and Pandas [29]. Most of the codes were present in the MIMIC-III dictionary of ICD9 diagnosis codes. For those that were not, names were found on a public website and enclosed in brackets [30]. When the choice of appropriate code name was not clear, we examined the procedure codes for the relevant admissions, and if necessary, the discharge notes to adjudicate the correct name.

We manually reviewed the information that was available for admissions that received an explicit TAE code despite being assigned to $\mathrm{C}$.

For each diagnosis code we calculated the rate difference (RD), rate ratio (RR), their normal approximate $95 \%$ lower and upper confidence limits (95\% LCL and $95 \% \mathrm{UCL}$ ), and $p$ values [31]. When any of the rate numerators had a value of 5 or less, we calculated the Fishers Exact Test (FET) $p$ value with Python and then derived the confidence limits [32].

Highly related codes were presented adjacent to each other in Tables 2 through 9 and subtotaled. All 524 diagnoses in the Tables met one of the following criteria [33-86]:

- Known TAE

- Hypercoagulation, embolism, or anemia diagnosis

- $\mathrm{RR}>2$

- $\mathrm{RR}>1.5$ and actual (T minus C) counts over 100

- The FET $p$ value is $<0.05$ (calculated when either of the T or $C$ counts $<6$ )

TAE codes in our study were compared to TAE codes in published literature with a Fisher's Exact Test calculator [87].

Our presentation of exact $p$ values as low as " $<0.0001$ " allows the reader to calculate their own adjustment of alpha based on their clinical interpretation of the interdependence of the diagnosis codes. If all 524 presented diagnoses are completely dependent, the alpha level to use is 0.0000979 [88]. Specific adjusted alpha levels assuming complete dependence are given with the results in tables organized by TAE-oriented system: iatrogenic (Table 2), circulation (3), bleeding and anemia (4), immune, neoplasm, and infection (5), lungs and oral (6), fluids regulation (7), digestion and hormones (8), and connective, nervous and reproductive (9).

We used published studies of TAEs in Medicare data $[19,20,89,90]$ to calculate expected TAE rates in MIMIC-III.

\section{RESULTS}


medRxiv preprint doi: https://doi.org/10.1101/2020.12.30.20218610; this version posted January 4, 2021. The copyright holder for this preprint (which was not certified by peer review) is the author/funder, who has granted medRxiv a license to display the preprint in perpetuity. This article is a US Government work. It is not subject to copyright under 17 USC 105 and is also made available for use under a CCO license.

Table 1 shows the explanations for all admissions that were assigned to the $C$ group and had an explicit TAE diagnosis code. For six of the twelve admissions, the notes say transfusion occurred. For four, the notes say there was transfusion just before admission to the hospital or CCU. For the remaining two, there was no mention of transfusion in the notes, so the TAE diagnosis codes were not explained.

The remaining tables have 524 diagnosis codes. The following TAE codes were found in the T group:

- ICD9 code 27661, Transfusion associated circulatory overload, in Table 7

- ICD9 code 27951, Acute graft-versus-host disease, in Table 5, which could apply to transplants or transfusion, in Table 5

- ICD9 code 78066, Febrile nonhemolytic transfusion reaction, in Table 5

- ICD9 code 9998, Other and unspecified transfusion reaction not elsewhere classified, in Table 2

- ICD9 code 99989, Other transfusion reaction, in Table 2

Most of them were at least one of: predated admission (53), known reasons or associated with reasons to transfuse (315), known risk factors for TAE (12), sequelae of TAE (120), clinically very similar to known TAE (120), or known TAE (13).

For two explicit TAE codes, codes for similar conditions were also statistically significantly more common in $\mathrm{T}$.

- For febrile nonhemolytic transfusion reaction in Table 5, 78061 (Fever presenting with conditions classified elsewhere) was also much more common in $\mathrm{T}$ than $\mathrm{C}$ and was assigned much more often (196 admissions vs 3).

- For transfusion associated circulatory overload in Table 7, 2766 (fluid overload disorder) was also much more common in $T$ than $C$ and was assigned much more often (571 admissions vs 13 ).

There were codes for conditions similar to TAE that were statistically significantly more common in T:

- Some of the hypercoagulation and emboli disorders in Table 3 and bleeding in Table 4 may have been alloimmune thrombocytopenic purpura [35].

- Some of the anemia diagnoses in Table 4 may have been hemolytic transfusion reactions [37, 40].

- Some of the infections in Table 5 may have been transmitted via transfusion 43, 75-79].

- Codes in Table 6 that might have signified TRALI [65] were:

- 5119 (Unspecified pleural effusion) [80]

- 5118 (Other specified forms of pleural effusion except tuberculous) [80]

- 9973 (Respiratory complications not elsewhere classified) $[49,72]$

- If transfusion was associated with the trauma or surgery [72]

- 5185 (Pulmonary insufficiency following trauma and surgery)

- 51851 (Acute respiratory failure following trauma and surgery)

- 51852 (Other pulmonary insufficiency, not elsewhere classified, following trauma and surgery)

Many other codes may have been consequences of TAE, for example:

- Kidney injury $[44,70]$ in Table 7 , such as:

- 5845 (Acute kidney failure with lesion of tubular necrosis)

- 5848 (Acute kidney failure with other specified pathological lesion in kidney)

- Esophagus injury or gastritis in Table 8 possibly due to intubation, such as:

○ 53010 (Esophagitis, unspecified) [43, 49, 86]

○ 53540 (Other specified gastritis, without mention of hemorrhage) [43]

"Use of Diagnosis Codes for Blood Transfusion Adverse Events in Electronic Health Records" page 5 of 64 
medRxiv preprint doi: https://doi.org/10.1101/2020.12.30.20218610; this version posted January 4, 2021. The copyright holder for this preprint

(which was not certified by peer review) is the author/funder, who has granted medRxiv a license to display the preprint in perpetuity.

This article is a US Government work. It is not subject to copyright under 17 USC 105 and is also made available for use under a CCO license.

- Pressure ulcer [81] due to extended bed rest in Table 9:

○ 70703 (Pressure ulcer, lower back)

○ 70711 (Ulcer of thigh)

As one would expect, many of the diagnosis codes that were statistically significantly more common in $T$ than $\mathrm{C}$ were, or could have been indicators of, reasons to transfuse (including preexisting conditions:

- Loss of blood due to spontaneous reasons, trauma, or surgery [33-35, 37, 47, 48], in Table 4

- Malignant cancers [37, 43, 47, 48, 70] in Table 5

Some codes might have been preexisting conditions that raise the risk or severity of TR, for example:

- 28262 (Hb-SS disease with crisis) [65] in Table 4

- 2690 (Deficiency of vitamin K) [37] in Table 8

Some codes may represent both reasons to transfuse and consequences of transfusion, for example:

- Emboli and thrombi in Table 3 [76]

- Bleeding in Table $4[35,37,47,48]$

- Hemolytic anemia in Table 4 [37, 76]

There are many codes that we were not able to explain. Most were vague, while some were specific, for example:

- Benign neoplasms in Table 5

- 5933 (Stricture or kinking of ureter) in Table 7

- 73342 (Aseptic necrosis of head and neck of femur) in Table 9.

Many medical care AEs occur at higher frequency in hospital critical care [91, 92].

As would be expected, many diagnosis codes that were associated with transfusion were reasons to transfuse or predated the admission.

A relatively small number were explicit TAE codes. Some codes were for conditions that are the same as explicit TAE codes, but without the attribution and many of them may have been TAE. The strategy of looking for codes for conditions similar to each other has been used to analyze adverse event reports [93]. One interpretation of this phenomenon is knowledge that it is TAE but reluctance to code as such; another could be lack of awareness that the condition was a TAE, and a remaining possibility is that the potential TAE occurred before transfusion.

Our findings on two TAE codes were statistically significantly less than would have been expected from Medicare studies of the frequencies of TRALI and febrile non-haemolytic transfusion reaction (ICD9 code 78066) $[20,90]$ (see Table 10). Our results were not statistically significantly different for TACO and posttransfusion purpura (ICD9 code 28741) [19, 89].

Our results showed that allowing additional diagnoses that could indicate TAE could be useful for widening the net for detection of signals of TAEs.

Some diagnoses may have been consequent to TAEs.

A number of diagnoses were not explained.

Our investigation of TAE codes in $\mathrm{C}$ demonstrated that codes alone may not provide the full clinical picture that is in the notes. Other studies have reported that while codes can provide more information than AE reports [4], the codes themselves provide an incomplete picture [12]. Our main measures of RD 
medRxiv preprint doi: https://doi.org/10.1101/2020.12.30.20218610; this version posted January 4, 2021. The copyright holder for this preprint (which was not certified by peer review) is the author/funder, who has granted medRxiv a license to display the preprint in perpetuity. This article is a US Government work. It is not subject to copyright under 17 USC 105 and is also made available for use under a CCO license.

and RR could be underestimates of the risks of $T$ if the loss of information due to reliance on codes is evenly distributed across the data or otherwise biased.

The analysis of codes is merely to generate signals of AE. All signals require further investigation to assess causality because diagnosis codes generally do not provide the sequence of events before, and never during, hospitalization or assess competing explanations of the associations.

\section{CONCLUSIONS}

This study successfully demonstrated simple surveillance of patient harm by using diagnosis codes in a large healthcare database, as a supplement to current post-marketing surveillance methods. In routine practice, automation of the interpretation phase could point human monitors to the codes that warrant further investigation by clinical experts.

The limitations of full reliance on diagnosis codes motivate exploring automated methods of using the notes for surveillance of AEs.

We look forward to accessible methods for public health analysts to observe patterns in patient care and experience in real time, by detecting both anticipated and unanticipated signals in electronic health records that indicate potential safety concerns with medical care. Such a method could supplement existing safety surveillance methods. 
medRxiv preprint doi: https://doi.org/10.1101/2020.12.30.20218610; this version posted January 4, 2021. The copyright holder for this preprint (which was not certified by peer review) is the author/funder, who has granted medRxiv a license to display the preprint in perpetuity.

This article is a US Government work. It is not subject to copyright under 17 USC 105 and is also made available for use under a CCO license.

Table 1. Explanations for all admissions that were assigned to the comparison group and had an explicit transfusion adverse event (TAE) diagnosis code (International Statistical Classification of Diseases and Related Health Problems 9-CM). Bracketed diagnosis code names were not in the MIMICIII database, therefore were looked up [30] and confirmed in the notes.

\begin{tabular}{|c|c|c|}
\hline $\begin{array}{l}\text { ICD9 diagnosis code } \\
\text { and name }\end{array}$ & $\begin{array}{c}\# \\
\text { admissions }\end{array}$ & Explanation \\
\hline $\begin{array}{l}27661 \text { Transfusion } \\
\text { associated circulatory } \\
\text { overload }\end{array}$ & 1 & Notes indicate transfusion occurred. \\
\hline $\begin{array}{l}\text { [999.8 Other and } \\
\text { unspecified } \\
\text { transfusion reaction } \\
\text { not elsewhere } \\
\text { classified. } \\
999.80 \text { is Transfusion } \\
\text { reaction, unspecified.] }\end{array}$ & 7 & $\begin{array}{l}\text { - For } 4 \text { admissions, notes say transfusion occurred. } \\
\text { - For } 1 \text { admission, notes do not mention transfusion or } \\
\text { TAE. } \\
\text { - For } 1 \text { admission, notes mention transfusion just } \\
\text { before admission to this hospital. } \\
\text { - For } 1 \text { admission, notes say patient was transfused and } \\
\text { had transfusion related acute lung injury (TRALI); also } \\
\text { had diagnosis codes } 51881 \text { (Acute respiratory failure) } \\
\text { and } 5184 \text { (Acute lung edema NOS). }\end{array}$ \\
\hline $\begin{array}{l}99989 \text { Other } \\
\text { transfusion reaction }\end{array}$ & 4 & $\begin{array}{l}\text { - For } 2 \text { admissions, notes say patients were transfused } \\
\text { in the hospital but not critical care unit. } \\
\text { - For } 1 \text { admission, notes say patient was transfused } \\
\text { before hospitalization. } \\
\text { - For } 1 \text { admission, there was no mention of transfusion } \\
\text { in the notes. }\end{array}$ \\
\hline
\end{tabular}


medRxiv preprint doi: https://doi.org/10.1101/2020.12.30.20218610; this version posted January 4, 2021. The copyright holder for this preprint (which was not certified by peer review) is the author/funder, who has granted medRxiv a license to display the preprint in perpetuity.

This article is a US Government work. It is not subject to copyright under 17 USC 105 and is also made available for use under a CCO license.

Table 2. Analysis of $\mathrm{T}$ (transfusion) and C (comparison) groups for iatrogenic diagnosis codes. If all diagnoses in the table are dependent, alpha is 0.0057. Bracketed diagnosis code names were not in the MIMIC-III database, therefore were looked up [30] and confirmed in some notes.

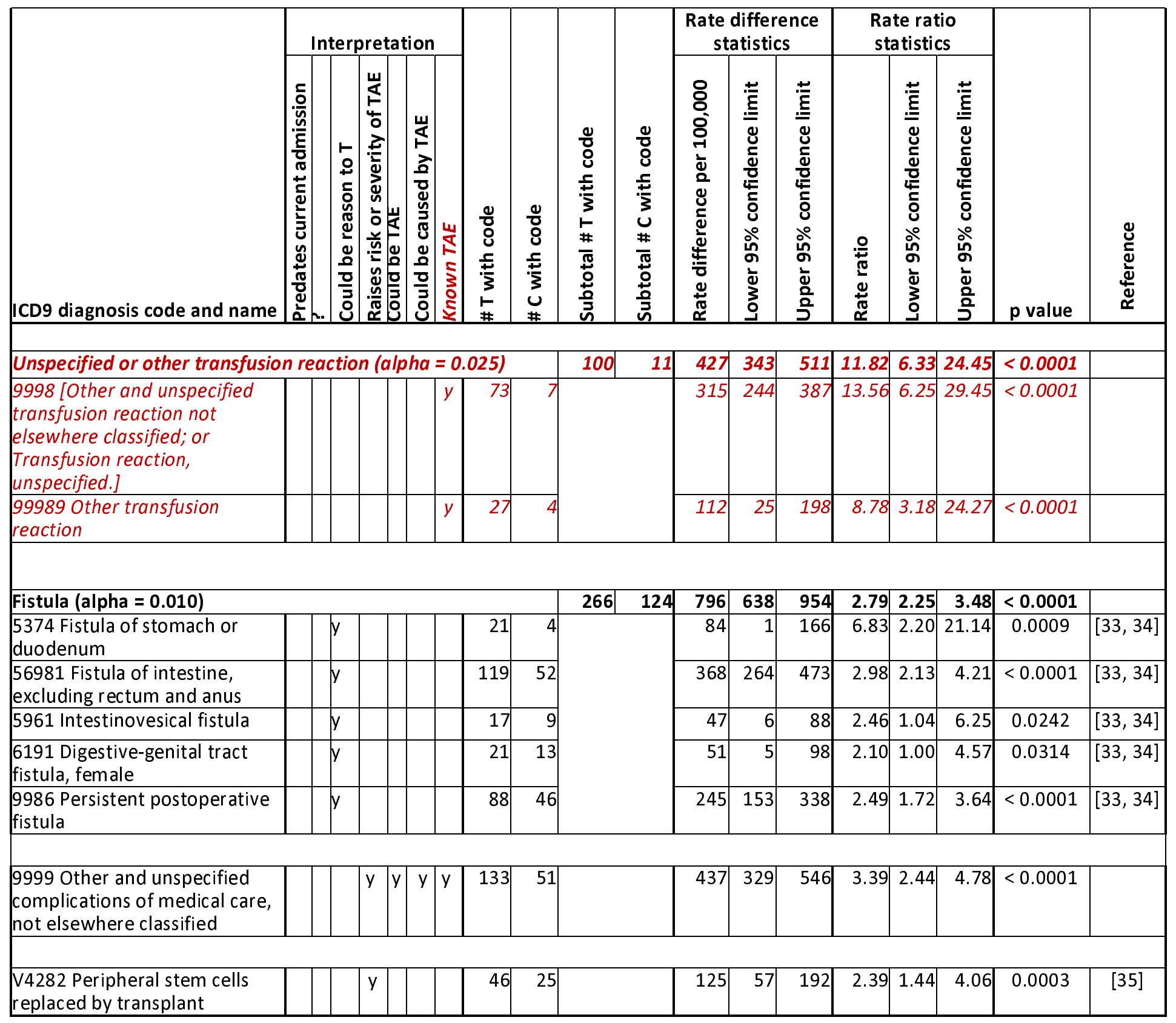


medRxiv preprint doi: https://doi.org/10.1101/2020.12.30.20218610; this version posted January 4, 2021. The copyright holder for this preprint (which was not certified by peer review) is the author/funder, who has granted medRxiv a license to display the preprint in perpetuity. This article is a US Government work. It is not subject to copyright under 17 USC 105 and is also made available for use under a CCO license.

Table 3. Analysis of $\mathrm{T}$ (transfusion) and $\mathrm{C}$ (comparison) groups for circulation diagnosis codes. If all diagnoses in the table are dependent, alpha is 0.00069 . Bracketed diagnosis code names were not in the MIMIC-III database, therefore were looked up [30] and confirmed in some notes.

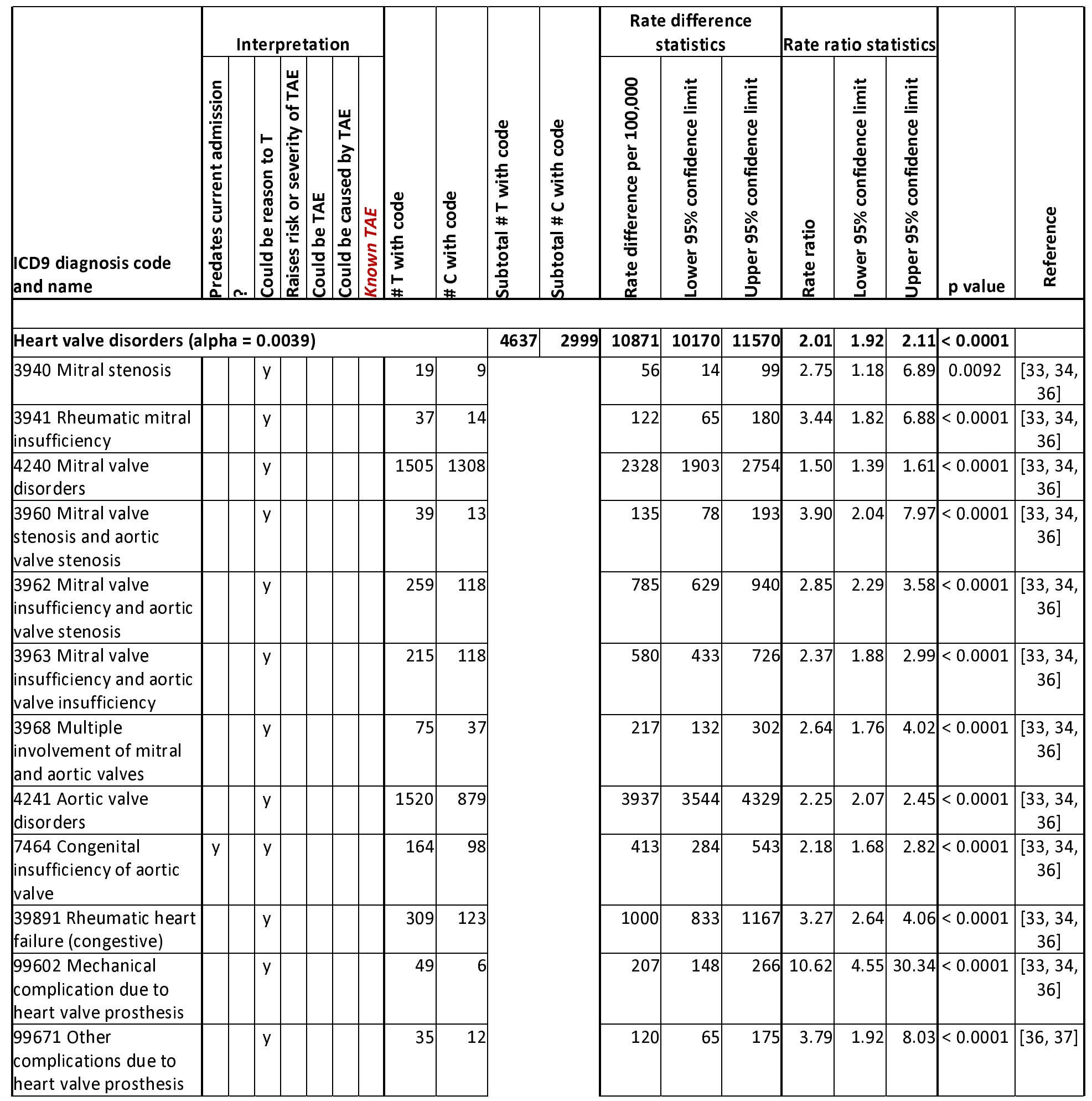


medRxiv preprint doi: https://doi.org/10.1101/2020.12.30.20218610; this version posted January 4, 2021. The copyright holder for this preprint (which was not certified by peer review) is the author/funder, who has granted medRxiv a license to display the preprint in perpetuity.

This article is a US Government work. It is not subject to copyright under 17 USC 105 and is also made available for use under a CCO license.

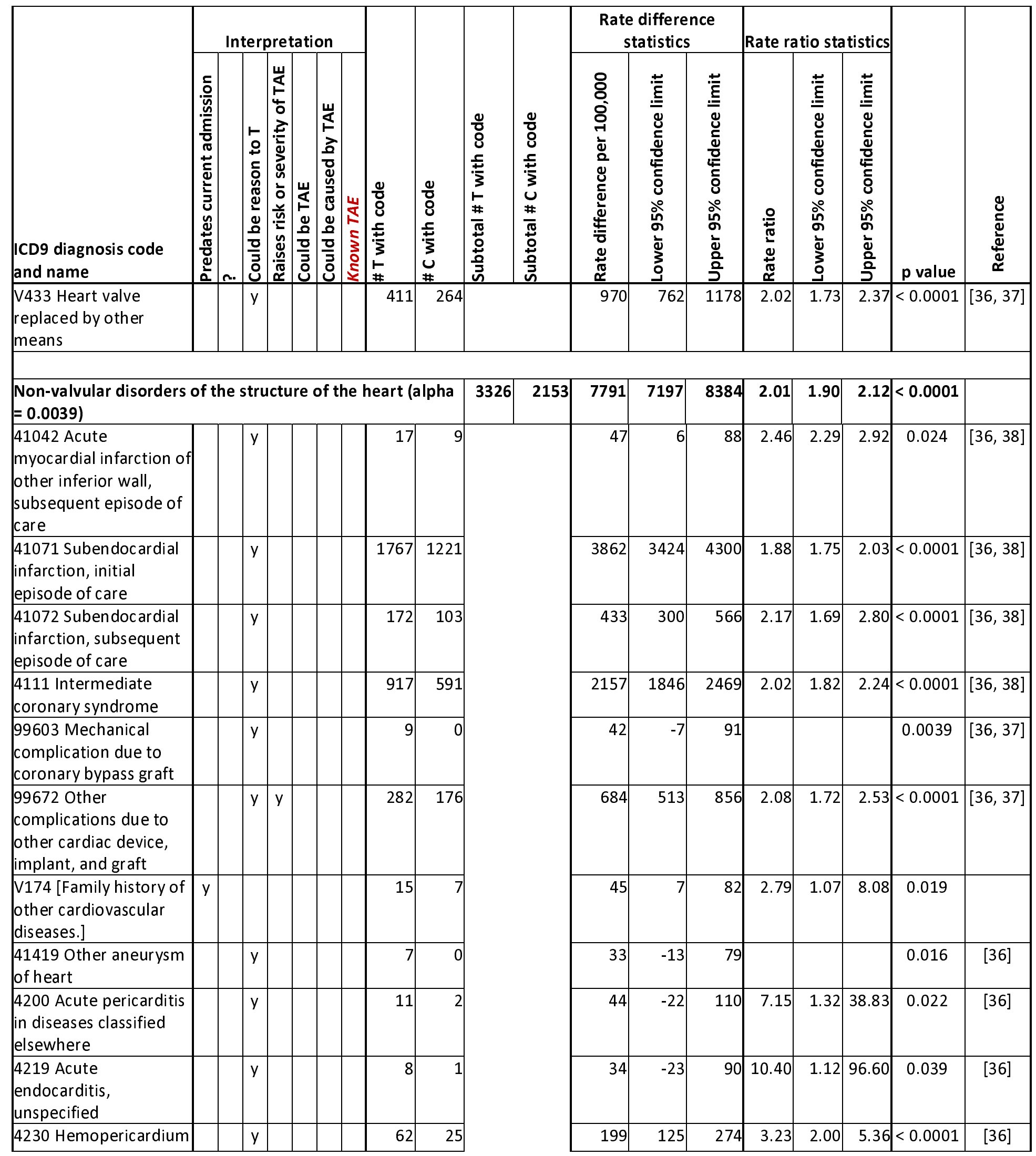


medRxiv preprint doi: https://doi.org/10.1101/2020.12.30.20218610; this version posted January 4, 2021. The copyright holder for this preprint (which was not certified by peer review) is the author/funder, who has granted medRxiv a license to display the preprint in perpetuity. This article is a US Government work. It is not subject to copyright under 17 USC 105 and is also made available for use under a CCO license.

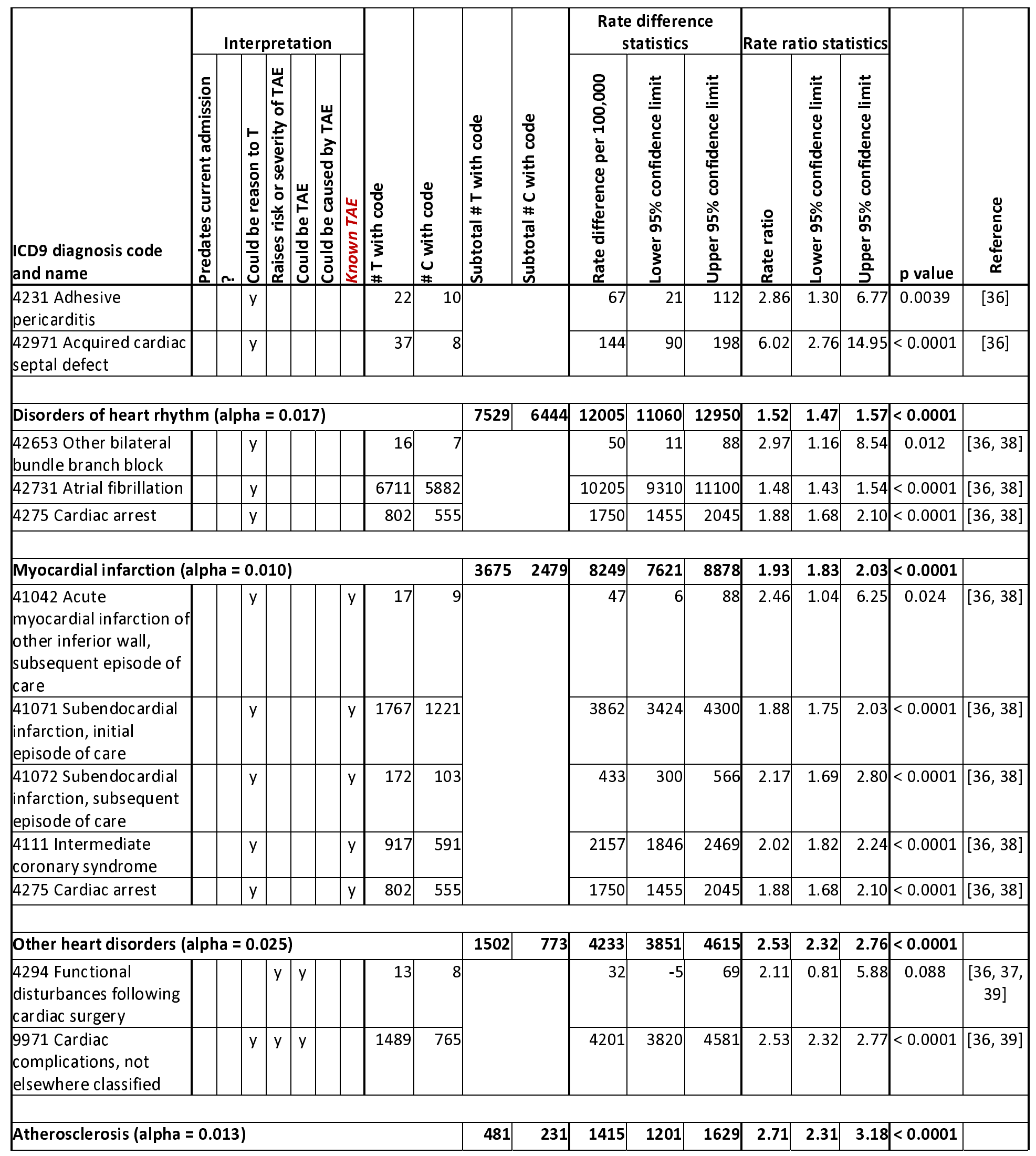


medRxiv preprint doi: https://doi.org/10.1101/2020.12.30.20218610; this version posted January 4, 2021. The copyright holder for this preprint (which was not certified by peer review) is the author/funder, who has granted medRxiv a license to display the preprint in perpetuity.

This article is a US Government work. It is not subject to copyright under 17 USC 105 and is also made available for use under a CCO license.

\begin{tabular}{|c|c|c|c|c|c|c|c|c|c|c|c|c|c|c|c|c|c|}
\hline \multirow[b]{2}{*}{$\begin{array}{l}\text { ICD9 diagnosis code } \\
\text { and name }\end{array}$} & \multicolumn{5}{|c|}{ Interpretation } & \multirow[b]{2}{*}{ 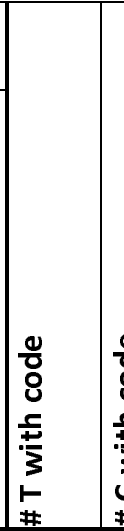 } & \multirow{2}{*}{\multicolumn{2}{|c|}{ 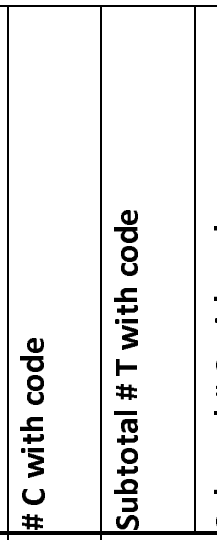 }} & \multirow[b]{2}{*}{ 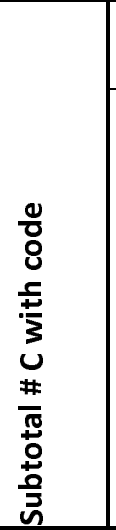 } & \multicolumn{3}{|c|}{$\begin{array}{l}\text { Rate difference } \\
\text { statistics }\end{array}$} & \multicolumn{3}{|c|}{ Rate ratio statistics } & \multirow[b]{2}{*}{$p$ value } & \multirow[b]{2}{*}{ 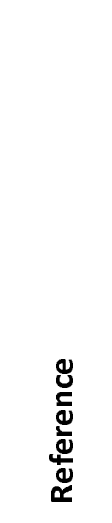 } \\
\hline & 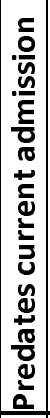 & 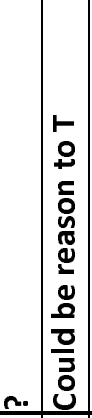 & 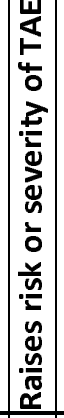 & 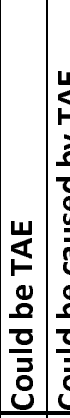 & 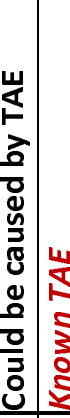 & & & & & 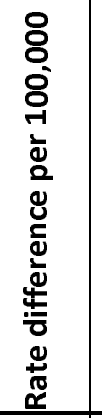 & 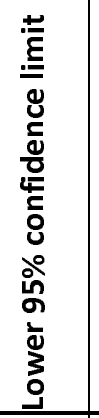 & 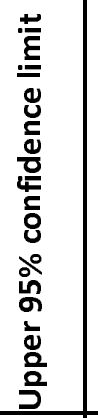 & 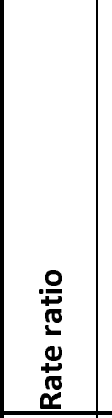 & 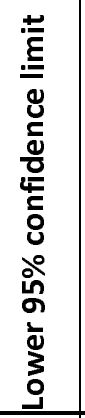 & 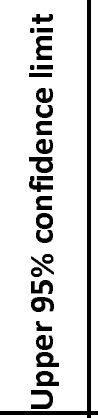 & & \\
\hline $\begin{array}{l}4400 \text { Atherosclerosis of } \\
\text { aorta }\end{array}$ & $\mathrm{y}$ & & & & & 180 & 96 & & & 495 & 362 & 628 & 2.44 & 1.89 & 3.16 & $<0.0001$ & [36] \\
\hline $\begin{array}{l}44024 \text { Atherosclerosis } \\
\text { of native arteries of the } \\
\text { extremities with } \\
\text { gangrene }\end{array}$ & y & & & & & 220 & 106 & & & 646 & 501 & 791 & 2.70 & 2.13 & 3.44 & $<0.0001$ & [36] \\
\hline $\begin{array}{l}44031 \text { Atherosclerosis } \\
\text { of autologous vein } \\
\text { bypass graft of the } \\
\text { extremities }\end{array}$ & $\mathrm{y}$ & & & & & 34 & 15 & & & 105 & 49 & 161 & 2.95 & 1.56 & 5.83 & 0.0003 & [36] \\
\hline $\begin{array}{l}4408 \text { Atherosclerosis of } \\
\text { other specified arteries }\end{array}$ & $\mathrm{y}$ & & & & & 47 & 14 & & & 169 & 106 & 232 & 4.37 & 2.36 & 8.59 & $<0.0001$ & [36] \\
\hline \multicolumn{8}{|c|}{ Weakened vascular wall (alpha $=0032)$} & 1805 & 848 & 5377 & 4964 & 5790 & 2.77 & 2.55 & 3.01 & $<0.0001$ & \\
\hline $\begin{array}{l}4412 \text { Thoracic } \\
\text { aneurysm without } \\
\text { mention of rupture }\end{array}$ & $y$ & $y$ & & & & 302 & 164 & & & 820 & 647 & 993 & 2.39 & 1.97 & 2.91 & $<0.0001$ & {$[36]$} \\
\hline $\begin{array}{l}4414 \text { Abdominal } \\
\text { aneurysm without } \\
\text { mention of rupture }\end{array}$ & $y$ & y & & & & 362 & 283 & & & 673 & 470 & 877 & 1.66 & 1.42 & 1.95 & $<0.0001$ & {$[36]$} \\
\hline $\begin{array}{l}4417 \\
\text { Thoracoabdominal } \\
\text { aneurysm, without } \\
\text { mention of rupture }\end{array}$ & $y$ & y & & & & 45 & 20 & & & 138 & 74 & 203 & 2.93 & 1.69 & 5.23 & $\mid<0.0001$ & {$[36]$} \\
\hline $\begin{array}{l}4420 \text { Aneurysm of } \\
\text { artery of upper } \\
\text { extremity }\end{array}$ & $y$ & y & & & & 8 & 1 & & & 34 & -23 & 90 & $\mid 10.40$ & 1.12 & 96.60 & 0.039 & {$[36]$} \\
\hline $\begin{array}{l}4422 \text { Aneurysm of iliac } \\
\text { artery }\end{array}$ & $y$ & $\mathrm{y}$ & & & & 51 & 28 & & & 137 & 66 & 209 & 2.37 & 1.47 & 3.90 & \begin{tabular}{|l|}
0.0002 \\
\end{tabular} & [36] \\
\hline $\begin{array}{l}4423 \text { Aneurysm of } \\
\text { artery of lower } \\
\text { extremity }\end{array}$ & $y$ & y & & & & 102 & 37 & & & 343 & 249 & 438 & 3.59 & 2.44 & 5.37 & $<0.0001$ & {$[36]$} \\
\hline $\begin{array}{l}44283 \text { Aneurysm of } \\
\text { splenic artery }\end{array}$ & $y$ & y & & & & 12 & 3 & & & 45 & -29 & 119 & 5.20 & 1.12 & 24.19 & 0.035 & [36] \\
\hline $\begin{array}{l}44284 \text { Aneurysm of } \\
\text { other visceral artery }\end{array}$ & y & $y$ & & & & 38 & 7 & & & 152 & 98 & 206 & 7.06 & 3.11 & 18.74 & $<0.0001$ & {$[36]$} \\
\hline $\begin{array}{l}4549 \text { Asymptomatic } \\
\text { varicose veins }\end{array}$ & & $\mathrm{y}$ & & & & 25 & 14 & & & 66 & 16 & 116 & 2.32 & 1.16 & 4.83 & 0.0093 & {$[40,41]$} \\
\hline
\end{tabular}


medRxiv preprint doi: https://doi.org/10.1101/2020.12.30.20218610; this version posted January 4, 2021. The copyright holder for this preprint (which was not certified by peer review) is the author/funder, who has granted medRxiv a license to display the preprint in perpetuity.

This article is a US Government work. It is not subject to copyright under 17 USC 105 and is also made available for use under a CCO license.

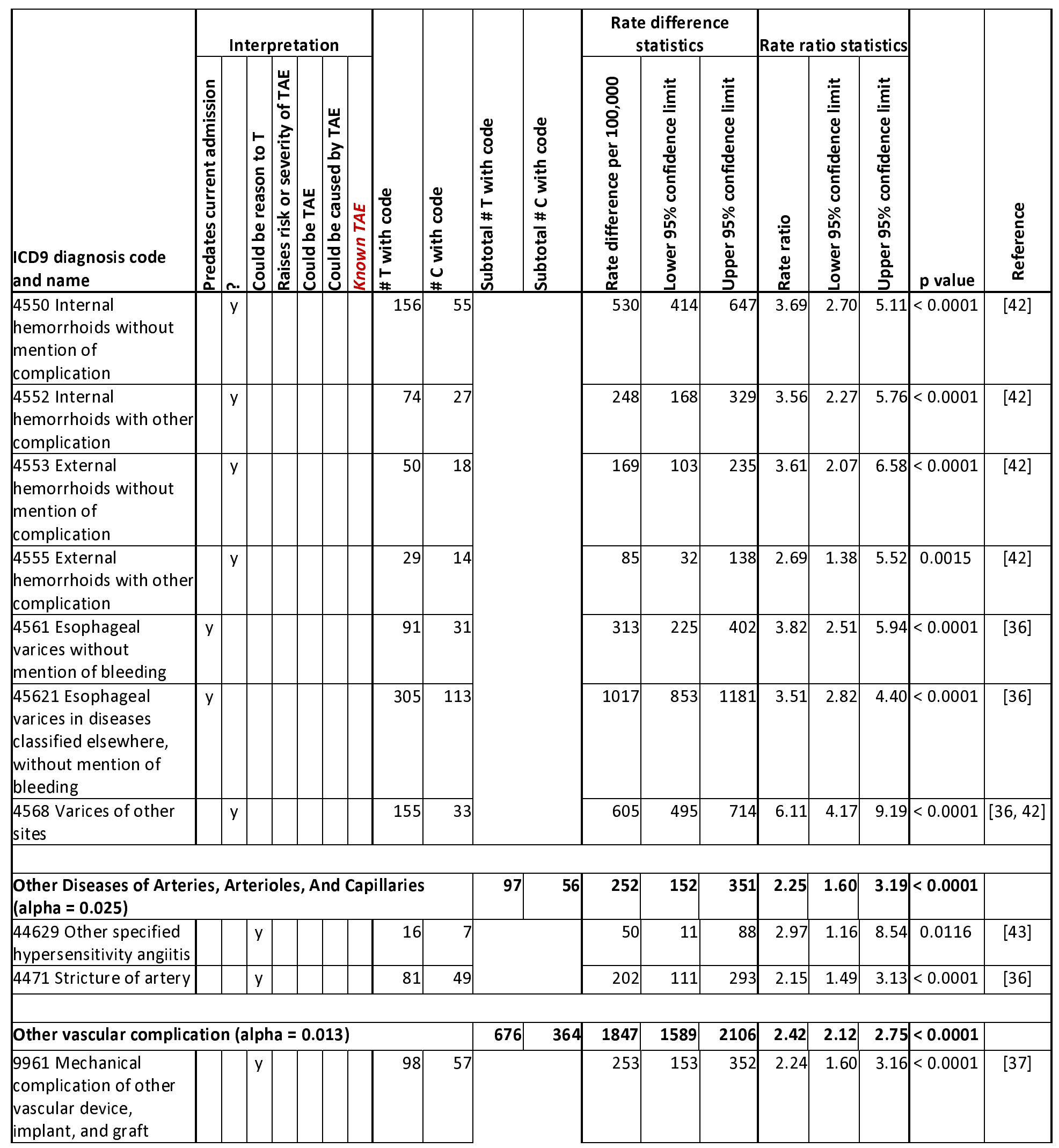


medRxiv preprint doi: https://doi.org/10.1101/2020.12.30.20218610; this version posted January 4, 2021. The copyright holder for this preprint (which was not certified by peer review) is the author/funder, who has granted medRxiv a license to display the preprint in perpetuity.

This article is a US Government work. It is not subject to copyright under 17 USC 105 and is also made available for use under a CCO license.

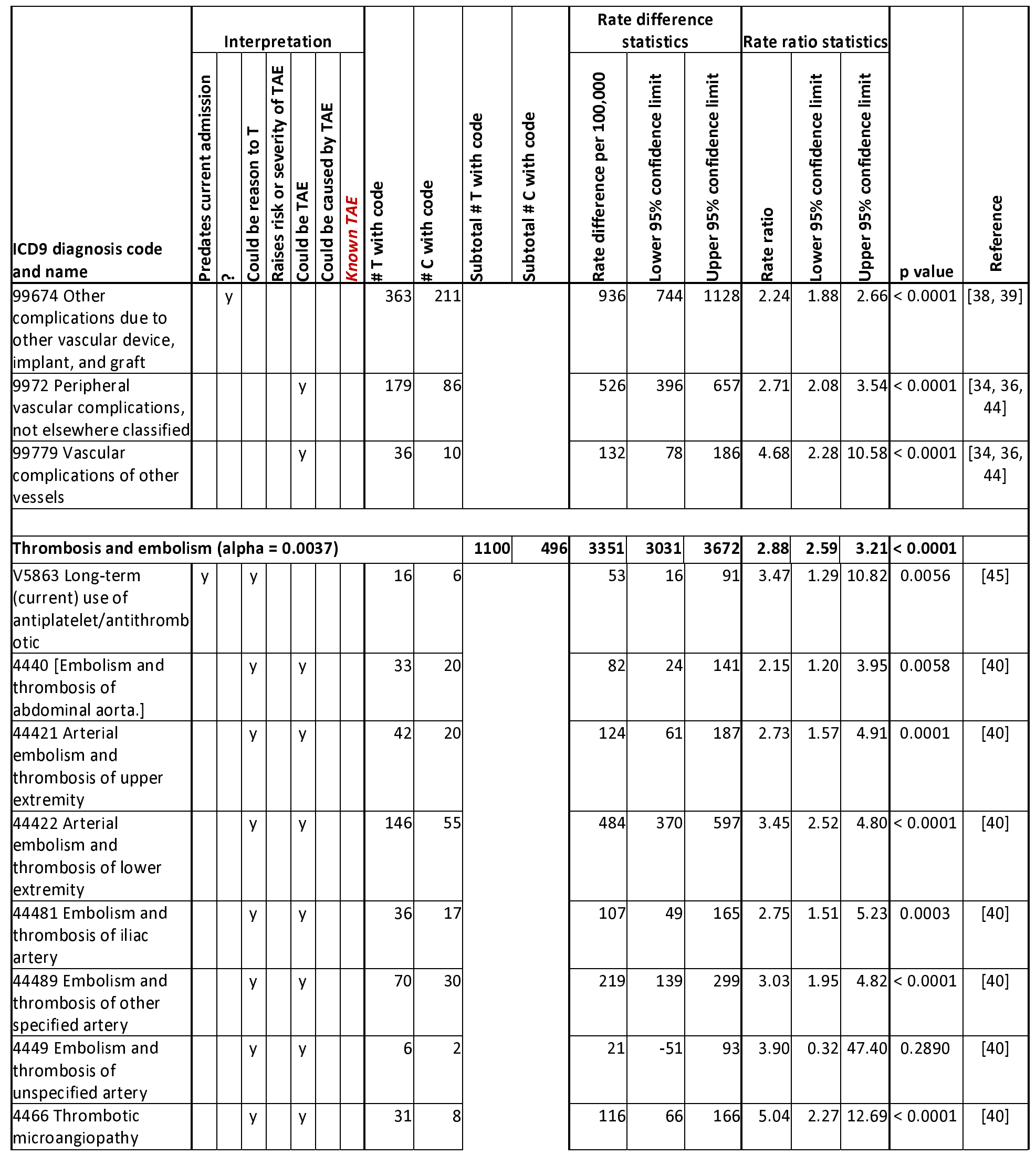


medRxiv preprint doi: https://doi.org/10.1101/2020.12.30.20218610; this version posted January 4, 2021. The copyright holder for this preprint (which was not certified by peer review) is the author/funder, who has granted medRxiv a license to display the preprint in perpetuity.

This article is a US Government work. It is not subject to copyright under 17 USC 105 and is also made available for use under a CCO license.

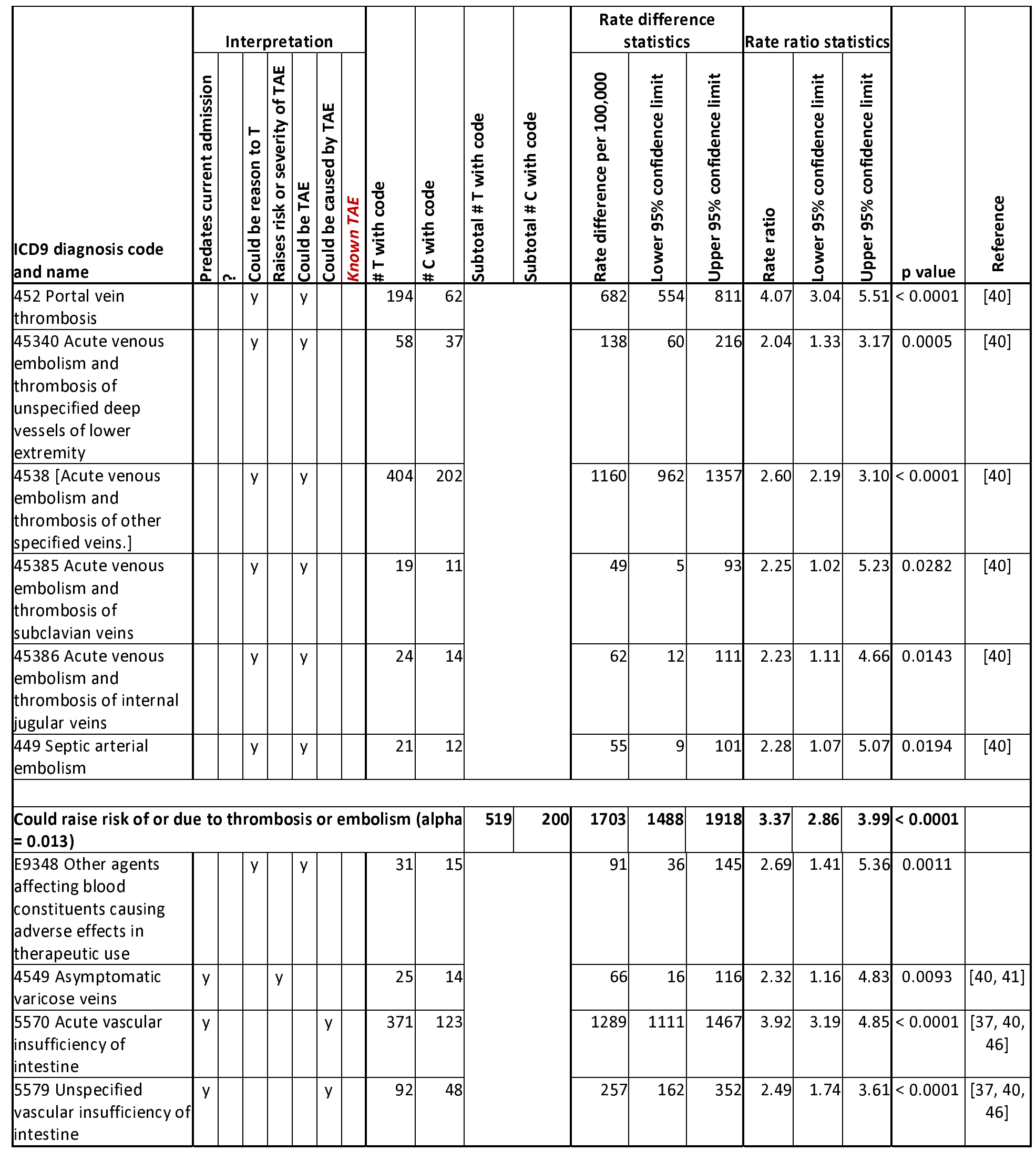


medRxiv preprint doi: https://doi.org/10.1101/2020.12.30.20218610; this version posted January 4, 2021. The copyright holder for this preprint (which was not certified by peer review) is the author/funder, who has granted medRxiv a license to display the preprint in perpetuity.

This article is a US Government work. It is not subject to copyright under 17 USC 105 and is also made available for use under a CCO license.

Table 4. Analysis of $\mathrm{T}$ (transfusion) and $\mathrm{C}$ (comparison) groups for bleeding and anemia diagnosis codes. If all diagnoses in the table are dependent, alpha is 0.00026. Bracketed diagnosis code names were not in the MIMIC-III database, therefore were looked up [30] and confirmed in some notes.

\begin{tabular}{|c|c|c|c|c|c|c|c|c|c|c|c|c|c|c|c|c|c|}
\hline \multirow[b]{2}{*}{$\begin{array}{l}\text { ICD9 diagnosis code and } \\
\text { name }\end{array}$} & \multicolumn{5}{|c|}{ Interpretation } & \multirow[b]{2}{*}{ 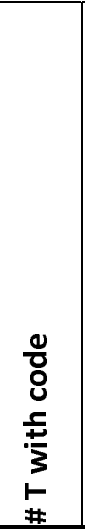 } & \multirow[b]{2}{*}{ 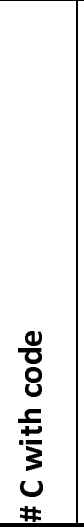 } & \multirow[b]{2}{*}{ 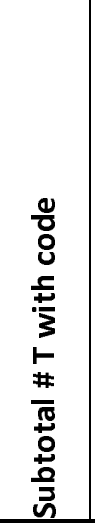 } & \multirow[b]{2}{*}{ 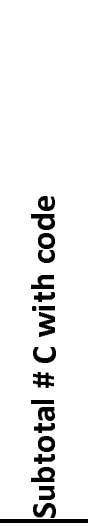 } & \multicolumn{3}{|c|}{$\begin{array}{l}\text { Rate difference } \\
\text { statistics }\end{array}$} & \multicolumn{3}{|c|}{ Rate ratio statistics } & \multirow[b]{2}{*}{$p$ value } & \multirow[b]{2}{*}{ 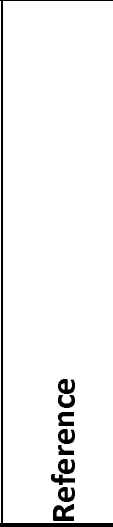 } \\
\hline & 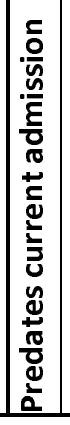 & 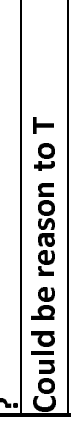 & 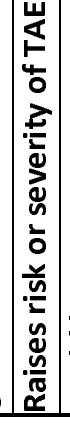 & 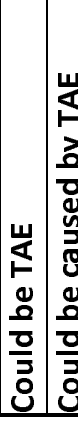 & 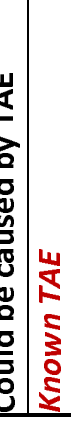 & & & & & 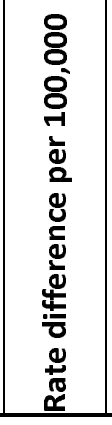 & 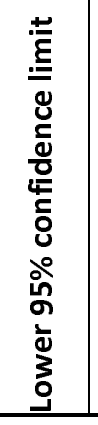 & 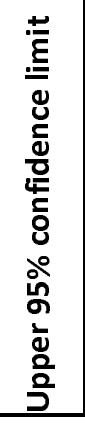 & 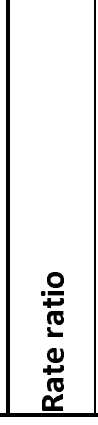 & 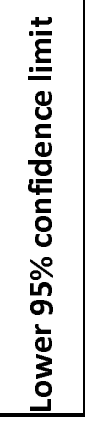 & 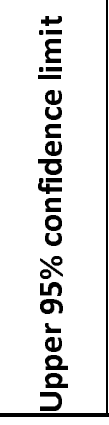 & & \\
\hline \multicolumn{8}{|c|}{$\begin{array}{l}\text { Bleeding or hemorrhage not for traumatic or injury or surgery } \\
\text { reasons (alpha }=0.00092 \text { ) }\end{array}$} & 6962 & 1941 & \multicolumn{3}{|c|}{$255072475026260 \mid$} & 4.66 & 4.44 & \multicolumn{2}{|c|}{$4.91 \mid<0.0001$} & \\
\hline $\begin{array}{l}7827 \text { Spontaneous } \\
\text { ecchymoses }\end{array}$ & & $y$ & & & & 15 & 8 & & & 41 & 3 & 80 & 2.44 & 0.97 & 6.64 & 0.035 & {$[37]$} \\
\hline 36281 Retinal hemorrhage & & $y$ & & & & 19 & 3 & & & 78 & 1 & 155 & 8.24 & 2.40 & 28.30 & 0.00 & [37] \\
\hline $\begin{array}{l}44101 \text { Dissection of aorta, } \\
\text { thoracic }\end{array}$ & & $y$ & & & & 151 & 77 & & & 428 & 307 & 549 & 2.55 & 1.93 & 3.40 & $<0.0001$ & {$\left[\begin{array}{c}33,34 \\
37]\end{array}\right.$} \\
\hline $\begin{array}{l}4411 \text { Thoracic aneurysm, } \\
\text { ruptured }\end{array}$ & & y & & & & 20 & 6 & & & 72 & 31 & 113 & 4.34 & 1.68 & 13.19 & 0.0006 & {$\left[\begin{array}{c}33,34 \\
37]\end{array}\right.$} \\
\hline $\begin{array}{l}4413 \text { Abdominal aneurysm, } \\
\text { ruptured }\end{array}$ & & $\mathrm{y}$ & & & & 67 & 9 & & & 280 & 210 & 350 & 9.68 & 4.81 & 22.09 & $<0.0001$ & {$\left[\begin{array}{c}{[33,34} \\
37]\end{array}\right.$} \\
\hline $\begin{array}{l}44322 \text { Dissection of iliac } \\
\text { artery }\end{array}$ & & y & & & & 23 & 7 & & & 82 & 38 & 126 & 4.27 & 1.78 & 11.79 & 0.0002 & {$\left[\begin{array}{c}33,34 \\
37]\end{array}\right.$} \\
\hline $\begin{array}{l}44329 \text { Dissection of other } \\
\text { artery }\end{array}$ & & y & & & & 31 & 15 & & & 91 & 36 & 145 & 2.69 & 1.41 & 5.36 & 0.0011 & {$\left[\begin{array}{c}33,34 \\
37]\end{array}\right.$} \\
\hline 4472 Rupture of artery & & $y$ & & & & 23 & 5 & & & 89 & 1 & 178 & 5.98 & 2.09 & 17.14 & 0.00 & {$\left[\begin{array}{c}33,34 \\
37]\end{array}\right.$} \\
\hline $\begin{array}{l}4550 \text { Internal hemorrhoids } \\
\text { without mention of } \\
\text { complication }\end{array}$ & $y$ & y & & & & 156 & 55 & & & 530 & 414 & 647 & 3.69 & 2.70 & 5.11 & $1<0.0001$ & {$[42]$} \\
\hline $\begin{array}{l}4552 \text { Internal hemorrhoids } \\
\text { with other complication }\end{array}$ & $y$ & $y$ & & & & 74 & 27 & & & 248 & 168 & 329 & 3.56 & 2.27 & 5.76 & $6<0.0001$ & {$[42]$} \\
\hline $\begin{array}{l}4553 \text { External hemorrhoids } \\
\text { without mention of } \\
\text { complication }\end{array}$ & $y$ & $y$ & & & & 50 & 18 & & & 169 & 103 & 235 & 3.61 & 2.07 & 6.58 & $<<0.0001$ & {$[42]$} \\
\hline $\begin{array}{l}4555 \text { External hemorrhoids } \\
\text { with other complication }\end{array}$ & y & $y$ & & & & 29 & 14 & & & 85 & 32 & 138 & 2.69 & 1.38 & 5.52 & 0.0015 & {$[42]$} \\
\hline 4568 Varices of other sites & $y$ & $y$ & & & & 155 & 33 & & & 605 & 495 & 714 & 6.11 & 4.17 & 9.19 & $9<0.0001$ & {$[36,42]$} \\
\hline $\begin{array}{l}4560 \text { Esophageal varices } \\
\text { with bleeding } \\
\end{array}$ & & $y$ & & y & & 30 & 3 & & & 129 & 44 & 214 & 13.01 & 4.66 & 36.31 & \begin{tabular}{l|l|l|} 
& 0.00
\end{tabular} & $\begin{array}{l}{[35,37} \\
47,48] \\
\end{array}$ \\
\hline
\end{tabular}


medRxiv preprint doi: https://doi.org/10.1101/2020.12.30.20218610; this version posted January 4, 2021. The copyright holder for this preprint (which was not certified by peer review) is the author/funder, who has granted medRxiv a license to display the preprint in perpetuity.

This article is a US Government work. It is not subject to copyright under 17 USC 105 and is also made available for use under a CCO license.

\begin{tabular}{|c|c|c|c|c|c|c|c|c|c|c|c|c|c|c|c|c|c|}
\hline \multirow[b]{2}{*}{$\begin{array}{l}\text { ICD9 diagnosis code and } \\
\text { name }\end{array}$} & \multicolumn{5}{|c|}{ Interpretation } & \multirow[b]{2}{*}{ 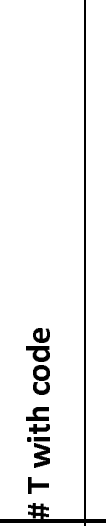 } & \multirow[b]{2}{*}{ 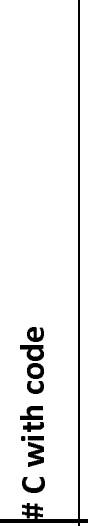 } & \multirow[b]{2}{*}{ 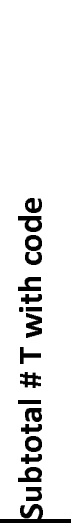 } & \multirow[b]{2}{*}{ 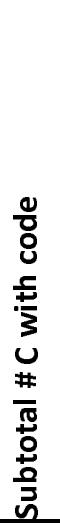 } & \multicolumn{3}{|c|}{$\begin{array}{c}\text { Rate difference } \\
\text { statistics }\end{array}$} & \multicolumn{3}{|c|}{ Rate ratio statistics } & \multirow[b]{2}{*}{$p$ value } & \multirow[b]{2}{*}{ 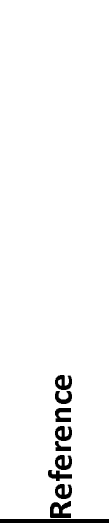 } \\
\hline & 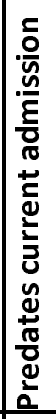 & 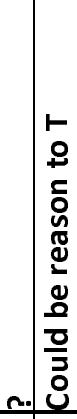 & 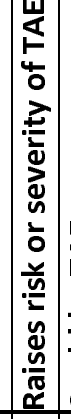 & 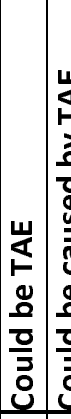 & 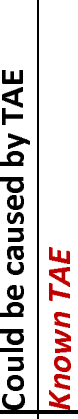 & & & & & 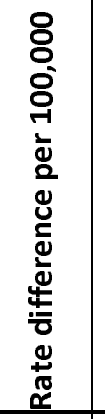 & 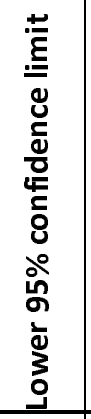 & 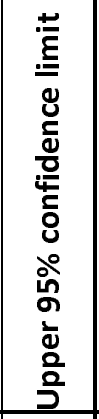 & 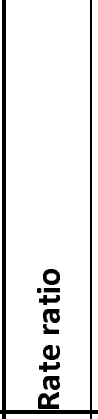 & 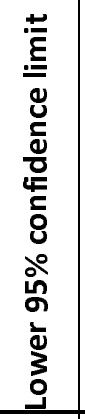 & 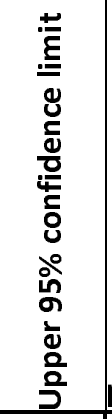 & & \\
\hline $\begin{array}{l}45620 \text { Esophageal varices in } \\
\text { diseases classified } \\
\text { elsewhere, with bleeding }\end{array}$ & & $y$ & & $\mathrm{y}$ & & 300 & 52 & & & 1213 & 1062 & 1363 & 7.50 & 5.57 & 10.28 & $<0.0001$ & $\begin{array}{l}{[35,37} \\
47,48]\end{array}$ \\
\hline $\begin{array}{l}4590 \text { Hemorrhage, } \\
\text { unspecified }\end{array}$ & & $y$ & & $y$ & & 93 & 22 & & & 355 & 269 & 441 & 5.50 & 3.43 & 9.19 & $<0.0001$ & $\begin{array}{l}{[35,37} \\
47,48] \\
\end{array}$ \\
\hline $\begin{array}{l}53021 \text { Ulcer of esophagus } \\
\text { with bleeding }\end{array}$ & & $y$ & & y $y$ & y & 45 & 11 & & & 170 & 110 & 230 & 5.32 & 2.71 & 11.41 & $<0.0001$ & $\begin{array}{l}{[35,37} \\
47,48, \\
49,50]\end{array}$ \\
\hline $\begin{array}{l}5307 \text { Gastroesophageal } \\
\text { laceration-hemorrhage } \\
\text { syndrome }\end{array}$ & & $y$ & & $y$ & & 121 & 70 & & & 313 & 203 & 424 & 2.25 & 1.66 & 3.06 & $<0.0001$ & $\begin{array}{c}{[35,37,} \\
47,48, \\
49]\end{array}$ \\
\hline $\begin{array}{l}53082 \text { Esophageal } \\
\text { hemorrhage }\end{array}$ & & $y$ & & y & & 67 & 18 & & & 248 & 174 & 322 & 4.84 & 2.84 & 8.66 & $<0.0001$ & $\begin{array}{c}{[35,37} \\
47,48, \\
49]\end{array}$ \\
\hline $\begin{array}{l}53100 \text { Acute gastric ulcer } \\
\text { with hemorrhage, without } \\
\text { mention of obstruction }\end{array}$ & & $y$ & & y & & 55 & 6 & & & 235 & 172 & 298 & 11.92 & 5.14 & 33.89 & $<0.0001$ & $\begin{array}{l}{[35,37} \\
47,48]\end{array}$ \\
\hline $\begin{array}{l}53110 \text { Acute gastric ulcer } \\
\text { with perforation, without } \\
\text { mention of obstruction }\end{array}$ & & $y$ & & y & & 8 & 1 & & & 34 & -23 & 90 & 10.40 & 1.12 & 96.60 & 0.04 & $\begin{array}{l}{[35,37,} \\
47,48]\end{array}$ \\
\hline $\begin{array}{l}53140 \text { Chronic or unspecified } \\
\text { gastric ulcer with } \\
\text { hemorrhage, without } \\
\text { mention of obstruction }\end{array}$ & $y$ & $y$ & & $y$ & & 231 & 38 & & & 941 & 810 & 1073 & \begin{tabular}{|l|}
7.91 \\
\end{tabular} & 5.59 & 11.46 & $<0.0001$ & $\begin{array}{l}{[35,37} \\
47,48]\end{array}$ \\
\hline \begin{tabular}{|l|}
53150 Chronic or unspecified \\
gastric ulcer with \\
perforation, without \\
mention of obstruction
\end{tabular} & $y$ & $y$ & & y & & 12 & 3 & & & 45 & -29 & 119 & 5.20 & 1.12 & 24.19 & 0.04 & $\begin{array}{l}{[35,37,} \\
47,48]\end{array}$ \\
\hline $\begin{array}{l}53200 \text { Acute duodenal ulcer } \\
\text { with hemorrhage, without } \\
\text { mention of obstruction }\end{array}$ & & $y$ & & y & & 73 & 1 & & & 337 & 229 & 444 & 94.94 & 37.93 & 237.63 & 0.00 & $\begin{array}{l}{[35,37,} \\
47,48]\end{array}$ \\
\hline \begin{tabular}{|l}
53240 Chronic or unspecified \\
duodenal ulcer with \\
hemorrhage, without \\
mention of obstruction
\end{tabular} & y & $y$ & & y & & 229 & 42 & & & 917 & 785 & 1049 & \begin{tabular}{|l|}
7.09 \\
\end{tabular} & 5.09 & 10.10 & $<0.0001$ & $\begin{array}{l}{[35,37} \\
47,48]\end{array}$ \\
\hline \begin{tabular}{|l}
53250 Chronic or unspecified \\
duodenal ulcer with \\
perforation, without \\
mention of obstruction
\end{tabular} & $y$ & $y$ & & y & & 17 & 4 & & & 65 & -16 & 146 & 5.53 & 1.59 & 19.22 & 0.01 & $\begin{array}{l}{[35,37,} \\
47,48]\end{array}$ \\
\hline
\end{tabular}


medRxiv preprint doi: https://doi.org/10.1101/2020.12.30.20218610; this version posted January 4, 2021. The copyright holder for this preprint (which was not certified by peer review) is the author/funder, who has granted medRxiv a license to display the preprint in perpetuity.

This article is a US Government work. It is not subject to copyright under 17 USC 105 and is also made available for use under a CCO license.

\begin{tabular}{|c|c|c|c|c|c|c|c|c|c|c|c|c|c|c|c|c|c|c|}
\hline \multirow[b]{2}{*}{$\begin{array}{l}\text { ICD9 diagnosis code and } \\
\text { name }\end{array}$} & \multicolumn{6}{|c|}{ Interpretation } & \multirow[b]{2}{*}{ 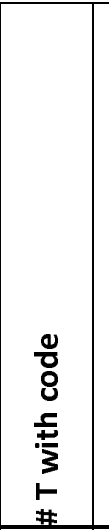 } & \multirow[b]{2}{*}{ 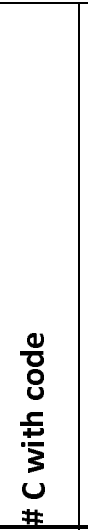 } & \multirow[b]{2}{*}{ 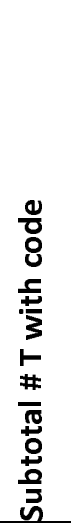 } & \multirow[b]{2}{*}{ 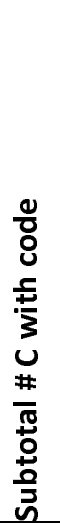 } & \multicolumn{3}{|c|}{$\begin{array}{l}\text { Rate difference } \\
\text { statistics }\end{array}$} & \multicolumn{3}{|c|}{ Rate ratio statistics } & \multirow[b]{2}{*}{$p$ value } & \multirow[b]{2}{*}{ 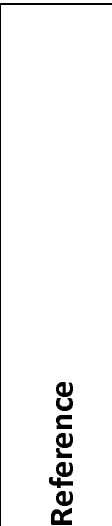 } \\
\hline & 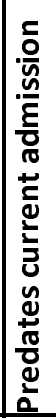 & 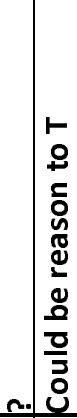 & 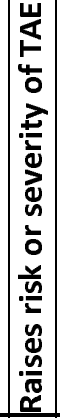 & 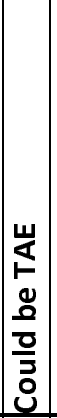 & 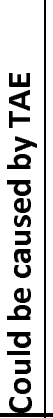 & 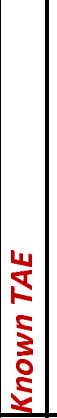 & & & & & 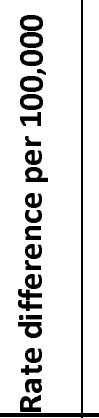 & 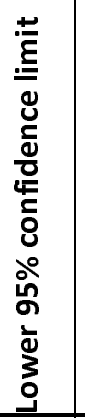 & 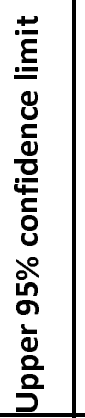 & 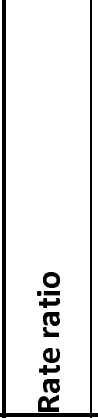 & 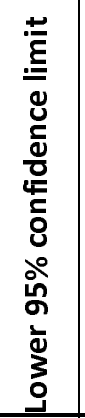 & 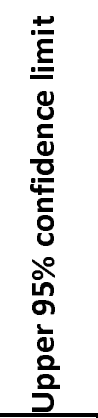 & & \\
\hline $\begin{array}{l}53260 \text { Chronic or unspecified } \\
\text { duodenal ulcer with } \\
\text { hemorrhage and perforation, } \\
\text { without mention of } \\
\text { obstruction }\end{array}$ & $y$ & $y$ & & $\mathrm{y}$ & & & 11 & 0 & & & 51 & 0 & 103 & & & & 0.00 & $\begin{array}{l}{[35,37} \\
47,48]\end{array}$ \\
\hline $\begin{array}{l}53340 \text { Chronic or unspecified } \\
\text { peptic ulcer of unspecified } \\
\text { site with hemorrhage, } \\
\text { without mention of } \\
\text { obstruction }\end{array}$ & $y$ & $y$ & & $y$ & & & 9 & 1 & & & 38 & -19 & 95 & 11.71 & 1.43 & 95.53 & 0.02 & $\begin{array}{l}{[35,37,} \\
47,48]\end{array}$ \\
\hline $\begin{array}{l}53400 \text { Acute gastrojejunal } \\
\text { ulcer with hemorrhage, } \\
\text { without mention of } \\
\text { obstruction }\end{array}$ & & y & & $y$ & & & 7 & 0 & & & 33 & -13 & 79 & & & & 0.02 & $\begin{array}{l}{[35,37,} \\
47,48]\end{array}$ \\
\hline $\begin{array}{l}53440 \text { Chronic or unspecified } \\
\text { gastrojejunal ulcer with } \\
\text { hemorrhage, without } \\
\text { mention of obstruction }\end{array}$ & $y$ & y & & $y$ & & & 29 & 7 & & & 110 & 62 & 158 & 5.39 & 2.31 & 14.57 & $<0.0001$ & $\begin{array}{l}{[35,37} \\
47,48]\end{array}$ \\
\hline $\begin{array}{l}53501 \text { Acute gastritis, with } \\
\text { hemorrhage }\end{array}$ & & $y$ & & $y$ & & & 34 & 5 & & & 141 & 46 & 235 & 8.84 & 3.62 & 21.61 & 0.00 & $\begin{array}{l}{[35,37,} \\
47,48]\end{array}$ \\
\hline $\begin{array}{l}53511 \text { Atrophic gastritis, } \\
\text { with hemorrhage }\end{array}$ & & $y$ & & $y$ & & & 8 & 1 & & & 34 & -23 & 90 & 10.40 & 1.12 & 96.60 & 0.04 & $\begin{array}{l}{[35,37} \\
47,48]\end{array}$ \\
\hline $\begin{array}{l}53541 \text { Other specified } \\
\text { gastritis, with hemorrhage }\end{array}$ & & $y$ & & y & & & 85 & 22 & & & 318 & 235 & 400 & 5.02 & 3.11 & 8.44 & $<0.0001$ & $\begin{array}{l}{[35,37} \\
47,48] \\
\end{array}$ \\
\hline $\begin{array}{l}53551 \text { Unspecified gastritis } \\
\text { and gastroduodenitis, with } \\
\text { hemorrhage }\end{array}$ & & y & & $y$ & & & 107 & 42 & & & 348 & 251 & 446 & 3.31 & 2.30 & 4.85 & $<0.0001$ & $\begin{array}{l}{[35,37} \\
47,48]\end{array}$ \\
\hline $\begin{array}{l}53561 \text { Duodenitis, with } \\
\text { hemorrhage }\end{array}$ & & y & & $y$ & & & 45 & 4 & & & 196 & 97 & 294 & 14.63 & 6.34 & 33.78 & 0.00 & $\begin{array}{l}{[35,37} \\
47,48] \\
\end{array}$ \\
\hline 5371 Gastric diverticulum & y & $y$ & & & & & 7 & 0 & & & 33 & -13 & 79 & & & & 0.02 & {$[51]$} \\
\hline $\begin{array}{l}53782 \text { Angiodysplasia of } \\
\text { stomach and duodenum } \\
\text { without mention of } \\
\text { hemorrhage }\end{array}$ & & $y$ & & & & & 42 & 11 & & & 156 & 98 & 215 & 4.97 & 2.51 & 10.70 & $<0.0001$ & {$[52]$} \\
\hline $\begin{array}{l}53783 \text { Angiodysplasia of } \\
\text { stomach and duodenum } \\
\text { with hemorrhage }\end{array}$ & & $y$ & & y & & & 113 & 14 & & & 477 & 387 & 567 & 10.50 & 6.00 & 19.82 & $<0.0001$ & $\begin{array}{l}{[35,37} \\
47,48]\end{array}$ \\
\hline
\end{tabular}


medRxiv preprint doi: https://doi.org/10.1101/2020.12.30.20218610; this version posted January 4, 2021. The copyright holder for this preprint (which was not certified by peer review) is the author/funder, who has granted medRxiv a license to display the preprint in perpetuity. This article is a US Government work. It is not subject to copyright under 17 USC 105 and is also made available for use under a CCO license.

\begin{tabular}{|c|c|c|c|c|c|c|c|c|c|c|c|c|c|c|c|c|c|c|}
\hline \multirow[b]{2}{*}{$\begin{array}{l}\text { ICD9 diagnosis code and } \\
\text { name }\end{array}$} & \multicolumn{6}{|c|}{ Interpretation } & \multirow[b]{2}{*}{ 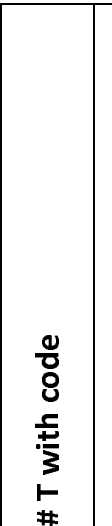 } & \multirow[b]{2}{*}{ 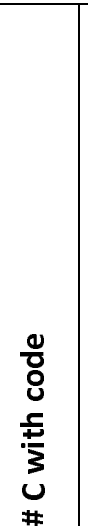 } & \multirow[b]{2}{*}{ 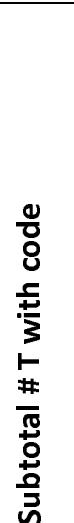 } & \multirow[b]{2}{*}{ 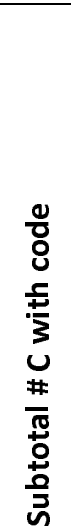 } & \multicolumn{3}{|c|}{$\begin{array}{l}\text { Rate difference } \\
\text { statistics }\end{array}$} & \multicolumn{3}{|c|}{ Rate ratio statistics } & \multirow[b]{2}{*}{$p$ value } & \multirow[b]{2}{*}{ 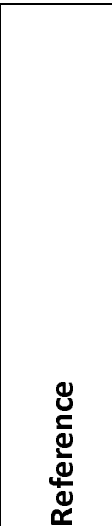 } \\
\hline & 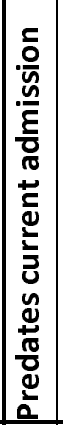 & 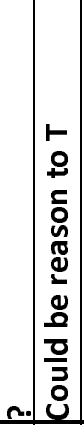 & 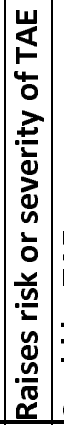 & 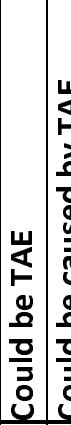 & 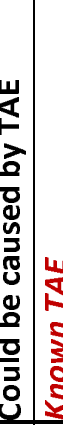 & 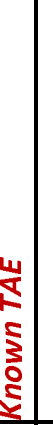 & & & & & 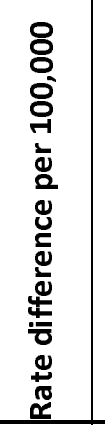 & 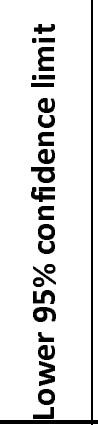 & 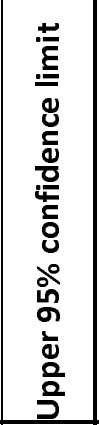 & 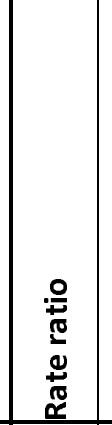 & 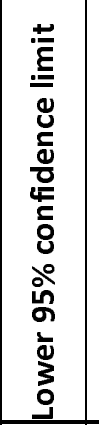 & 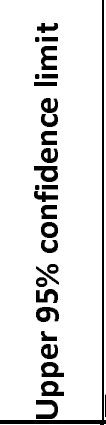 & & \\
\hline $\begin{array}{l}53784 \text { Dieulafoy lesion } \\
\text { (hemorrhagic) of stomach } \\
\text { and duodenum }\end{array}$ & & $y$ & & y & & & 46 & 4 & & & 200 & 101 & 299 & 14.96 & 6.52 & 34.30 & 0.00 & $\begin{array}{l}{[35,37} \\
47,48]\end{array}$ \\
\hline $\begin{array}{l}56212 \text { Diverticulosis of colon } \\
\text { with hemorrhage }\end{array}$ & & $y$ & & $y$ & & & 293 & 41 & & & 1219 & 1073 & 1366 & 9.29 & 6.69 & 13.22 & $<0.0001$ & $\begin{array}{l}{[35,37} \\
47,48]\end{array}$ \\
\hline $\begin{array}{l}56213 \text { Diverticulitis of colon } \\
\text { with hemorrhage }\end{array}$ & & $y$ & & $y$ & & & 23 & 7 & & & 82 & 38 & 126 & 4.27 & 1.78 & 11.79 & 0.0002 & $\begin{array}{l}{[35,37} \\
47,48]\end{array}$ \\
\hline $\begin{array}{l}56881 \text { Hemoperitoneum } \\
\text { (nontraumatic) }\end{array}$ & & $y$ & & & & & 174 & 29 & & & 707 & 593 & 822 & 7.80 & 5.25 & 12.00 & $<0.0001$ & [53] \\
\hline 5690 Anal and rectal polyp & & $y$ & & & & & 13 & 2 & & & 53 & -14 & 121 & 8.45 & 1.77 & 40.28 & 0.01 & $\begin{array}{l}{[33,34} \\
40,54]\end{array}$ \\
\hline $\begin{array}{l}5693 \text { Hemorrhage of rectum } \\
\text { and anus }\end{array}$ & & $y$ & & $y$ & & & 66 & 37 & & & 175 & 94 & 257 & 2.32 & 1.53 & 3.57 & $<0.0001$ & $\begin{array}{l}{[35,37} \\
47,48]\end{array}$ \\
\hline $\begin{array}{l}56983 \text { Perforation of } \\
\text { intestine }\end{array}$ & & $y$ & & & & & 158 & 72 & & & 479 & 357 & 600 & 2.85 & 2.15 & 3.83 & $<0.0001$ & $\begin{array}{r}{[33,34} \\
37,52]\end{array}$ \\
\hline $\begin{array}{l}56985 \text { Angiodysplasia of } \\
\text { intestine with hemorrhage }\end{array}$ & & $y$ & & $y$ & & & 91 & 7 & & & 399 & 320 & 479 & 16.91 & 7.88 & 43.24 & $<0.0001$ & $\begin{array}{l}{[35,37} \\
47,48]\end{array}$ \\
\hline $\begin{array}{l}56986 \text { Dieulafoy lesion } \\
\text { (hemorrhagic) of intestine }\end{array}$ & & $y$ & & $y$ & & & 7 & 0 & & & 33 & -13 & 79 & & & & 0.02 & $\begin{array}{l}{[35,37} \\
47,48]\end{array}$ \\
\hline 5723 Portal hypertension & & $y$ & & & & & 757 & 249 & & & 2637 & 2383 & 2892 & 3.95 & 3.42 & 4.58 & $<0.0001$ & $\begin{array}{l}{[33,34} \\
37,55]\end{array}$ \\
\hline 5724 Hepatorenal syndrome & & $\mathrm{y}$ & & & & & 301 & 45 & & & 1242 & 1093 & 1391 & 8.70 & 6.34 & 12.18 & $<0.0001$ & {$[56]$} \\
\hline 5780 Hematemesis & & $\mathrm{y}$ & & $y$ & & & 288 & 138 & & & 848 & 683 & 1014 & 2.71 & 2.21 & 3.35 & $<0.0001$ & $\begin{array}{l}{[35,37} \\
47,48] \\
\end{array}$ \\
\hline 5781 Blood in stool & & $y$ & & $y$ & & & 521 & 163 & & & 1845 & 1636 & 2055 & 4.16 & $\mid 3.48$ & 4.99 & $<0.0001$ & $\begin{array}{l}{[35,37} \\
47,48]\end{array}$ \\
\hline $\begin{array}{l}5789 \text { Hemorrhage of } \\
\text { gastrointestinal tract, } \\
\text { unspecified }\end{array}$ & & $y$ & & $y$ & & & 1158 & 237 & & & 4551 & 4251 & 4850 & 6.35 & 5.52 & 7.34 & $<0.0001$ & $\begin{array}{l}{[35,37} \\
47,48]\end{array}$ \\
\hline $\begin{array}{l}66612 \text { Other immediate } \\
\text { postpartum hemorrhage, } \\
\text { delivered, with mention of } \\
\text { postpartum complication }\end{array}$ & & $y$ & & $\mathrm{y}$ & & & 21 & 0 & & & 98 & 35 & 161 & & & & 0.00 & {$\left[\begin{array}{l}{[35,37} \\
47,48]\end{array}\right.$} \\
\hline $\begin{array}{l}66624 \text { Delayed and } \\
\text { secondary postpartum } \\
\text { hemorrhage, postpartum } \\
\text { condition or complication }\end{array}$ & & $y$ & & $y$ & & & 8 & 0 & & & 37 & -10 & 85 & & & & 0.01 & $\begin{array}{l}{[35,37} \\
47,48]\end{array}$ \\
\hline 7847 Epistaxis & & & $y$ & & $y$ & & 202 & 99 & & & 587 & 448 & 726 & 2.65 & 2.08 & 3.41 & $<0.0001$ & {$[57]$} \\
\hline
\end{tabular}


medRxiv preprint doi: https://doi.org/10.1101/2020.12.30.20218610; this version posted January 4, 2021. The copyright holder for this preprint (which was not certified by peer review) is the author/funder, who has granted medRxiv a license to display the preprint in perpetuity.

This article is a US Government work. It is not subject to copyright under 17 USC 105 and is also made available for use under a CCO license.

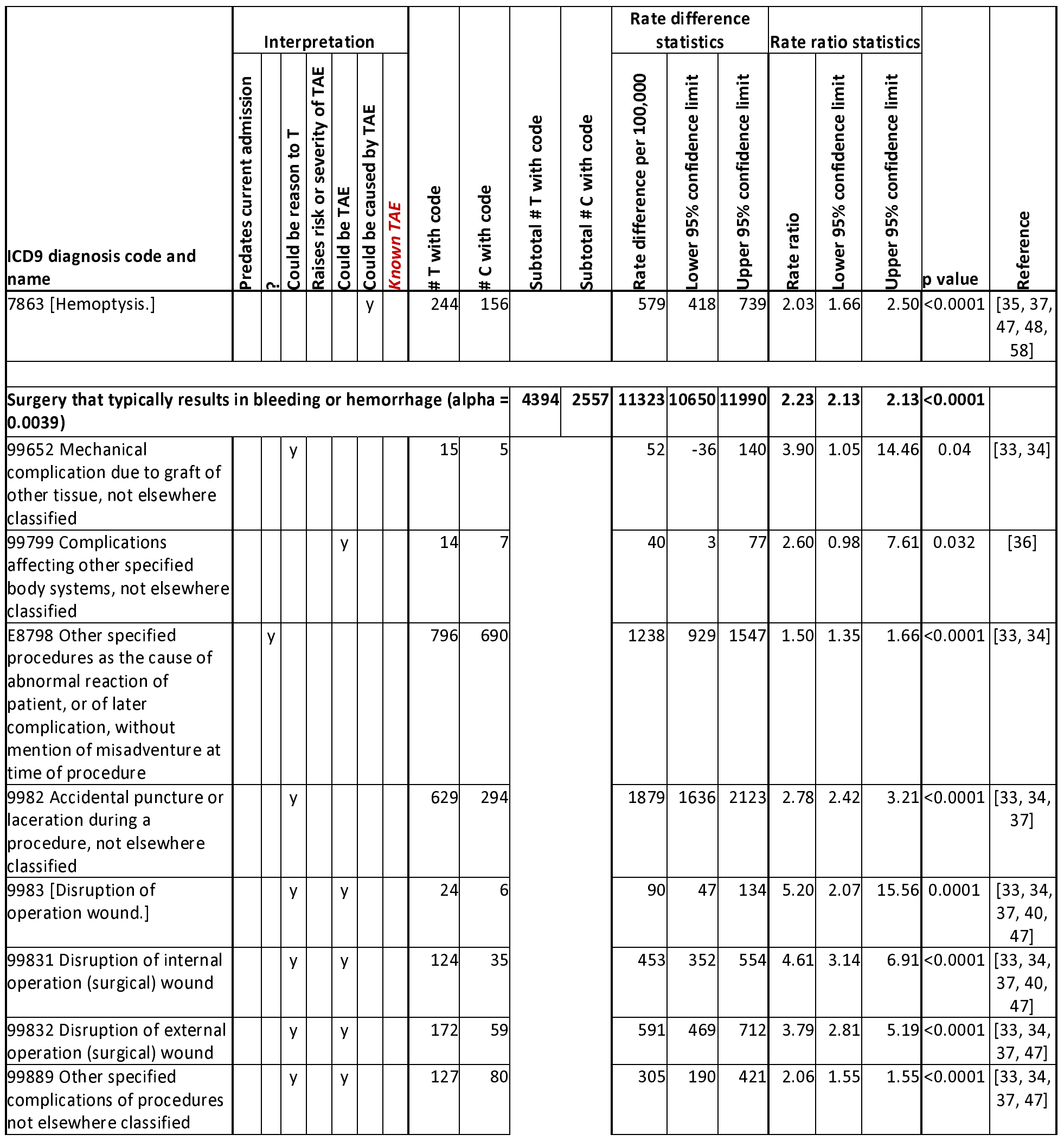


medRxiv preprint doi: https://doi.org/10.1101/2020.12.30.20218610; this version posted January 4, 2021. The copyright holder for this preprint (which was not certified by peer review) is the author/funder, who has granted medRxiv a license to display the preprint in perpetuity.

This article is a US Government work. It is not subject to copyright under 17 USC 105 and is also made available for use under a CCO license.

\begin{tabular}{|c|c|c|c|c|c|c|c|c|c|c|c|c|c|c|c|c|}
\hline \multirow[b]{2}{*}{$\begin{array}{l}\text { ICD9 diagnosis code and } \\
\text { name }\end{array}$} & \multicolumn{4}{|c|}{ Interpretation } & \multirow[b]{2}{*}{ 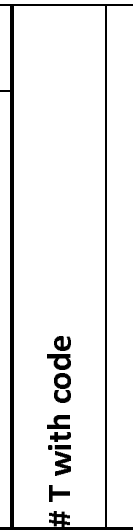 } & \multirow[b]{2}{*}{ 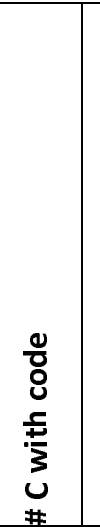 } & \multirow[b]{2}{*}{ 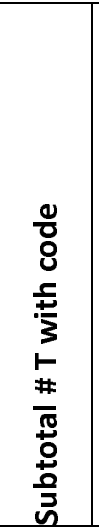 } & \multirow[b]{2}{*}{ 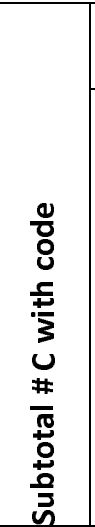 } & \multicolumn{3}{|c|}{$\begin{array}{c}\text { Rate difference } \\
\text { statistics }\end{array}$} & \multicolumn{3}{|c|}{ Rate ratio statistics } & \multirow[b]{2}{*}{$p$ value } & \multirow[b]{2}{*}{ 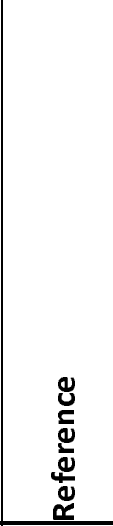 } \\
\hline & 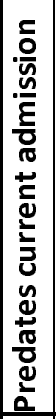 & 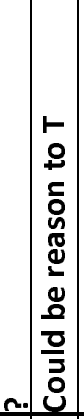 & 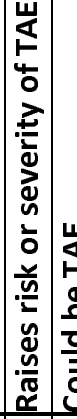 & 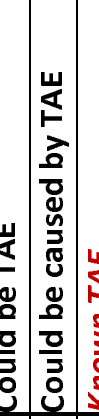 & & & & & 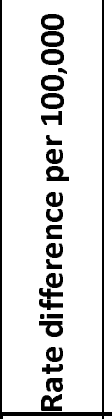 & 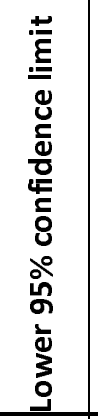 & 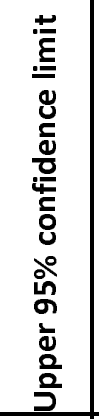 & 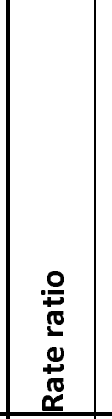 & 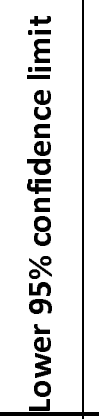 & 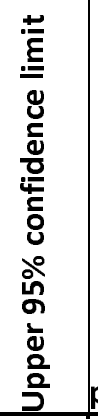 & & \\
\hline $\begin{array}{l}\text { E8781 Surgical operation } \\
\text { with implant of artificial } \\
\text { internal device causing } \\
\text { abnormal patient reaction, } \\
\text { or later complication, } \\
\text { without mention of } \\
\text { misadventure at time of } \\
\text { operation }\end{array}$ & & $y$ & $y$ & \begin{tabular}{l|l}
$y$ & \\
\end{tabular} & 411 & 278 & & & 920 & 710 & 1130 & 1.92 & 1.65 & 2.25 & $<0.0001$ & $\begin{array}{l}{[33,34} \\
37,47]\end{array}$ \\
\hline $\begin{array}{l}\text { E8782 Surgical operation } \\
\text { with anastomosis, bypass, or } \\
\text { graft, with natural or } \\
\text { artificial tissues used as } \\
\text { implant causing abnormal } \\
\text { patient reaction, or later } \\
\text { complication, without } \\
\text { mention of misadventure at } \\
\text { time of operation }\end{array}$ & & $y$ & $y$ & y & 826 & 302 & & & 2769 & 2500 & 3038 & 3.56 & 3.11 & 4.07 & $<0.0001$ & $\begin{array}{l}{[33,34} \\
37,47]\end{array}$ \\
\hline $\begin{array}{l}\text { E8788 Other specified } \\
\text { surgical operations and } \\
\text { procedures causing } \\
\text { abnormal patient reaction, } \\
\text { or later complication, } \\
\text { without mention of } \\
\text { misadventure at time of } \\
\text { operation }\end{array}$ & & $y$ & $y$ & $y$ & 764 & 567 & & & 1530 & 1237 & 1822 & 1.75 & 1.57 & 1.96 & $<0.0001$ & $\begin{array}{l}{[33,34} \\
37,47]\end{array}$ \\
\hline $\begin{array}{l}\text { V5331 Fitting and } \\
\text { adjustment of cardiac } \\
\text { pacemaker }\end{array}$ & & $y$ & $y$ & y & 95 & 42 & & & 292 & 199 & 386 & 2.94 & 2.03 & 4.34 & $<0.0001$ & $\begin{array}{l}{[33,34} \\
37,47]\end{array}$ \\
\hline $\begin{array}{l}\text { V6441 Laparoscopic surgical } \\
\text { procedure converted to } \\
\text { open procedure }\end{array}$ & & $y$ & $y$ & y & 89 & 56 & & & 214 & 118 & 311 & 2.07 & 1.46 & 2.94 & $<0.0001$ & $\begin{array}{l}{[33,34} \\
37,47]\end{array}$ \\
\hline $\begin{array}{l}\text { Injury or trauma that typical } \\
\text { hemorrhage (alpha }=0.0006\end{array}$ & & sults i & in ble & eeding & & & 5340 & 2045 & 17570 & 16880 & 18260 & 3.40 & 3.23 & 3.58 & $<0.0001$ & \\
\hline
\end{tabular}


medRxiv preprint doi: https://doi.org/10.1101/2020.12.30.20218610; this version posted January 4, 2021. The copyright holder for this preprint (which was not certified by peer review) is the author/funder, who has granted medRxiv a license to display the preprint in perpetuity.

This article is a US Government work. It is not subject to copyright under 17 USC 105 and is also made available for use under a CCO license.

\begin{tabular}{|c|c|c|c|c|c|c|c|c|c|c|c|c|c|c|c|c|c|}
\hline \multirow[b]{2}{*}{$\begin{array}{l}\text { ICD9 diagnosis code and } \\
\text { name }\end{array}$} & \multicolumn{5}{|c|}{ Interpretation } & \multirow[b]{2}{*}{ 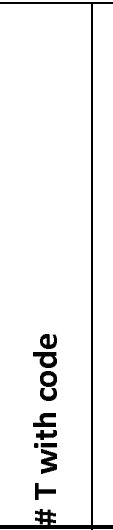 } & \multirow[b]{2}{*}{ 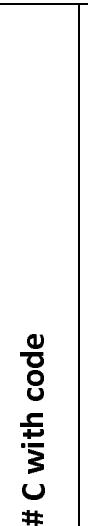 } & \multirow[b]{2}{*}{ 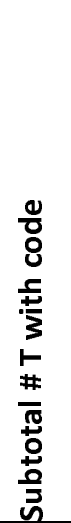 } & \multirow[b]{2}{*}{ 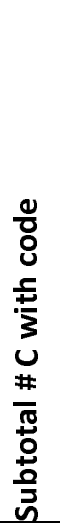 } & \multicolumn{3}{|c|}{$\begin{array}{l}\text { Rate difference } \\
\text { statistics }\end{array}$} & \multicolumn{3}{|c|}{ Rate ratio statistics } & \multirow[b]{2}{*}{$p$ value } & \multirow[b]{2}{*}{ 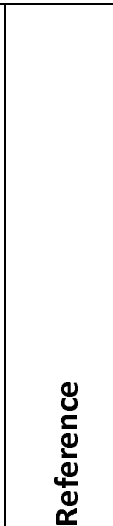 } \\
\hline & 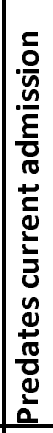 & 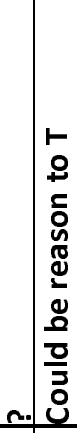 & 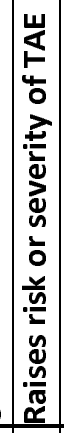 & 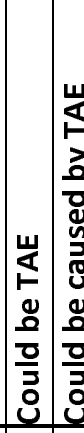 & 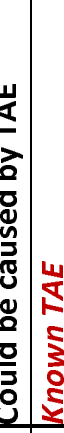 & & & & & 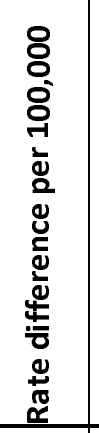 & 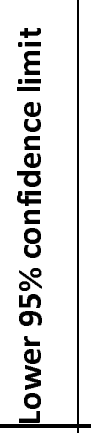 & 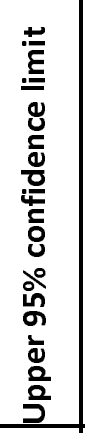 & 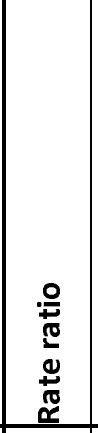 & 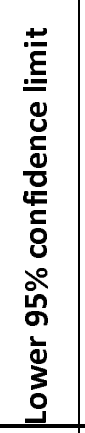 & 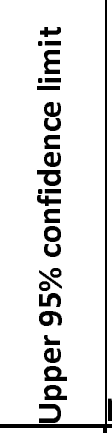 & & \\
\hline $\begin{array}{l}80425 \text { Closed fractures } \\
\text { involving skull or face with } \\
\text { other bones with } \\
\text { subarachnoid, subdural, and } \\
\text { extradural hemorrhage, with } \\
\text { prolonged (more than } 24 \\
\text { hours) loss of consciousness, } \\
\text { without return to pre- } \\
\text { existing conscious level }\end{array}$ & & $y$ & & & & 7 & 0 & & & 33 & -13 & 79 & & & & 0.02 & $\begin{array}{c}{[33,34,} \\
37]\end{array}$ \\
\hline $\begin{array}{l}8603 \text { Traumatic hemothorax } \\
\text { with open wound into thorax }\end{array}$ & & $y$ & & & & 15 & 5 & & & 52 & -36 & 140 & 3.90 & 1.05 & 14.46 & 0.04 & $\begin{array}{c}{[33,34,} \\
37]\end{array}$ \\
\hline $\begin{array}{l}8605 \text { Traumatic } \\
\text { pneumohemothorax with } \\
\text { open wound into thorax }\end{array}$ & & $y$ & & & & 16 & 6 & & & 53 & 16 & 91 & \begin{tabular}{|l|}
3.47 \\
\end{tabular} & 1.29 & 10.82 & 0.0056 & $\begin{array}{c}{[33,34,} \\
37]\end{array}$ \\
\hline $\begin{array}{l}86122 \text { Laceration of lung } \\
\text { without mention of open } \\
\text { wound into thorax }\end{array}$ & & y & & & & 13 & 6 & & & 39 & 4 & 74 & 2.82 & 1.00 & 9.04 & 0.0282 & $\begin{array}{c}{[33,34,} \\
37]\end{array}$ \\
\hline $\begin{array}{l}86132 \text { Laceration of lung } \\
\text { with open wound into thorax }\end{array}$ & & $y$ & & & & 14 & 2 & & & 58 & -10 & 126 & 9.10 & 2.01 & 41.18 & 0.00 & $\begin{array}{c}{[33,34,} \\
37]\end{array}$ \\
\hline $\begin{array}{l}8621 \text { Injury to diaphragm, } \\
\text { with open wound into cavity }\end{array}$ & & $y$ & & & & 14 & 6 & & & 44 & 8 & 80 & 3.03 & 1.10 & 9.63 & 0.0167 & $\begin{array}{c}{[33,34,} \\
37]\end{array}$ \\
\hline $\begin{array}{l}8900 \text { Open wound of hip and } \\
\text { thigh, without mention of } \\
\text { complication }\end{array}$ & & $y$ & & & & 15 & 7 & & & 45 & 7 & 82 & 2.79 & 1.07 & 8.08 & 0.0194 & $\begin{array}{c}{[33,34,} \\
37]\end{array}$ \\
\hline $\begin{array}{l}8901 \text { Open wound of hip and } \\
\text { thigh, complicated }\end{array}$ & & y & & & & 8 & 0 & & & 37 & -10 & 85 & & & & 0.01 & $\begin{array}{c}{\left[\begin{array}{c}33,34 \\
37]\end{array}\right.} \\
\end{array}$ \\
\hline $\begin{array}{l}90089 \text { Injury to other } \\
\text { specified blood vessels of } \\
\text { head and neck }\end{array}$ & & $y$ & & & & 14 & 7 & & & 40 & 3 & 77 & 2.60 & 0.98 & 7.61 & 0.032 & $\begin{array}{c}{[33,34,} \\
37]\end{array}$ \\
\hline 9010 Injury to thoracic aorta & & $y$ & & & & 23 & 5 & & & 89 & 1 & 178 & 5.98 & 2.09 & 17.14 & 0.00 & $\begin{array}{c}{[33,34,} \\
37]\end{array}$ \\
\hline 90253 Injury to iliac artery & & y & & & & 11 & 0 & & & 51 & 0 & 103 & & & & 0.00 & $\begin{array}{c}{[33,34,} \\
37]\end{array}$ \\
\hline $\begin{array}{l}90289 \text { Injury to other } \\
\text { specified blood vessels of } \\
\text { abdomen and pelvis }\end{array}$ & & $y$ & & & & 14 & 1 & & & 62 & 0 & 123 & 18.21 & 3.27 & 101.48 & 0.00 & $\begin{array}{c}{[33,34,} \\
37]\end{array}$ \\
\hline $\begin{array}{l}90441 \text { Injury to popliteal } \\
\text { artery }\end{array}$ & & y & & & & 8 & 1 & & & 34 & -23 & 90 & 10.40 & 1.12 & 96.60 & 0.04 & $\begin{array}{c}{[33,34,} \\
37]\end{array}$ \\
\hline
\end{tabular}


medRxiv preprint doi: https://doi.org/10.1101/2020.12.30.20218610; this version posted January 4, 2021. The copyright holder for this preprint (which was not certified by peer review) is the author/funder, who has granted medRxiv a license to display the preprint in perpetuity.

This article is a US Government work. It is not subject to copyright under 17 USC 105 and is also made available for use under a CCO license.

\begin{tabular}{|c|c|c|c|c|c|c|c|c|c|c|c|c|c|c|c|c|c|c|}
\hline \multirow[b]{2}{*}{$\begin{array}{l}\text { ICD9 diagnosis code and } \\
\text { name }\end{array}$} & \multicolumn{6}{|c|}{ Interpretation } & \multirow[b]{2}{*}{ 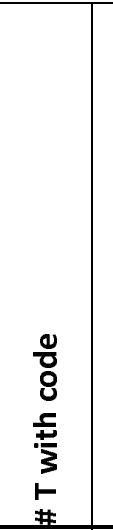 } & \multirow[b]{2}{*}{ 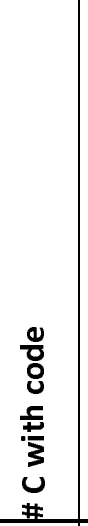 } & \multirow[b]{2}{*}{ 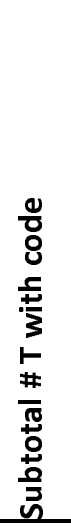 } & \multirow[b]{2}{*}{ 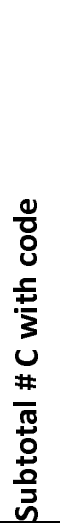 } & \multicolumn{3}{|c|}{$\begin{array}{c}\text { Rate difference } \\
\text { statistics }\end{array}$} & \multicolumn{3}{|c|}{ Rate ratio statistics } & \multirow[b]{2}{*}{$p$ value } & \multirow[b]{2}{*}{ 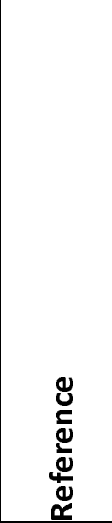 } \\
\hline & 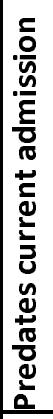 & 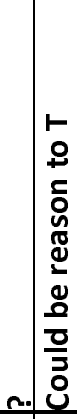 & 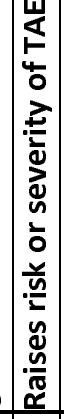 & $=$ & 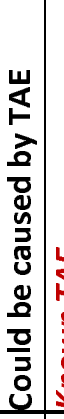 & 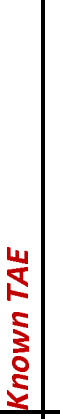 & & & & & 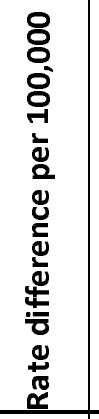 & 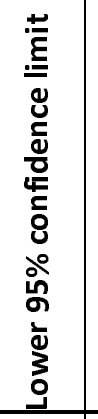 & 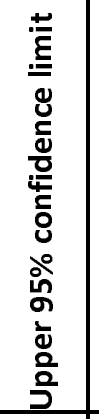 & 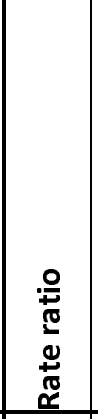 & 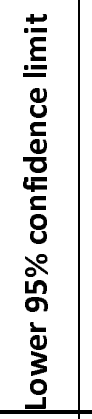 & 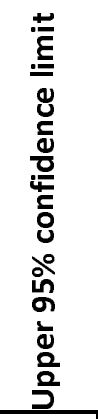 & & \\
\hline $\begin{array}{l}9047 \text { Injury to other } \\
\text { specified blood vessels of } \\
\text { lower extremity }\end{array}$ & & $y$ & & & & & 10 & 1 & & & 43 & -15 & 101 & 13.01 & 1.77 & 95.69 & 0.01 & $\begin{array}{c}{[33,34,} \\
37]\end{array}$ \\
\hline $\begin{array}{l}9582 \text { Secondary and } \\
\text { recurrent hemorrhage }\end{array}$ & & $y$ & & & & & 15 & 0 & & & 70 & 14 & 126 & & & & 0.00 & \begin{tabular}{|c}
{$[33,34$,} \\
$37]$
\end{tabular} \\
\hline $\begin{array}{l}95892 \text { Traumatic } \\
\text { compartment syndrome of } \\
\text { lower extremity }\end{array}$ & & & & & $\mathrm{y}$ & & 26 & 9 & & & 89 & 42 & 136 & 3.76 & 1.71 & 9.11 & 0.0002 & {$[59]$} \\
\hline $\begin{array}{l}95893 \text { Traumatic } \\
\text { compartment syndrome of } \\
\text { abdomen }\end{array}$ & & & & & y & & 10 & 0 & & & 47 & -3 & 97 & & & & 0.00 & {$[60]$} \\
\hline $\begin{array}{l}99702 \text { latrogenic } \\
\text { cerebrovascular infarction or } \\
\text { hemorrhage }\end{array}$ & & $y$ & & & & & 279 & 134 & & & 821 & 658 & 984 & 2.71 & 2.20 & 3.35 & $<0.0001$ & $\begin{array}{c}{[33,34,} \\
37]\end{array}$ \\
\hline \begin{tabular}{|l|}
99811 Hemorrhage \\
complicating a procedure
\end{tabular} & & y & & & & & 1320 & 204 & & & 5424 & 5111 & 5737 & 8.42 & 7.26 & 9.80 & $<0.0001$ & $\begin{array}{c}{[33,34,} \\
37]\end{array}$ \\
\hline $\begin{array}{l}99812 \text { Hematoma } \\
\text { complicating a procedure }\end{array}$ & & $y$ & & & & & 885 & 329 & & & 2948 & 2668 & 3227 & 3.50 & 3.08 & 3.98 & $<0.0001$ & $\begin{array}{c}{[33,34,} \\
37]\end{array}$ \\
\hline $\begin{array}{l}72992 \text { Nontraumatic } \\
\text { hematoma of soft tissue }\end{array}$ & & y & & & & & 64 & 21 & & & 223 & 149 & 297 & 3.96 & 2.39 & 6.83 & $<0.0001$ & $\begin{array}{c}{[33,34,} \\
37]\end{array}$ \\
\hline $\begin{array}{l}\text { E8700 Accidental cut, } \\
\text { puncture, perforation or } \\
\text { hemorrhage during surgical } \\
\text { operation }\end{array}$ & & y & & & & & 119 & 63 & & & 329 & 221 & 437 & 2.46 & 1.80 & 3.39 & $<0.0001$ & $\begin{array}{c}{[33,34,} \\
37]\end{array}$ \\
\hline $\begin{array}{l}\text { E8708 Accidental cut, } \\
\text { puncture, perforation or } \\
\text { hemorrhage during other } \\
\text { specified medical care }\end{array}$ & & y & & & & & 52 & 30 & & & 135 & 62 & 208 & 2.25 & 1.41 & 3.66 & 0.0003 & $\begin{array}{c}{[33,34,} \\
37]\end{array}$ \\
\hline $\begin{array}{l}\text { E8152 Other motor vehicle } \\
\text { traffic accident involving } \\
\text { collision on the highway } \\
\text { injuring motorcyclist }\end{array}$ & & $y$ & & & & & 14 & 6 & & & 44 & 8 & 80 & 3.03 & 1.10 & 9.63 & 0.0167 & $\begin{array}{c}{[33,34,} \\
37]\end{array}$ \\
\hline $\begin{array}{l}\text { E8230 Other motor vehicle } \\
\text { nontraffic accident involving } \\
\text { collision with stationary } \\
\text { object injuring driver of } \\
\text { motor vehicle other than } \\
\text { motorcycle }\end{array}$ & & $y$ & & & & & 40 & 21 & & & 111 & 49 & 174 & 2.48 & 1.43 & 4.42 & 0.0005 & $\begin{array}{c}{[33,34,} \\
37]\end{array}$ \\
\hline
\end{tabular}


medRxiv preprint doi: https://doi.org/10.1101/2020.12.30.20218610; this version posted January 4, 2021. The copyright holder for this preprint (which was not certified by peer review) is the author/funder, who has granted medRxiv a license to display the preprint in perpetuity.

This article is a US Government work. It is not subject to copyright under 17 USC 105 and is also made available for use under a CCO license.

\begin{tabular}{|c|c|c|c|c|c|c|c|c|c|c|c|c|c|c|c|c|c|}
\hline \multirow[b]{2}{*}{$\begin{array}{l}\text { ICD9 diagnosis code and } \\
\text { name }\end{array}$} & \multicolumn{5}{|c|}{ Interpretation } & \multirow[b]{2}{*}{ 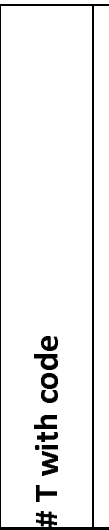 } & \multirow[b]{2}{*}{ 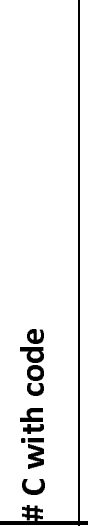 } & \multirow[b]{2}{*}{ 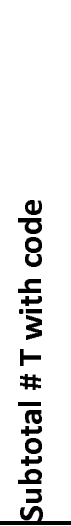 } & \multirow[b]{2}{*}{ 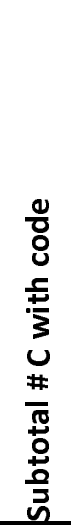 } & \multicolumn{3}{|c|}{$\begin{array}{c}\text { Rate difference } \\
\text { statistics } \\
\end{array}$} & \multicolumn{3}{|c|}{ Rate ratio statistics } & \multirow[b]{2}{*}{$p$ value } & \multirow[b]{2}{*}{ 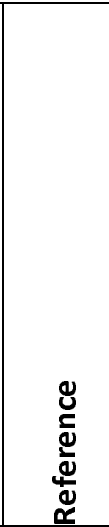 } \\
\hline & 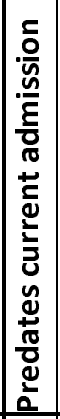 & 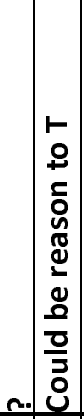 & 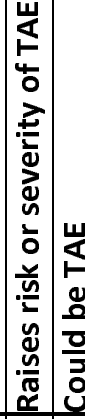 & 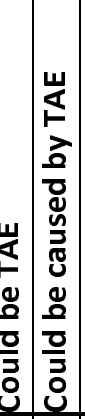 & 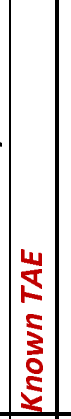 & & & & & 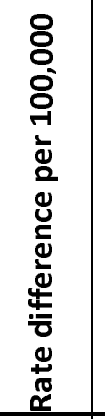 & 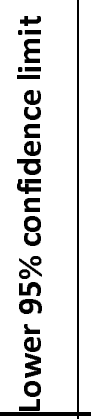 & 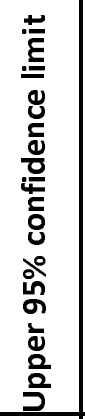 & 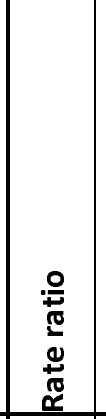 & 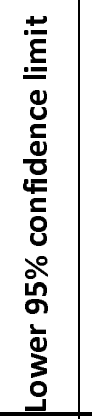 & 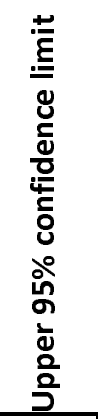 & & \\
\hline $\begin{array}{l}\text { E9353 Salicylates causing } \\
\text { adverse effects in } \\
\text { therapeutic use }\end{array}$ & & $y$ & & & & 23 & 12 & & & 64 & 17 & 112 & 2.49 & 1.19 & 5.50 & 0.0079 & $\begin{array}{c}{[33,34,} \\
37]\end{array}$ \\
\hline $\begin{array}{l}8602 \text { Traumatic hemothorax } \\
\text { without mention of open } \\
\text { wound into thorax }\end{array}$ & & $y$ & & y & & 72 & 26 & & & 243 & 163 & 322 & 3.60 & 2.27 & 5.88 & $<0.0001$ & $\begin{array}{l}{[33,34} \\
37,61]\end{array}$ \\
\hline $\begin{array}{l}8604 \text { Traumatic } \\
\text { pneumohemothorax without } \\
\text { mention of open wound into } \\
\text { thorax }\end{array}$ & & $y$ & & $y$ & & 87 & 51 & & & 223 & 129 & 317 & 2.22 & 1.55 & 3.20 & $<0.0001$ & $\begin{array}{l}{[33,34} \\
37,61]\end{array}$ \\
\hline $\begin{array}{l}8620 \text { Injury to diaphragm, } \\
\text { without mention of open } \\
\text { wound into cavity }\end{array}$ & & $y$ & & & & 22 & 7 & & & 77 & 34 & 121 & 4.09 & 1.69 & 11.33 & 0.0004 & {$\left[\begin{array}{c}{[33,34,} \\
37]\end{array}\right.$} \\
\hline $\begin{array}{l}6271 \text { Postmenopausal } \\
\text { bleeding }\end{array}$ & & $y$ & & & & 15 & 8 & & & 41 & 3 & 80 & 2.44 & 0.97 & 6.64 & 0.0354 & $\begin{array}{c}{[33,34,} \\
37]\end{array}$ \\
\hline $\begin{array}{l}64421 \text { Early onset of } \\
\text { delivery, delivered, with or } \\
\text { without mention of } \\
\text { antepartum condition }\end{array}$ & & y & & & & 19 & 6 & & & 67 & 27 & 107 & 4.12 & 1.58 & 12.60 & 0.001 & $\begin{array}{c}{[33,34,} \\
37]\end{array}$ \\
\hline \begin{tabular}{|l|}
86389 Injury to other \\
gastrointestinal sites, \\
without mention of open \\
wound into cavity \\
\end{tabular} & & $y$ & & & & 25 & 16 & & & 59 & 8 & 111 & 2.03 & 1.04 & 4.07 & 0.0237 & $\begin{array}{c}{[33,34,} \\
37]\end{array}$ \\
\hline $\begin{array}{l}86803 \text { Injury to other intra- } \\
\text { abdominal organs without } \\
\text { mention of open wound into } \\
\text { cavity, peritoneum }\end{array}$ & & $y$ & & & & 87 & 43 & & & 252 & 160 & 343 & 2.63 & 1.81 & 3.89 & $<0.0001$ & $\begin{array}{c}{[33,34,} \\
37]\end{array}$ \\
\hline $\begin{array}{l}86804 \text { Injury to other intra- } \\
\text { abdominal organs without } \\
\text { mention of open wound into } \\
\text { cavity, retroperitoneum }\end{array}$ & & $y$ & & & & 61 & 23 & & & 202 & 129 & 276 & 3.45 & 2.10 & 5.84 & $<0.0001$ & $\begin{array}{c}{[33,34,} \\
37]\end{array}$ \\
\hline 92232 Contusion of buttock & & $y$ & & & & 28 & 4 & & & 116 & 29 & 203 & 9.10 & 3.34 & 24.80 & 0.00 & $\begin{array}{c}{[33,34,} \\
37]\end{array}$ \\
\hline $\begin{array}{l}80620 \text { Closed fracture of T1- } \\
\text { T6 level with unspecified } \\
\text { spinal cord injury }\end{array}$ & & $y$ & & & & 24 & 4 & & & 98 & 13 & 182 & 7.80 & 2.68 & 22.69 & 0.00 & $\begin{array}{c}{[33,34,} \\
37]\end{array}$ \\
\hline $\begin{array}{l}80621 \text { Closed fracture of T1- } \\
\text { T6 level with complete lesion } \\
\text { of cord }\end{array}$ & & $\mathrm{y}$ & & & & 9 & 0 & & & 42 & -7 & 91 & & & & 0.00 & $\begin{array}{c}{[33,34,} \\
37]\end{array}$ \\
\hline
\end{tabular}


medRxiv preprint doi: https://doi.org/10.1101/2020.12.30.20218610; this version posted January 4, 2021. The copyright holder for this preprint (which was not certified by peer review) is the author/funder, who has granted medRxiv a license to display the preprint in perpetuity. This article is a US Government work. It is not subject to copyright under 17 USC 105 and is also made available for use under a CCO license.

\begin{tabular}{|c|c|c|c|c|c|c|c|c|c|c|c|c|c|c|c|c|c|c|}
\hline \multirow[b]{2}{*}{$\begin{array}{l}\text { ICD9 diagnosis code and } \\
\text { name }\end{array}$} & \multicolumn{6}{|c|}{ Interpretation } & \multirow[b]{2}{*}{ 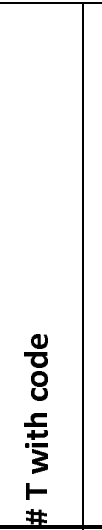 } & \multirow[b]{2}{*}{ 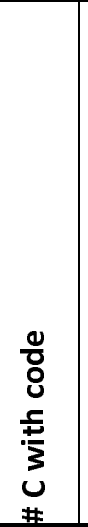 } & \multirow[b]{2}{*}{ 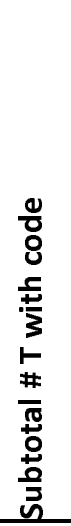 } & \multirow[b]{2}{*}{ 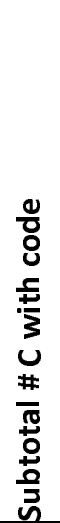 } & \multicolumn{3}{|c|}{$\begin{array}{c}\text { Rate difference } \\
\text { statistics }\end{array}$} & \multicolumn{3}{|c|}{ Rate ratio statistics } & \multirow[b]{2}{*}{$p$ value } & \multirow[b]{2}{*}{ 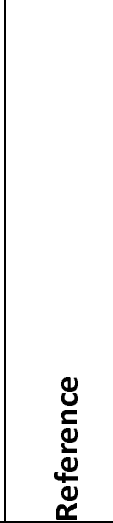 } \\
\hline & 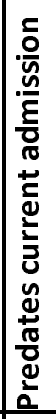 & ז. & 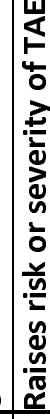 & 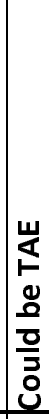 & 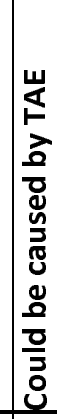 & 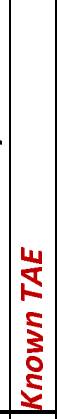 & & & & & 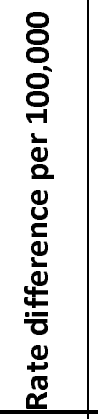 & 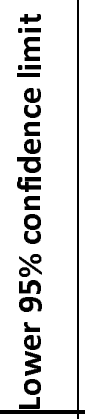 & 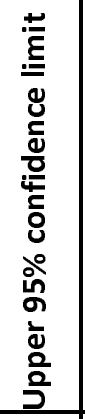 & 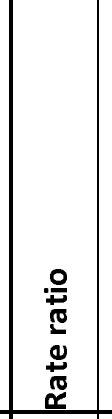 & 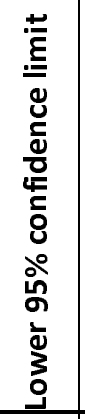 & 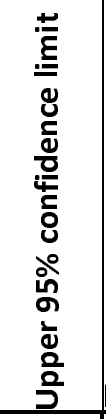 & & \\
\hline $\begin{array}{l}80625 \text { Closed fracture of T7- } \\
\text { T12 level with unspecified } \\
\text { spinal cord injury }\end{array}$ & & $y$ & & & & & 17 & 6 & & & 58 & 19 & 96 & 3.68 & 1.39 & $\overline{11.41}$ & 0.0032 & $\begin{array}{c}{[33,34,} \\
37]\end{array}$ \\
\hline $\begin{array}{l}80629 \text { Closed fracture of T7- } \\
T 12 \text { level with other } \\
\text { specified spinal cord injury }\end{array}$ & & $y$ & & & & & 14 & 2 & & & 58 & -10 & 126 & 9.10 & 2.01 & 41.18 & 0.00 & {$\left[\begin{array}{c}{[33,34,} \\
37]\end{array}\right.$} \\
\hline $\begin{array}{l}8064 \text { Closed fracture of } \\
\text { lumbar spine with spinal } \\
\text { cord injury }\end{array}$ & & $\mathrm{y}$ & & & & & 18 & 10 & & & 48 & 6 & 91 & 2.34 & 1.02 & 5.68 & 0.0263 & {$\left[\begin{array}{c}{[33,34} \\
37]\end{array}\right.$} \\
\hline $\begin{array}{l}8056 \text { Closed fracture of } \\
\text { sacrum and coccyx without } \\
\text { mention of spinal cord injury }\end{array}$ & & $y$ & & & & & 107 & 54 & & & 305 & 204 & 407 & 2.58 & 1.84 & 3.64 & $<0.0001$ & {$\left[\begin{array}{c}{[33,34} \\
37]\end{array}\right.$} \\
\hline $\begin{array}{l}81201 \text { Closed fracture of } \\
\text { surgical neck of humerus }\end{array}$ & & $y$ & & & & & 26 & 13 & & & 75 & 25 & 125 & 2.60 & 1.29 & 5.51 & 0.0035 & {$\left[\begin{array}{c}33,34, \\
37]\end{array}\right.$} \\
\hline $\begin{array}{l}81209 \text { Other closed fracture } \\
\text { of upper end of humerus }\end{array}$ & & $y$ & & & & & 22 & 13 & & & 56 & 9 & 103 & 2.20 & 1.06 & 4.76 & 0.0207 & $\begin{array}{c}{[33,34,} \\
37]\end{array}$ \\
\hline $\begin{array}{l}81221 \text { Closed fracture of } \\
\text { shaft of humerus }\end{array}$ & & $y$ & & & & & 21 & 13 & & & 51 & 5 & 98 & 2.10 & 1.00 & 4.57 & 0.0314 & $\begin{array}{c}{[33,34,} \\
37]\end{array}$ \\
\hline $\begin{array}{l}81250 \text { Open fracture of } \\
\text { unspecified part of lower } \\
\text { end of humerus }\end{array}$ & & $y$ & & & & & 7 & 0 & & & 33 & -13 & 79 & & & & 0.02 & $\begin{array}{c}{[33,34,} \\
37]\end{array}$ \\
\hline \begin{tabular}{|l|}
81311 Open fracture of \\
olecranon process of ulna
\end{tabular} & & $y$ & & & & & 11 & 1 & & & 48 & -11 & 106 & 14.31 & 2.12 & 96.57 & 0.01 & {$\left[\begin{array}{c}33,34, \\
37]\end{array}\right.$} \\
\hline 8082 Closed fracture of pubis & & $y$ & & & & & 180 & 78 & & & 560 & 431 & 689 & 3.00 & 2.29 & 3.97 & $<0.0001$ & $\begin{array}{c}{[33,34,} \\
37]\end{array}$ \\
\hline 8083 Open fracture of pubis & & $y$ & & & & & 12 & 1 & & & 52 & -7 & 112 & 15.61 & 2.49 & 97.93 & 0.00 & $\begin{array}{c}{[33,34,} \\
37]\end{array}$ \\
\hline $\begin{array}{l}80841 \text { Closed fracture of } \\
\text { ilium }\end{array}$ & & $y$ & & & & & 42 & 17 & & & 135 & 73 & 197 & 3.21 & 1.79 & 6.02 & $<0.0001$ & $\begin{array}{c}{[33,34,} \\
37]\end{array}$ \\
\hline $\begin{array}{l}80843 \text { Multiple closed pelvic } \\
\text { fractures with disruption of } \\
\text { pelvic circle }\end{array}$ & & $y$ & & & & & 23 & 8 & & & 79 & 34 & 123 & 3.74 & 1.61 & 9.67 & 0.0006 & {$\left[\begin{array}{c}{[33,34,} \\
37]\end{array}\right.$} \\
\hline $\begin{array}{l}80849 \text { Closed fracture of } \\
\text { other specified part of pelvis }\end{array}$ & & $y$ & & & & & 8 & 0 & & & 37 & -10 & 85 & & & & 0.01 & $\begin{array}{c}{[33,34,} \\
37]\end{array}$ \\
\hline $\begin{array}{l}80853 \text { Multiple open pelvic } \\
\text { fractures with disruption of } \\
\text { pelvic circle }\end{array}$ & & $y$ & & & & & 9 & 1 & & & 38 & -19 & 95 & 11.71 & 1.43 & 95.53 & 0.02 & $\begin{array}{c}{[33,34,} \\
37]\end{array}$ \\
\hline $\begin{array}{l}8088 \text { Closed unspecified } \\
\text { fracture of pelvis }\end{array}$ & & $y$ & & & & & 13 & 6 & & & 39 & 4 & 74 & 2.82 & 1.00 & 9.04 & 0.0282 & {$\left[\begin{array}{c}33,34, \\
37]\end{array}\right.$} \\
\hline
\end{tabular}


medRxiv preprint doi: https://doi.org/10.1101/2020.12.30.20218610; this version posted January 4, 2021. The copyright holder for this preprint (which was not certified by peer review) is the author/funder, who has granted medRxiv a license to display the preprint in perpetuity. This article is a US Government work. It is not subject to copyright under 17 USC 105 and is also made available for use under a CCO license.

\begin{tabular}{|c|c|c|c|c|c|c|c|c|c|c|c|c|c|c|c|c|c|}
\hline \multirow[b]{2}{*}{$\begin{array}{l}\text { ICD9 diagnosis code and } \\
\text { name }\end{array}$} & \multicolumn{5}{|c|}{ Interpretation } & \multirow[b]{2}{*}{ 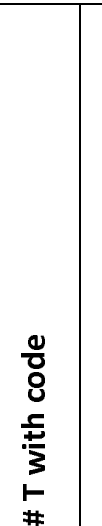 } & \multirow[b]{2}{*}{ 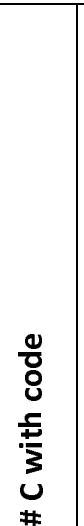 } & \multirow[b]{2}{*}{ 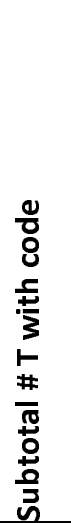 } & \multirow[b]{2}{*}{ 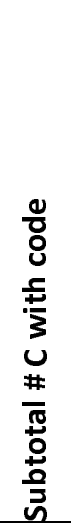 } & \multicolumn{3}{|c|}{$\begin{array}{l}\text { Rate difference } \\
\text { statistics }\end{array}$} & \multicolumn{3}{|c|}{ Rate ratio statistics } & \multirow[b]{2}{*}{$p$ value } & \multirow[b]{2}{*}{ 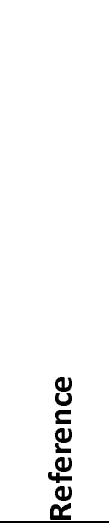 } \\
\hline & 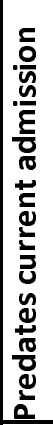 & 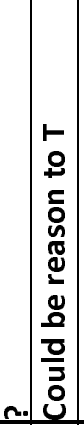 & 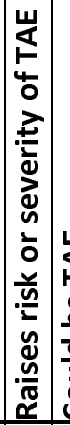 & 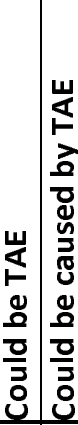 & 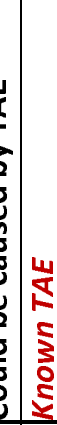 & & & & & 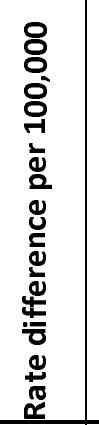 & 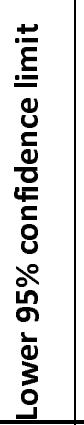 & 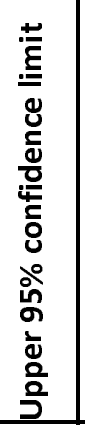 & 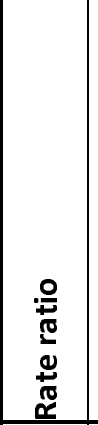 & 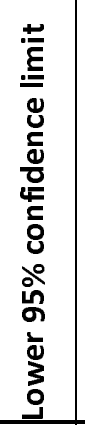 & 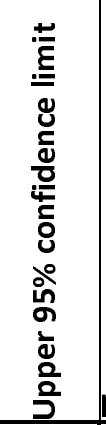 & & \\
\hline $\begin{array}{l}8080 \text { Closed fracture of } \\
\text { acetabulum }\end{array}$ & & $y$ & & & & 139 & 52 & & & 462 & 351 & 573 & \begin{tabular}{|l|}
3.48 \\
\end{tabular} & 2.51 & 4.88 & $<0.0001$ & $\begin{array}{c}{[33,34,} \\
37]\end{array}$ \\
\hline $\begin{array}{l}82021 \text { Closed fracture of } \\
\text { intertrochanteric section of } \\
\text { neck of femur }\end{array}$ & & y & & & & 98 & 43 & & & 303 & 208 & 398 & 2.96 & 2.05 & 4.35 & $<0.0001$ & $\begin{array}{c}{[33,34,} \\
37]\end{array}$ \\
\hline $\begin{array}{l}82022 \text { Closed fracture of } \\
\text { subtrochanteric section of } \\
\text { neck of femur }\end{array}$ & & $y$ & & & & 49 & 11 & & & 189 & 127 & 251 & \begin{tabular}{|l|}
5.79 \\
\end{tabular} & 2.97 & 12.36 & $<0.0001$ & $\begin{array}{c}{[33,34,} \\
37]\end{array}$ \\
\hline $\begin{array}{l}8208 \text { Closed fracture of } \\
\text { unspecified part of neck of } \\
\text { femur }\end{array}$ & & $y$ & & & & 45 & 27 & & & 113 & 45 & 181 & \begin{tabular}{|l|}
2.17 \\
\end{tabular} & 1.32 & 3.63 & 0.0011 & $\begin{array}{c}{[33,34,} \\
37]\end{array}$ \\
\hline $\begin{array}{l}82101 \text { Closed fracture of } \\
\text { shaft of femur }\end{array}$ & & $y$ & & & & 63 & 17 & & & 233 & 161 & 305 & \begin{tabular}{|l|}
4.82 \\
\end{tabular} & 2.79 & 8.79 & $<0.0001$ & $\begin{array}{c}{[33,34,} \\
37]\end{array}$ \\
\hline $\begin{array}{l}82111 \text { Open fracture of shaft } \\
\text { of femur }\end{array}$ & & $y$ & & & & 22 & 2 & & & 95 & 21 & 170 & 14.31 & 4.10 & 49.91 & 0.00 & $\begin{array}{c}{[33,34,} \\
37]\end{array}$ \\
\hline $\begin{array}{l}82121 \text { Closed fracture of } \\
\text { condyle, femoral }\end{array}$ & & $y$ & & & & 13 & 6 & & & 39 & 4 & 74 & \begin{tabular}{|l|}
2.82 \\
\end{tabular} & 1.00 & 9.04 & 0.0282 & $\begin{array}{c}{[33,34,} \\
37]\end{array}$ \\
\hline $\begin{array}{l}82123 \text { Closed supracondylar } \\
\text { fracture of femur }\end{array}$ & & $y$ & & & & 24 & 10 & & & 76 & 29 & 123 & \begin{tabular}{|l|}
3.12 \\
\end{tabular} & 1.44 & 7.31 & 0.0014 & $\begin{array}{l}{[33,34,} \\
37]\end{array}$ \\
\hline $\begin{array}{l}82131 \text { Open fracture of } \\
\text { condyle, femoral }\end{array}$ & & y & & & & 6 & 0 & & & 28 & -17 & 73 & & & & 0.03 & $\begin{array}{c}{[33,34,} \\
37]\end{array}$ \\
\hline $\begin{array}{l}82133 \text { Open supracondylar } \\
\text { fracture of femur }\end{array}$ & & $y$ & & & & 8 & 1 & & & 34 & -23 & 90 & 10.40 & 1.12 & 96.60 & 0.04 & $\begin{array}{c}{[33,34,} \\
37]\end{array}$ \\
\hline 92400 Contusion of thigh & & $\mathrm{y}$ & & & & 25 & 15 & & & 63 & 12 & 113 & 2.17 & 1.10 & 4.42 & 0.0152 & $\begin{array}{l}{[33,34,} \\
37]\end{array}$ \\
\hline $\begin{array}{l}8220 \text { Closed fracture of } \\
\text { patella }\end{array}$ & & $y$ & & & & 22 & 12 & & & 60 & 13 & 106 & 2.38 & 1.13 & 5.286 & 0.0125 & $\begin{array}{c}{[33,34,} \\
37]\end{array}$ \\
\hline $\begin{array}{l}8221 \text { Open fracture of } \\
\text { patella }\end{array}$ & & $y$ & & & & 6 & 0 & & & 28 & -17 & 73 & & & & 0.03 & $\begin{array}{c}{[33,34,} \\
37]\end{array}$ \\
\hline $\begin{array}{l}82300 \text { Closed fracture of } \\
\text { upper end of tibia alone }\end{array}$ & & y & & & & 44 & 19 & & & 137 & 73 & 201 & 3.01 & 1.72 & 5.46 & $<0.0001$ & $\begin{array}{c}{[33,34,} \\
37]\end{array}$ \\
\hline $\begin{array}{l}82302 \text { Closed fracture of } \\
\text { upper end of fibula with tibia }\end{array}$ & & y & & & & 28 & 11 & & & 91 & 41 & 141 & 3.31 & 1.60 & 7.37 & 0.0004 & $\begin{array}{c}{[33,34,} \\
37]\end{array}$ \\
\hline $\begin{array}{l}82312 \text { Open fracture of } \\
\text { upper end of fibula with tibia }\end{array}$ & & y & & & & 9 & 1 & & & 38 & -19 & 95 & 11.71 & 1.43 & 95.53 & 0.02 & $\begin{array}{c}{[33,34,} \\
37]\end{array}$ \\
\hline $\begin{array}{l}82330 \text { Open fracture of shaft } \\
\text { of tibia alone }\end{array}$ & & $y$ & & & & 10 & 2 & & & 39 & -26 & 105 & 6.50 & 1.10 & 38.43 & 0.04 & $\begin{array}{c}{[33,34,} \\
37]\end{array}$ \\
\hline $\begin{array}{l}82332 \text { Open fracture of shaft } \\
\text { of fibula with tibia }\end{array}$ & & $y$ & & & & 30 & 12 & & & 97 & 45 & 149 & 3.25 & 1.62 & 6.97 & 0.0003 & $\begin{array}{c}{[33,34,} \\
37]\end{array}$ \\
\hline
\end{tabular}


medRxiv preprint doi: https://doi.org/10.1101/2020.12.30.20218610; this version posted January 4, 2021. The copyright holder for this preprint (which was not certified by peer review) is the author/funder, who has granted medRxiv a license to display the preprint in perpetuity. This article is a US Government work. It is not subject to copyright under 17 USC 105 and is also made available for use under a CCO license.

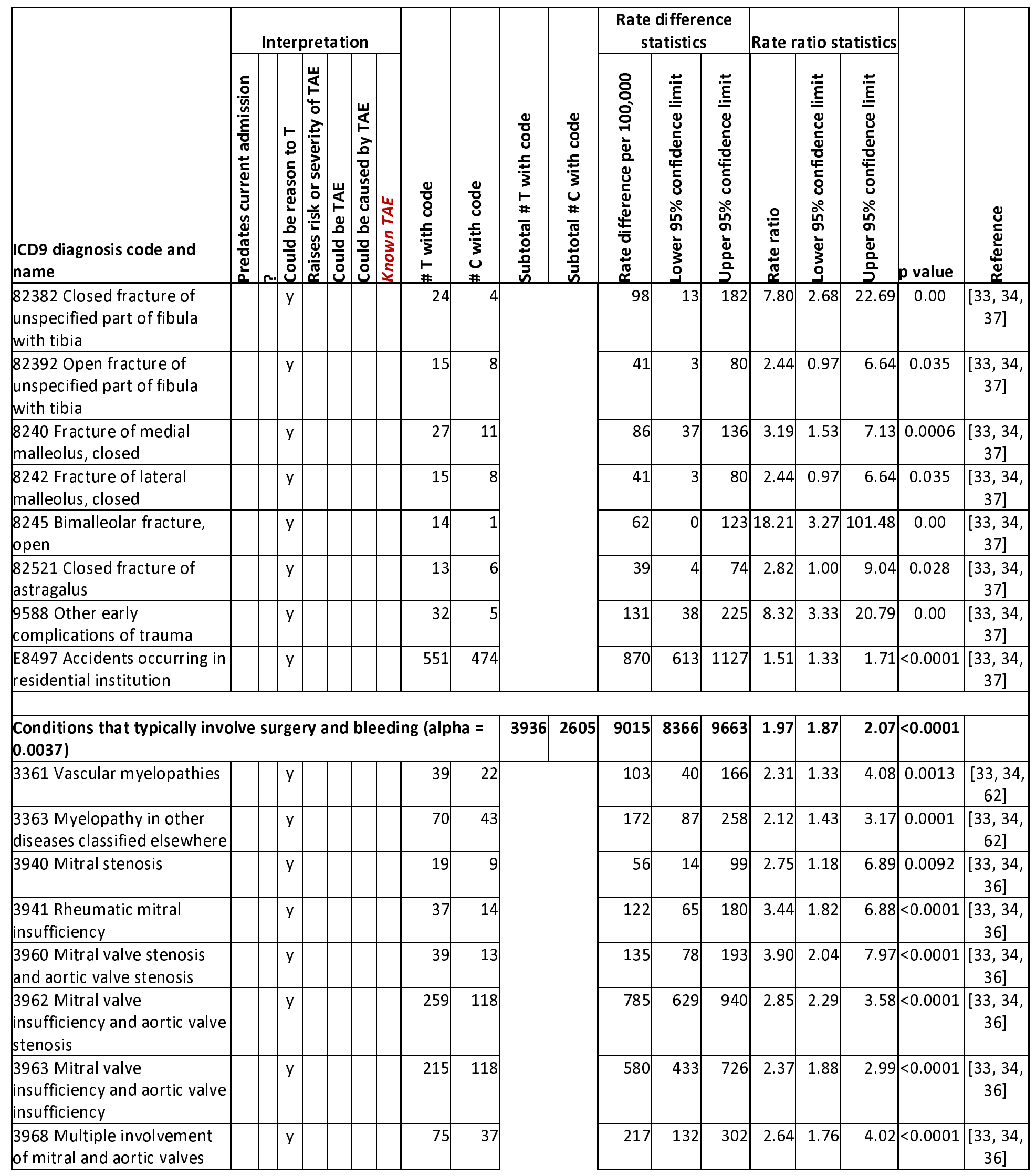


medRxiv preprint doi: https://doi.org/10.1101/2020.12.30.20218610; this version posted January 4, 2021. The copyright holder for this preprint (which was not certified by peer review) is the author/funder, who has granted medRxiv a license to display the preprint in perpetuity. This article is a US Government work. It is not subject to copyright under 17 USC 105 and is also made available for use under a CCO license.

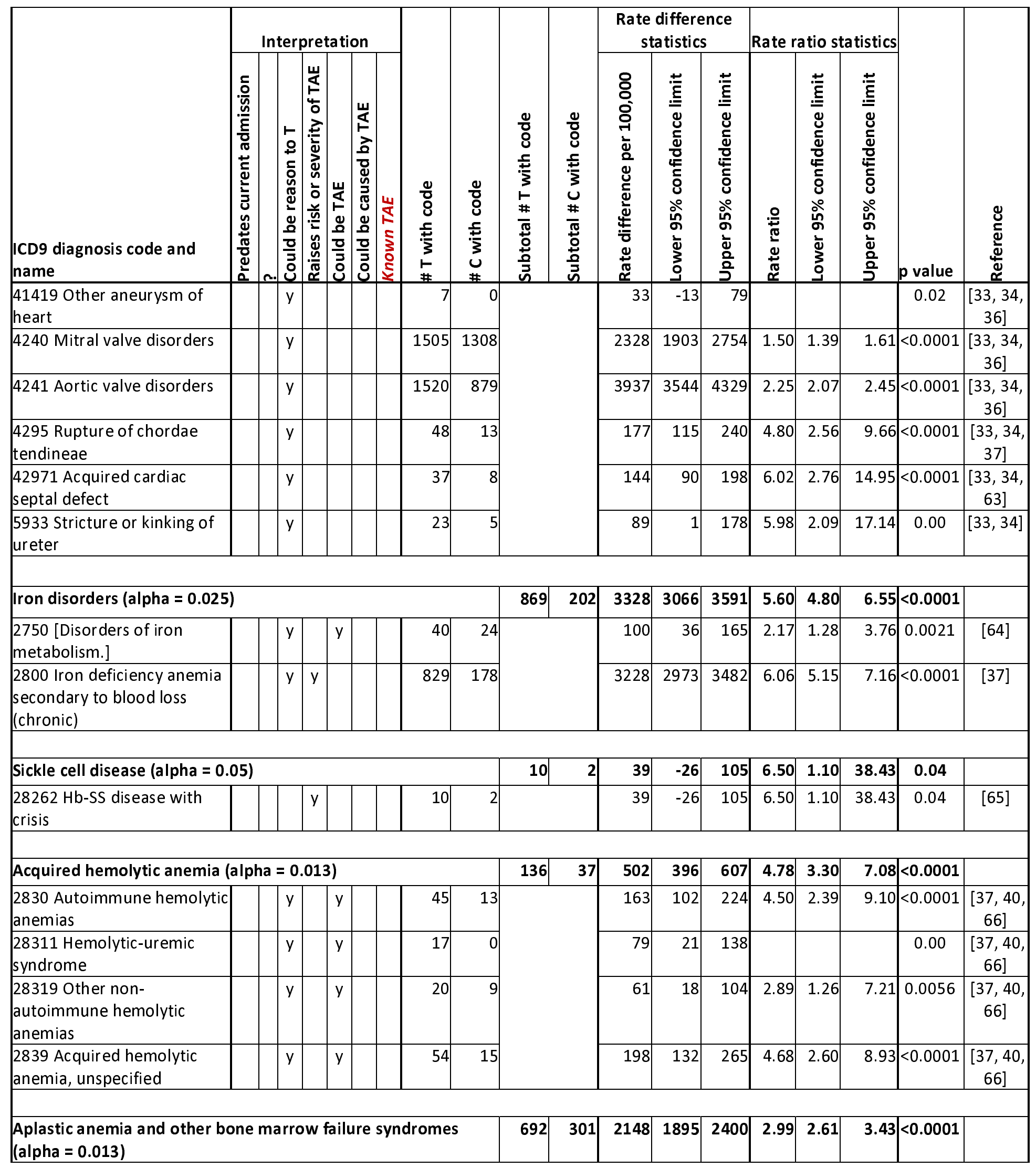


medRxiv preprint doi: https://doi.org/10.1101/2020.12.30.20218610; this version posted January 4, 2021. The copyright holder for this preprint (which was not certified by peer review) is the author/funder, who has granted medRxiv a license to display the preprint in perpetuity. This article is a US Government work. It is not subject to copyright under 17 USC 105 and is also made available for use under a CCO license.

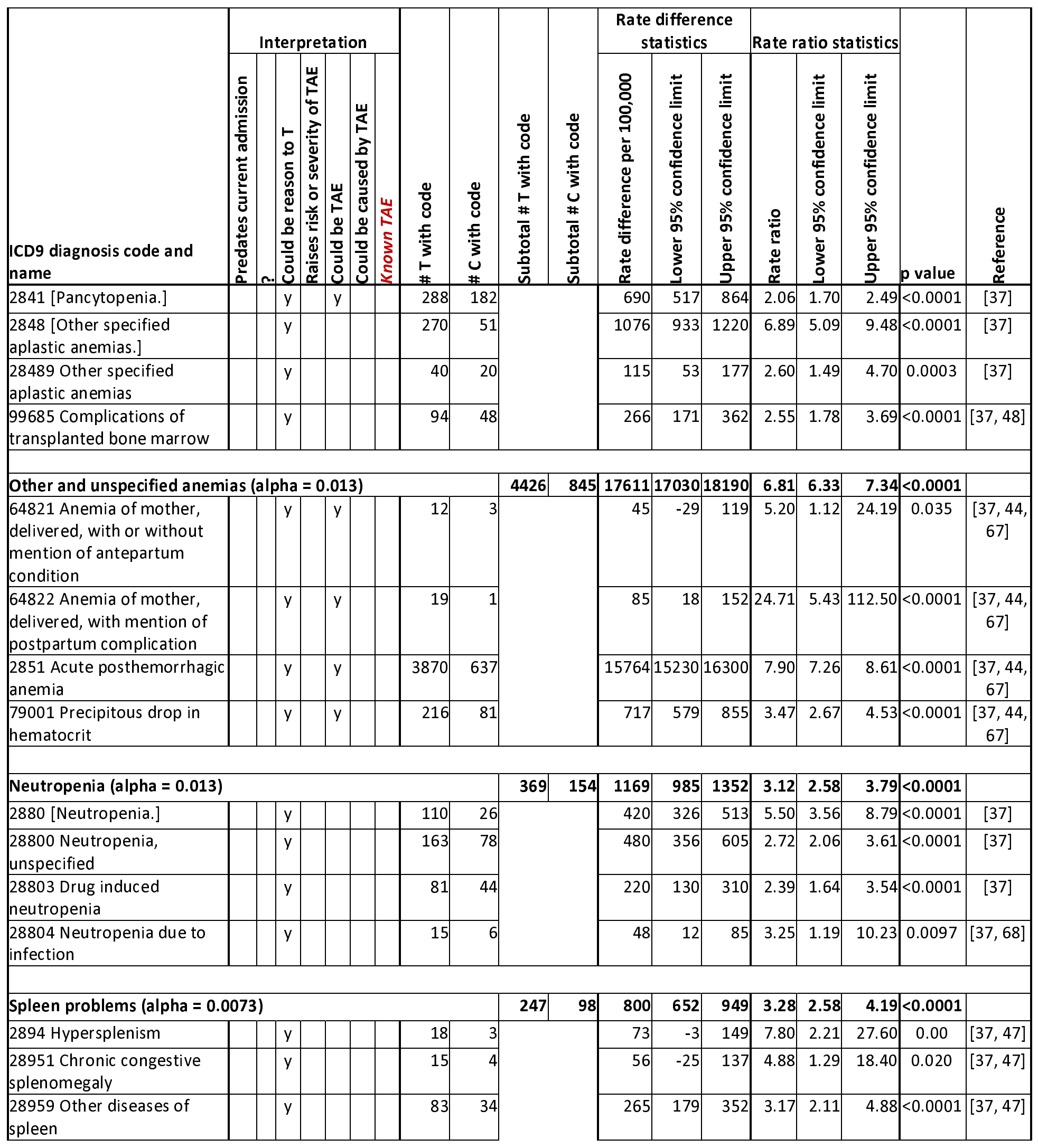


medRxiv preprint doi: https://doi.org/10.1101/2020.12.30.20218610; this version posted January 4, 2021. The copyright holder for this preprint (which was not certified by peer review) is the author/funder, who has granted medRxiv a license to display the preprint in perpetuity. This article is a US Government work. It is not subject to copyright under 17 USC 105 and is also made available for use under a CCO license.

\begin{tabular}{|c|c|c|c|c|c|c|c|c|c|c|c|c|c|c|c|c|c|}
\hline \multirow[b]{2}{*}{$\begin{array}{l}\text { ICD9 diagnosis code and } \\
\text { name }\end{array}$} & \multicolumn{5}{|c|}{ Interpretation } & \multirow[b]{2}{*}{ 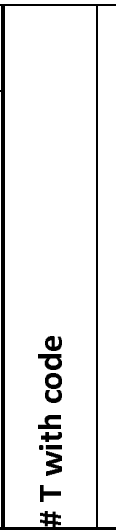 } & \multirow[b]{2}{*}{ 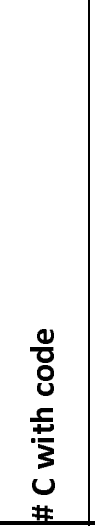 } & \multirow[b]{2}{*}{ 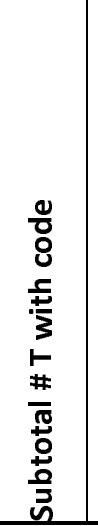 } & \multirow[b]{2}{*}{ 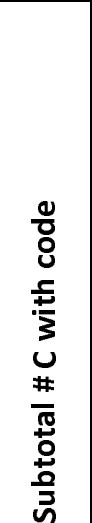 } & \multicolumn{3}{|c|}{$\begin{array}{c}\text { Rate difference } \\
\text { statistics }\end{array}$} & \multicolumn{3}{|c|}{ Rate ratio statistics } & \multirow[b]{2}{*}{$p$ value } & \multirow[b]{2}{*}{ 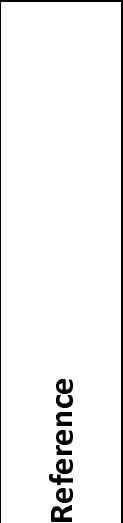 } \\
\hline & 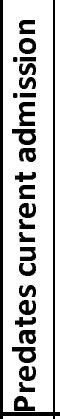 & 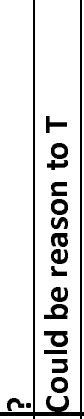 & 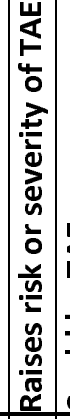 & 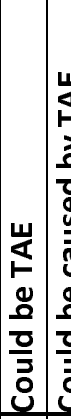 & & & & & & 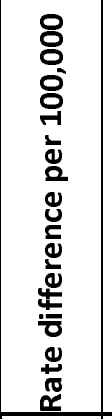 & 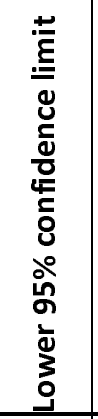 & 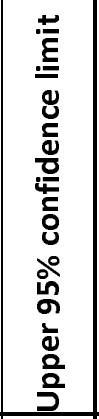 & 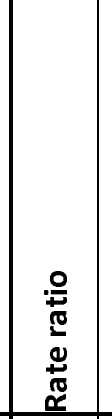 & 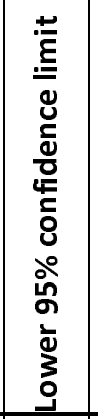 & 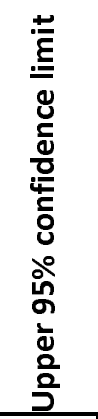 & & \\
\hline $\begin{array}{l}86502 \text { Injury to spleen } \\
\text { without mention of open } \\
\text { wound into cavity, capsular } \\
\text { tears, without major } \\
\text { disruption of parenchyma }\end{array}$ & & $y$ & & & & 28 & 13 & & & 84 & 33 & 135 & 2.80 & 1.40 & 5.89 & 0.0013 & {$[37,47]$} \\
\hline $\begin{array}{l}86504 \text { Injury to spleen } \\
\text { without mention of open } \\
\text { wound into cavity, massive } \\
\text { parenchymal disruption }\end{array}$ & & $y$ & & & & 27 & 3 & & & 115 & 33 & 198 & 11.71 & 4.02 & 34.10 & 0.00 & {$[37,47]$} \\
\hline $\begin{array}{l}86509 \text { Other injury into } \\
\text { spleen without mention of } \\
\text { open wound into cavity }\end{array}$ & & $\mathrm{y}$ & & & & 25 & 15 & & & 63 & 12 & 113 & 2.17 & $\mid 1.10$ & 4.42 & 0.0152 & {$[37,47]$} \\
\hline 7892 Splenomegaly & & y & & & & 51 & 26 & & & 145 & 74 & 215 & 2.55 & 1.56 & 4.26 & 0.0001 & {$[37,47]$} \\
\hline \multicolumn{8}{|c|}{ Coagulation problems that promote bleeding (alpha $=0.0047$ ) } & 5096 & 2395 & \multicolumn{3}{|c|}{151771448015870} & 2.77 & \begin{tabular}{|l|}
2.64 \\
\end{tabular} & 2.91 & $<0.0001$ & \\
\hline 2866 Defibrination syndrome & & y & & y & & 387 & 65 & & & 1572 & 1401 & 1742 & 7.74 & 5.94 & 10.23 & $<0.0001$ & [69] \\
\hline $\begin{array}{l}2867 \text { Acquired coagulation } \\
\text { factor deficiency }\end{array}$ & & y & & y & & 373 & 93 & & & 1406 & 1233 & 1579 & 5.22 & 4.15 & 6.62 & $<0.0001$ & $\begin{array}{l}{[37,40,} \\
47,69]\end{array}$ \\
\hline $\begin{array}{l}2869 \text { Other and unspecified } \\
\text { coagulation defects }\end{array}$ & & $y$ & & $\mathrm{y}$ & & 751 & 256 & & & 2584 & 2330 & 2839 & 3.82 & 3.31 & 4.41 & $<0.0001$ & $\begin{array}{l}{[37,40,} \\
47,69]\end{array}$ \\
\hline $\begin{array}{l}2873 \text { [Primary } \\
\text { thrombocytopenia.] }\end{array}$ & $y$ & $y$ & & & & 36 & 17 & & & 107 & 49 & 165 & 2.75 & 1.51 & 5.23 & 0.0003 & [45] \\
\hline $\begin{array}{l}28731 \text { Immune } \\
\text { thrombocytopenic purpura }\end{array}$ & & $y$ & & $y$ & & 66 & 32 & & & 193 & 114 & 272 & 2.68 & 1.73 & 4.23 & $3<0.0001$ & $\begin{array}{l}{[35,37,} \\
40,47]\end{array}$ \\
\hline $\begin{array}{l}2874 \text { [Secondary } \\
\text { thrombocytopenia.] }\end{array}$ & & y & & y & & 398 & 181 & & & 1207 & 1014 & 1400 & 2.86 & 2.39 & 3.43 & $<0.0001$ & $\begin{array}{l}{[35,37} \\
40,47]\end{array}$ \\
\hline $\begin{array}{l}28749 \text { Other secondary } \\
\text { thrombocytopenia }\end{array}$ & & $y$ & & $y$ & & 79 & 51 & & & 186 & 94 & 277 & 2.01 & 1.40 & 2.92 & 0.0001 & $\begin{array}{l}{[35,37} \\
40,47]\end{array}$ \\
\hline $\begin{array}{l}2875 \text { Thrombocytopenia, } \\
\text { unspecified }\end{array}$ & & $y$ & & $y$ & & 1928 & 1103 & & & 5036 & 4595 & 5477 & 2.27 & 2.11 & 2.45 & $<0.0001$ & $\begin{array}{l}{[35,37} \\
40,47]\end{array}$ \\
\hline $\begin{array}{l}66632 \text { Postpartum } \\
\text { coagulation defects, } \\
\text { delivered, with mention of } \\
\text { postpartum complication }\end{array}$ & & $y$ & & $y$ & & 10 & 0 & & & 47 & -3 & 97 & & & & 0.00 & $\begin{array}{l}{[35,37} \\
40,47]\end{array}$ \\
\hline $\begin{array}{l}79092 \text { Abnormal coagulation } \\
\text { profile }\end{array}$ & & $y$ & & y & & 591 & 394 & & & 1343 & 1092 & 1595 & 1.95 & 1.71 & 2.22 & $<0.0001$ & $\begin{array}{l}{[35,37,} \\
40,47] \\
\end{array}$ \\
\hline $\begin{array}{l}\text { E9342 Anticoagulants } \\
\text { causing adverse effects in } \\
\text { therapeutic use }\end{array}$ & & $y$ & & y & & 477 & 203 & & & 1497 & 1288 & 1706 & 3.06 & 2.59 & 3.62 & $<0.0001$ & $\begin{array}{l}{[35,37} \\
40,47]\end{array}$ \\
\hline
\end{tabular}


medRxiv preprint doi: https://doi.org/10.1101/2020.12.30.20218610; this version posted January 4, 2021. The copyright holder for this preprint (which was not certified by peer review) is the author/funder, who has granted medRxiv a license to display the preprint in perpetuity.

This article is a US Government work. It is not subject to copyright under 17 USC 105 and is also made available for use under a CCO license. 
medRxiv preprint doi: https://doi.org/10.1101/2020.12.30.20218610; this version posted January 4, 2021. The copyright holder for this preprint (which was not certified by peer review) is the author/funder, who has granted medRxiv a license to display the preprint in perpetuity.

This article is a US Government work. It is not subject to copyright under 17 USC 105 and is also made available for use under a CCO license.

Table 5. Analysis of $\mathrm{T}$ (transfusion) and C (comparison) groups for immune, neoplasm, and infection diagnosis codes. If all diagnoses in the table are dependent, alpha is 0.00049 . Bracketed diagnosis code names were not in the MIMIC-III database, therefore were looked up [30] and confirmed in some notes.

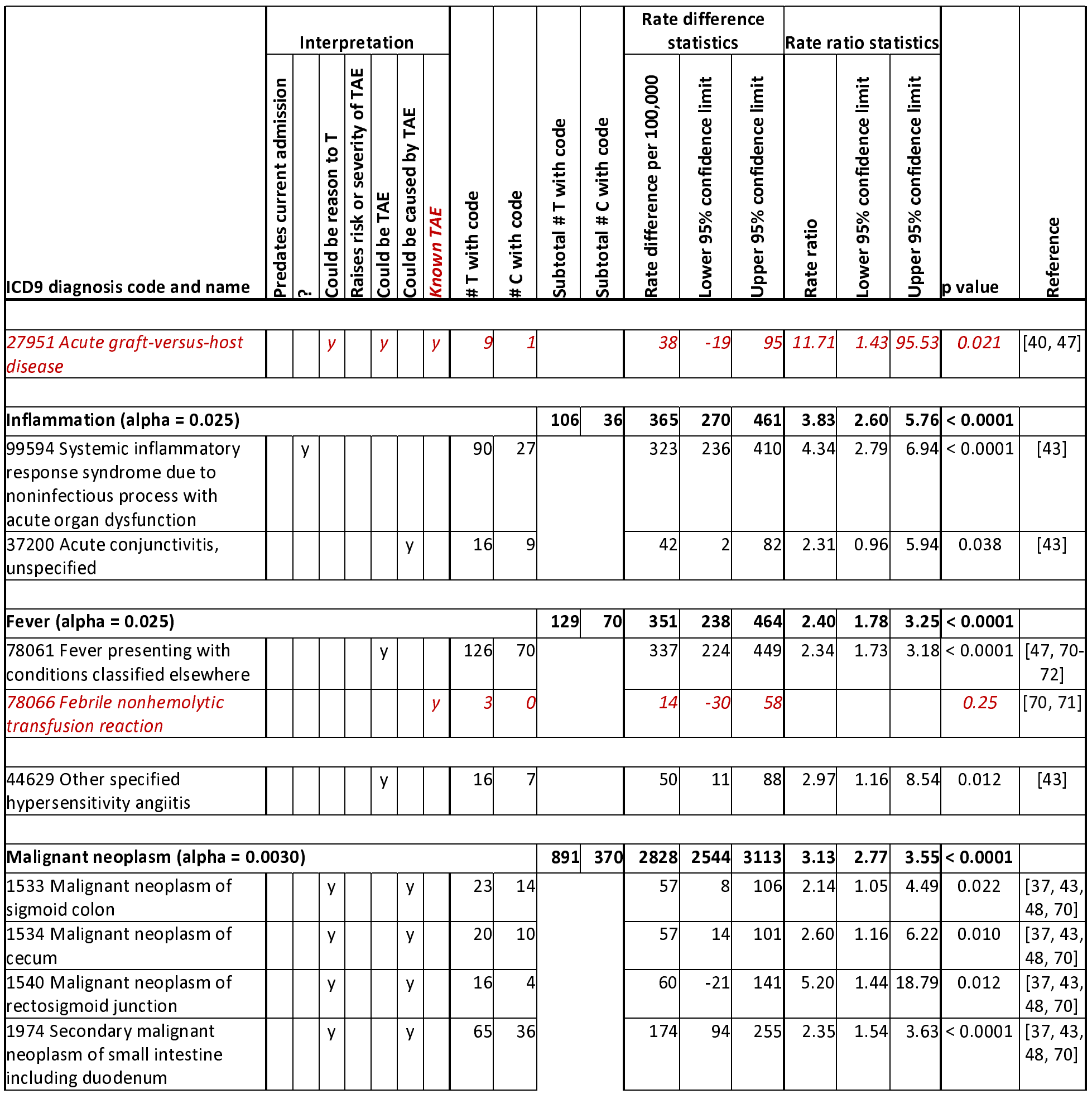


medRxiv preprint doi: https://doi.org/10.1101/2020.12.30.20218610; this version posted January 4, 2021. The copyright holder for this preprint (which was not certified by peer review) is the author/funder, who has granted medRxiv a license to display the preprint in perpetuity. This article is a US Government work. It is not subject to copyright under 17 USC 105 and is also made available for use under a CCO license.

\begin{tabular}{|c|c|c|c|c|c|c|c|c|c|c|c|c|c|c|c|c|c|c|}
\hline \multirow[b]{2}{*}{ ICD9 diagnosis code and name } & \multicolumn{6}{|c|}{ Interpretation } & \multirow[b]{2}{*}{ 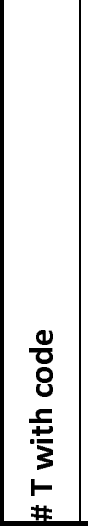 } & \multirow[b]{2}{*}{ 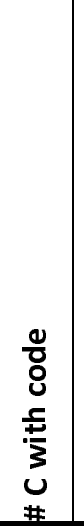 } & \multirow[b]{2}{*}{ 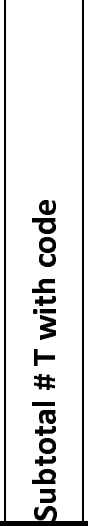 } & \multirow[b]{2}{*}{ 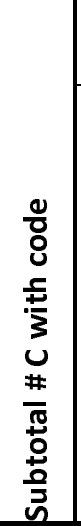 } & \multicolumn{3}{|c|}{$\begin{array}{c}\text { Rate difference } \\
\text { statistics }\end{array}$} & \multicolumn{3}{|c|}{ Rate ratio statistics } & \multirow[b]{2}{*}{ p value } & \multirow[b]{2}{*}{ 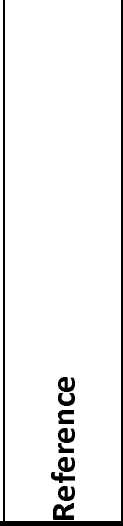 } \\
\hline & 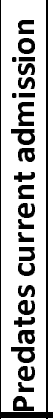 & & 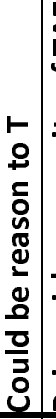 & 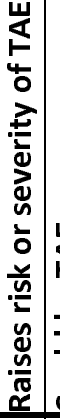 & 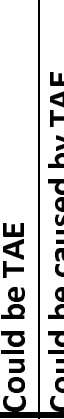 & 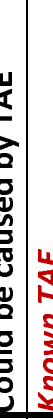 & & & & & 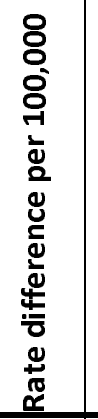 & 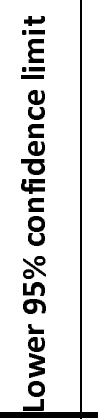 & 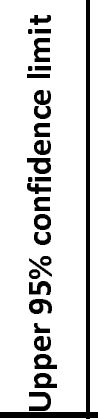 & 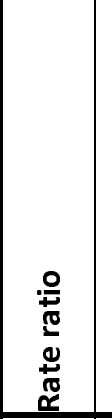 & 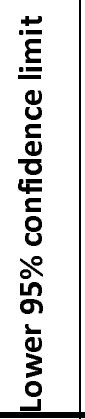 & 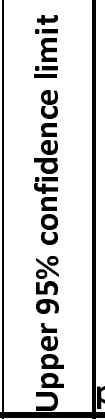 & & \\
\hline $\begin{array}{l}1975 \text { Secondary malignant } \\
\text { neoplasm of large intestine and } \\
\text { rectum }\end{array}$ & & & $\mathrm{y}$ & & $y$ & y & 50 & 25 & & & 144 & 74 & 213 & 2.60 & 1.58 & 4.39 & 0.0001 & $\begin{array}{l}{[37,43} \\
48,70]\end{array}$ \\
\hline $\begin{array}{l}1830 \text { Malignant neoplasm of } \\
\text { ovary }\end{array}$ & & & $y$ & & $y$ & $y$ & 50 & 31 & & & 122 & 50 & 194 & 2.10 & 1.31 & 3.40 & 0.0009 & $\begin{array}{l}{[37,43,} \\
48,70] \\
\end{array}$ \\
\hline $\begin{array}{l}1986 \text { Secondary malignant } \\
\text { neoplasm of ovary }\end{array}$ & & & y & & $y$ & $y$ & 14 & 6 & & & 44 & 8 & 80 & 3.03 & 1.10 & 9.63 & 0.017 & \begin{tabular}{|l}
37,43 \\
$48,70]$ \\
\end{tabular} \\
\hline $\begin{array}{l}1888 \text { Malignant neoplasm of } \\
\text { other specified sites of bladder }\end{array}$ & & & y & & $y$ & $y$ & 43 & 26 & & & 107 & 41 & 174 & 2.15 & 1.29 & 3.65 & 0.0016 & $\begin{array}{l}37,43 \\
48,70]\end{array}$ \\
\hline $\begin{array}{l}1981 \text { Secondary malignant } \\
\text { neoplasm of other urinary } \\
\text { organs }\end{array}$ & & & y & & $y$ & $y$ & 29 & 13 & & & 89 & 37 & 141 & 2.90 & 1.46 & 6.08 & 0.0008 & $\begin{array}{l}{[37,43} \\
48,70]\end{array}$ \\
\hline $\begin{array}{l}19882 \text { Secondary malignant } \\
\text { neoplasm of genital organs }\end{array}$ & & & y & & $y$ & $y$ & 32 & 13 & & & 103 & 49 & 156 & 3.20 & 1.63 & 6.65 & 0.0002 & $\begin{array}{l}{[37,43} \\
48,70] \\
\end{array}$ \\
\hline $\begin{array}{l}20400 \text { Acute lymphoid leukemia, } \\
\text { without mention of having } \\
\text { achieved remission }\end{array}$ & & & y & & y & & 27 & 12 & & & 83 & 33 & 133 & 2.93 & 1.43 & 6.34 & 0.0012 & {$\left[\begin{array}{c}{[37,67} \\
73]\end{array}\right.$} \\
\hline $\begin{array}{l}20500 \text { Acute myeloid leukemia, } \\
\text { without mention of having } \\
\text { achieved remission }\end{array}$ & & & y & & y & & 163 & 32 & & & 645 & 534 & 757 & 6.62 & 4.51 & 10.01 & $<0.0001$ & {$[37,47]$} \\
\hline $\begin{array}{l}20501 \text { Acute myeloid leukemia, } \\
\text { in remission }\end{array}$ & $y$ & & & & & & 20 & 10 & & & 57 & 14 & 101 & 2.60 & 1.16 & 6.22 & 0.010 & \\
\hline $\begin{array}{l}20510 \text { Chronic myeloid } \\
\text { leukemia, without mention of } \\
\text { having achieved remission }\end{array}$ & & & y & & y & & 42 & 23 & & & 113 & 49 & 178 & 2.37 & 1.40 & 4.14 & 0.0006 & [37] \\
\hline 27788 Tumor lysis syndrome & & y & & & & & 20 & 10 & & & 57 & 14 & 101 & 2.60 & 1.16 & 6.22 & 0.010 & \begin{tabular}{|c|}
37,43 \\
48,70, \\
$74]$
\end{tabular} \\
\hline $\begin{array}{l}1550 \text { Malignant neoplasm of } \\
\text { liver, primary }\end{array}$ & & & $y$ & & $y$ & $y$ & 237 & 100 & & & 747 & 600 & 894 & 3.08 & 2.43 & 3.93 & $<0.0001$ & $\begin{array}{l}{[37,43} \\
48,70]\end{array}$ \\
\hline $\begin{array}{l}1552 \text { Malignant neoplasm of } \\
\text { liver, not specified as primary or } \\
\text { secondary }\end{array}$ & & & y & & $y$ & $y$ & 40 & 5 & & & 169 & 115 & 222 & 10.40 & 4.11 & 33.78 & $<0.0001$ & $\begin{array}{l}{[37,43} \\
48,70]\end{array}$ \\
\hline Benign neoplasms (alpha $=0.004$ & & & & & & & & & 663 & 211 & 2335 & 2098 & 2572 & 4.09 & 3.49 & 4.79 & $<0.0001$ & \\
\hline $\begin{array}{l}2111 \text { Benign neoplasm of } \\
\text { stomach }\end{array}$ & & $\mathrm{y}$ & & & & & 58 & 22 & & & 192 & 120 & 263 & 3.43 & 2.07 & 5.88 & $<0.0001$ & \\
\hline $\begin{array}{l}2112 \text { Benign neoplasm of } \\
\text { duodenum, jejunum, and ileum }\end{array}$ & & y & & & & & 37 & 9 & & & 140 & 86 & 195 & 5.35 & 2.53 & 12.60 & $<0.0001$ & \\
\hline
\end{tabular}


medRxiv preprint doi: https://doi.org/10.1101/2020.12.30.20218610; this version posted January 4, 2021. The copyright holder for this preprint (which was not certified by peer review) is the author/funder, who has granted medRxiv a license to display the preprint in perpetuity. This article is a US Government work. It is not subject to copyright under 17 USC 105 and is also made available for use under a CCO license.

\begin{tabular}{|c|c|c|c|c|c|c|c|c|c|c|c|c|c|c|c|c|c|}
\hline \multirow[b]{2}{*}{ ICD9 diagnosis code and name } & \multicolumn{6}{|c|}{ Interpretation } & \multirow[b]{2}{*}{ 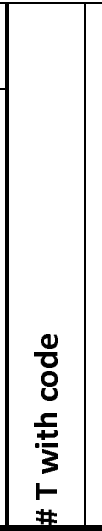 } & \multirow[b]{2}{*}{ 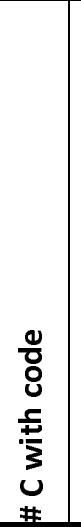 } & \multirow[b]{2}{*}{ 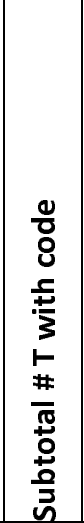 } & \multicolumn{3}{|c|}{$\begin{array}{l}\text { Rate difference } \\
\text { statistics }\end{array}$} & \multicolumn{3}{|c|}{ Rate ratio statistics } & \multirow[b]{2}{*}{ p value } & \multirow[b]{2}{*}{ 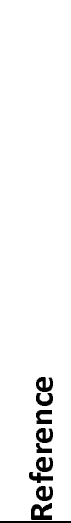 } \\
\hline & 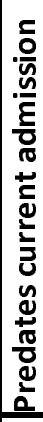 & & 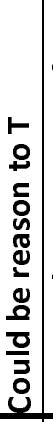 & 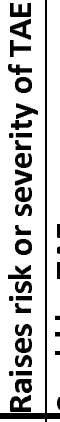 & 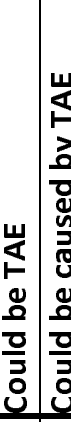 & & & & & 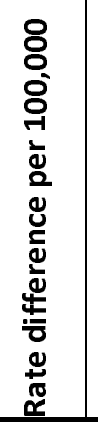 & 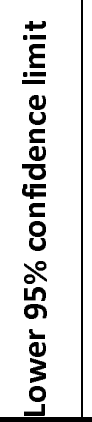 & 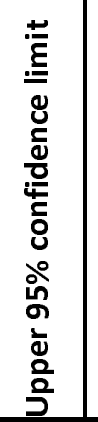 & 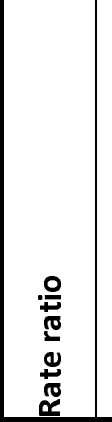 & 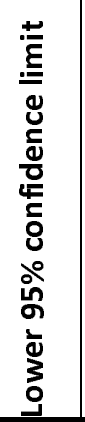 & 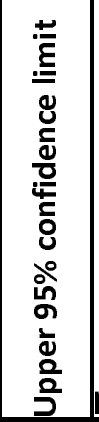 & & \\
\hline 2113 Benign neoplasm of colon & & $\mathrm{y}$ & & & & & 245 & 74 & & 877 & 734 & 1020 & 4.31 & 3.31 & 5.66 & $<0.0001$ & \\
\hline $\begin{array}{l}2114 \text { Benign neoplasm of } \\
\text { rectum and anal canal }\end{array}$ & & $y$ & & & & & 24 & 10 & & 76 & 29 & 123 & 3.12 & 1.44 & 7.31 & 0.0014 & \\
\hline $\begin{array}{l}2115 \text { Benign neoplasm of liver } \\
\text { and biliary passages }\end{array}$ & & $y$ & & & & & 11 & 6 & & 30 & -3 & 63 & 2.38 & 0.81 & 7.85 & 0.077 & \\
\hline $\begin{array}{l}2180 \text { Submucous leiomyoma of } \\
\text { uterus }\end{array}$ & & & y & $y$ & & & 6 & 0 & & 28 & -17 & 73 & & & & 0.031 & \\
\hline $\begin{array}{l}2181 \text { Intramural leiomyoma of } \\
\text { uterus }\end{array}$ & & $y$ & & & & & 14 & 6 & & 44 & 8 & 80 & 3.03 & 1.10 & 9.63 & 0.017 & \\
\hline $\begin{array}{l}2230 \text { Benign neoplasm of } \\
\text { kidney, except pelvis }\end{array}$ & & $y$ & & & & & 8 & 1 & & 34 & -23 & 90 & 10.40 & 1.12 & 96.60 & 0.039 & \\
\hline $\begin{array}{l}2352 \text { Neoplasm of uncertain } \\
\text { behavior of stomach, intestines, } \\
\text { and rectum }\end{array}$ & & $y$ & & & & & 10 & 0 & & 47 & -3 & 97 & & & & 0.0020 & \\
\hline $\begin{array}{l}2381 \text { Neoplasm of uncertain } \\
\text { behavior of connective and } \\
\text { other soft tissue }\end{array}$ & & $y$ & & & & & 13 & 3 & & 50 & -24 & 124 & 5.64 & 1.29 & 24.59 & 0.021 & \\
\hline $\begin{array}{l}2387 \text { [Neoplasm of uncertain } \\
\text { behavior of other lymphatic and } \\
\text { hematopoietic tissues.] }\end{array}$ & & $y$ & & & & & 96 & 24 & & 362 & 274 & 449 & 5.20 & 3.30 & 8.51 & $<0.0001$ & \\
\hline $\begin{array}{l}23875 \text { Myelodysplastic } \\
\text { syndrome, unspecified }\end{array}$ & & $y$ & & & & & 141 & 56 & & 457 & 344 & 569 & 3.27 & 2.39 & 4.55 & $<0.0001$ & \\
\hline $\begin{array}{l}\text { V1000 Personal history of } \\
\text { malignant neoplasm of } \\
\text { gastrointestinal tract, } \\
\text { unspecified }\end{array}$ & $y$ & & & & & & 20 & 11 & & 54 & 9 & 98 & 2.36 & 1.08 & 5.46 & 0.018 & \\
\hline Septicemia (alpha $=0.0085)$ & & & & & & & & & 26562062 & 4992 & 4442 & 5543 & 1.68 & 1.58 & 1.78 & $<0.0001$ & \\
\hline $\begin{array}{l}3811 \text { Methicillin susceptible } \\
\text { Staphylococcus aureus } \\
\text { septicemia }\end{array}$ & & & & & $y$ & & 332 & 180 & & 903 & 722 & 1084 & 2.40 & 1.99 & 2.89 & $<0.0001$ & [75] \\
\hline $\begin{array}{l}3819 \text { Other staphylococcal } \\
\text { septicemia }\end{array}$ & & & & & $y$ & & 89 & 58 & & 207 & 110 & 304 & 2.00 & 1.42 & 2.83 & $<0.0001$ & [75] \\
\hline $\begin{array}{l}3843 \text { Septicemia due to } \\
\text { pseudomonas }\end{array}$ & & & & & $y$ & & 84 & 41 & & 245 & 155 & 334 & 2.66 & 1.81 & 3.97 & $<0.0001$ & [75] \\
\hline 3844 Septicemia due to serratia & & & & & y & & 18 & 9 & & 52 & 10 & 93 & 2.60 & 1.11 & 6.57 & 0.015 & [75] \\
\hline 388 Other specified septicemias & & & & & y & & 143 & 61 & & 448 & 334 & 563 & 3.05 & 2.24 & 4.19 & $<0.0001$ & [43] \\
\hline
\end{tabular}


medRxiv preprint doi: https://doi.org/10.1101/2020.12.30.20218610; this version posted January 4, 2021. The copyright holder for this preprint (which was not certified by peer review) is the author/funder, who has granted medRxiv a license to display the preprint in perpetuity. This article is a US Government work. It is not subject to copyright under 17 USC 105 and is also made available for use under a CCO license.

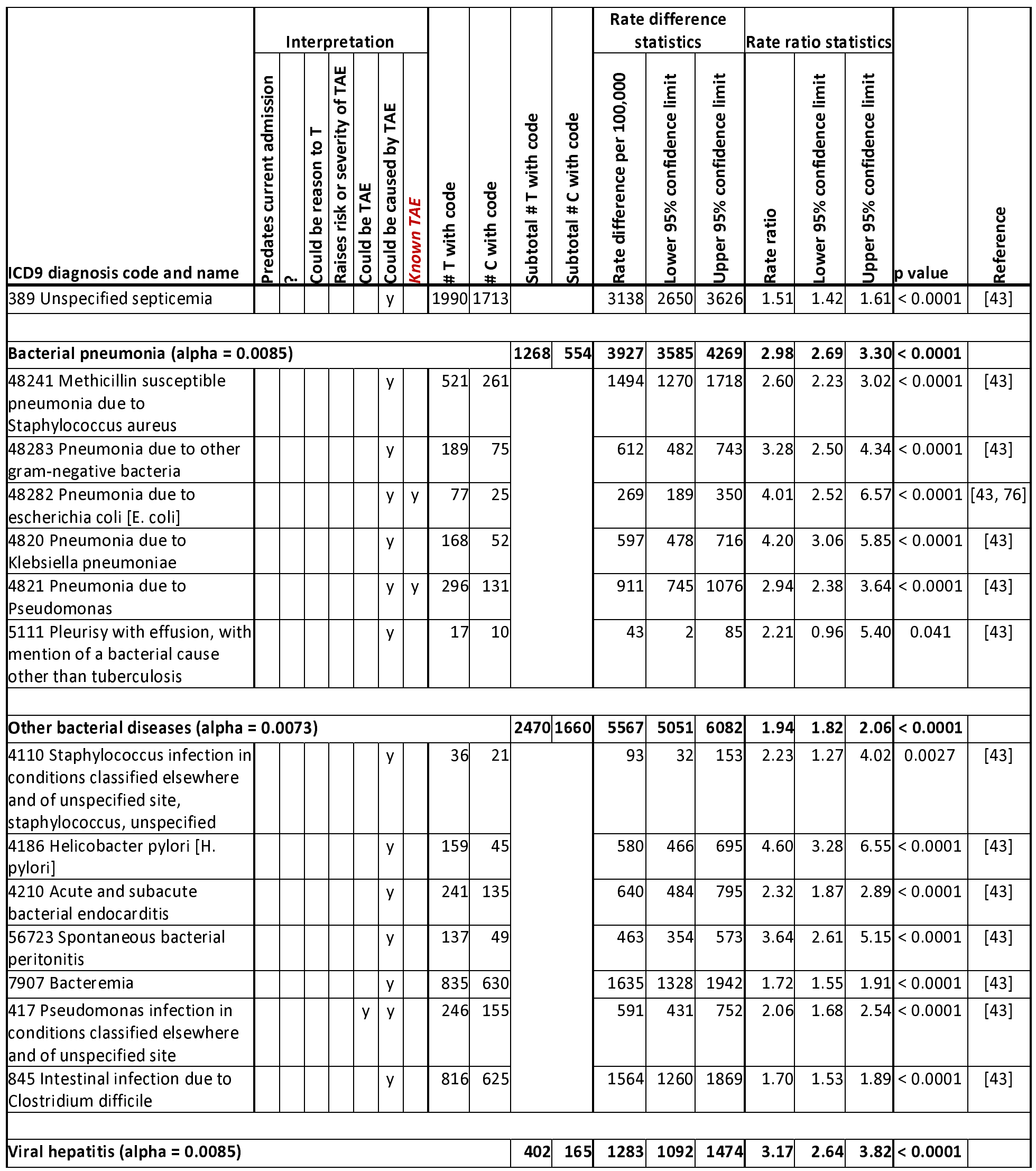


medRxiv preprint doi: https://doi.org/10.1101/2020.12.30.20218610; this version posted January 4, 2021. The copyright holder for this preprint (which was not certified by peer review) is the author/funder, who has granted medRxiv a license to display the preprint in perpetuity. This article is a US Government work. It is not subject to copyright under 17 USC 105 and is also made available for use under a CCO license.

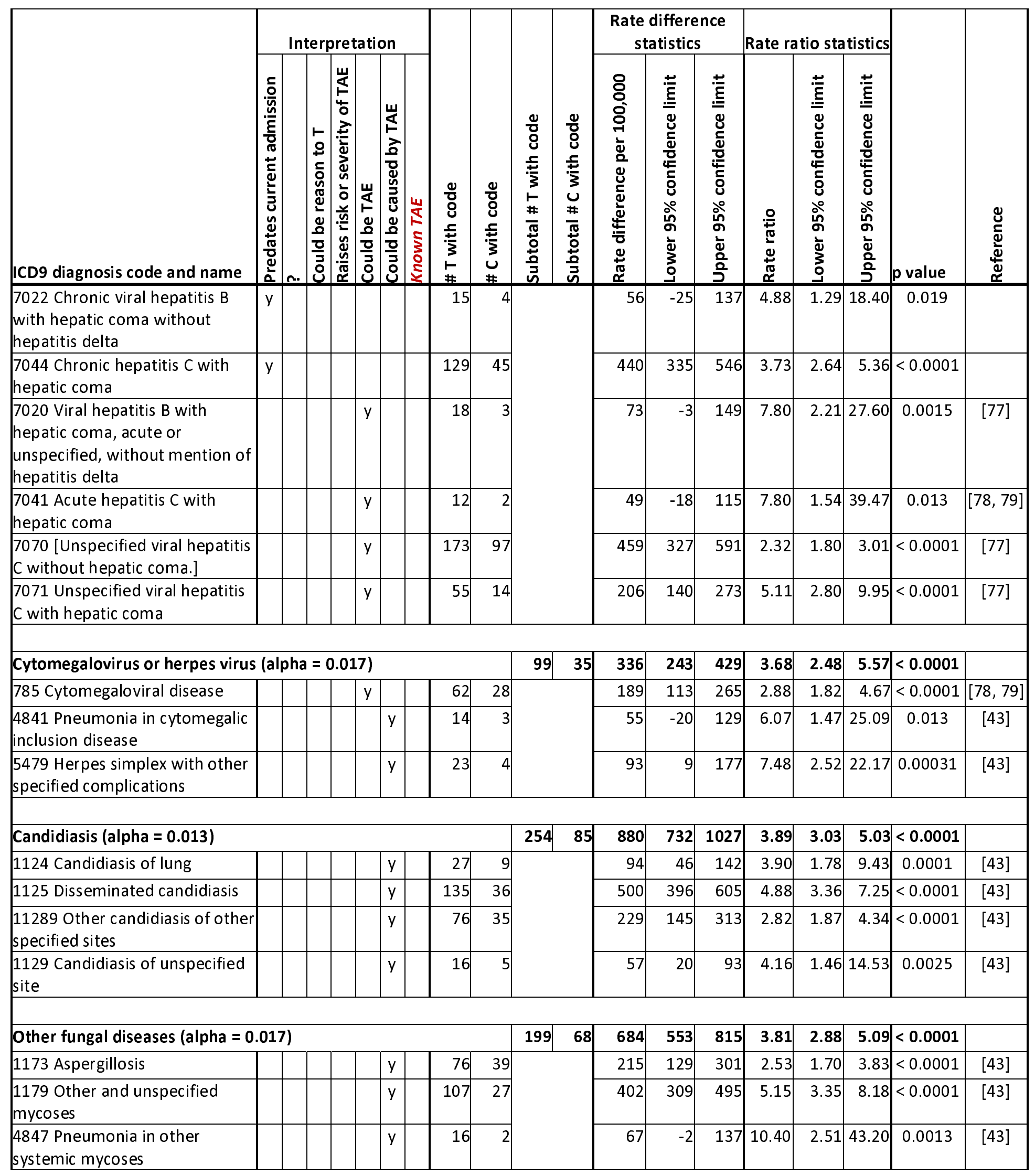


medRxiv preprint doi: https://doi.org/10.1101/2020.12.30.20218610; this version posted January 4, 2021. The copyright holder for this preprint (which was not certified by peer review) is the author/funder, who has granted medRxiv a license to display the preprint in perpetuity. This article is a US Government work. It is not subject to copyright under 17 USC 105 and is also made available for use under a CCO license.

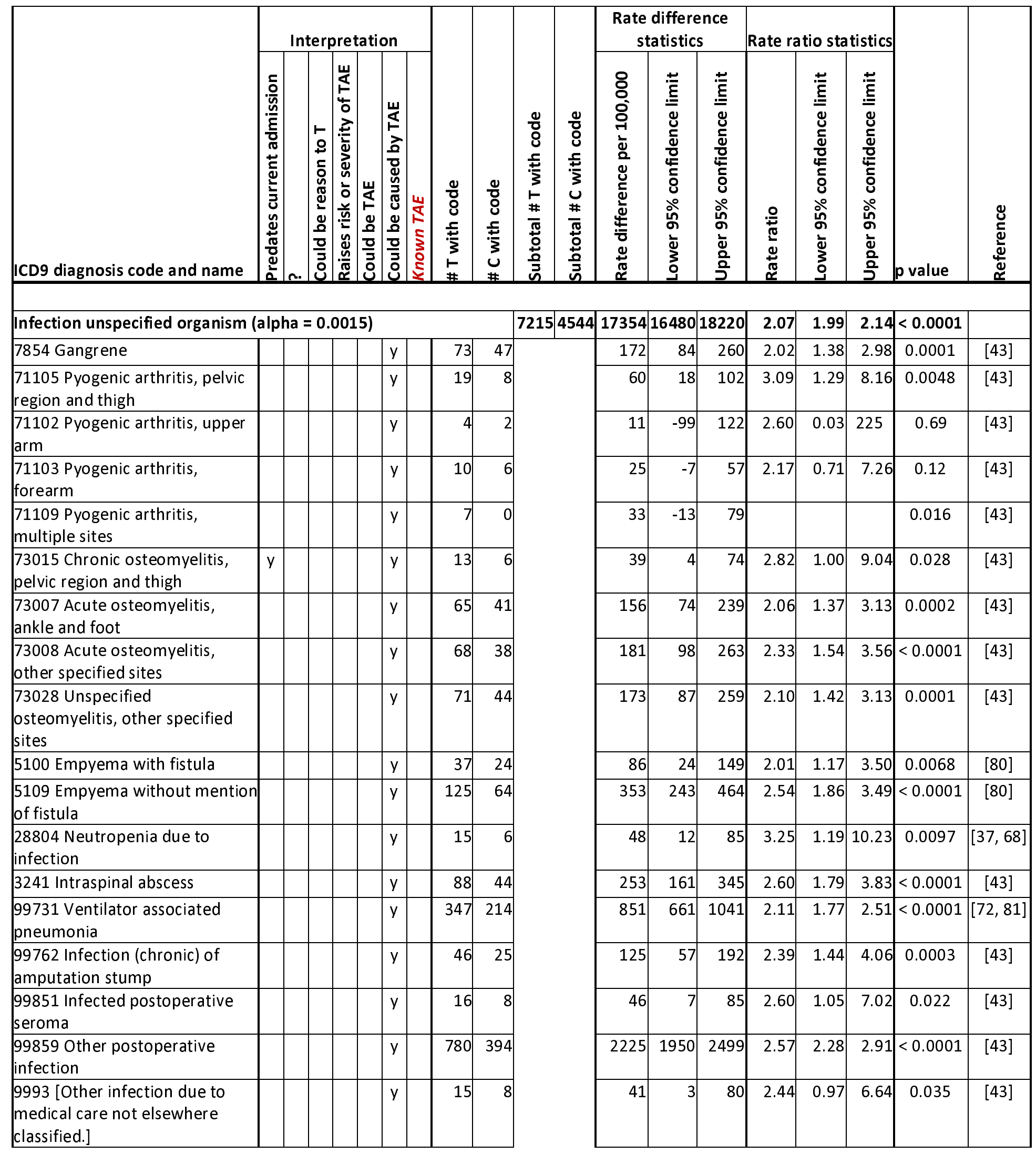


medRxiv preprint doi: https://doi.org/10.1101/2020.12.30.20218610; this version posted January 4, 2021. The copyright holder for this preprint (which was not certified by peer review) is the author/funder, who has granted medRxiv a license to display the preprint in perpetuity.

This article is a US Government work. It is not subject to copyright under 17 USC 105 and is also made available for use under a CCO license.

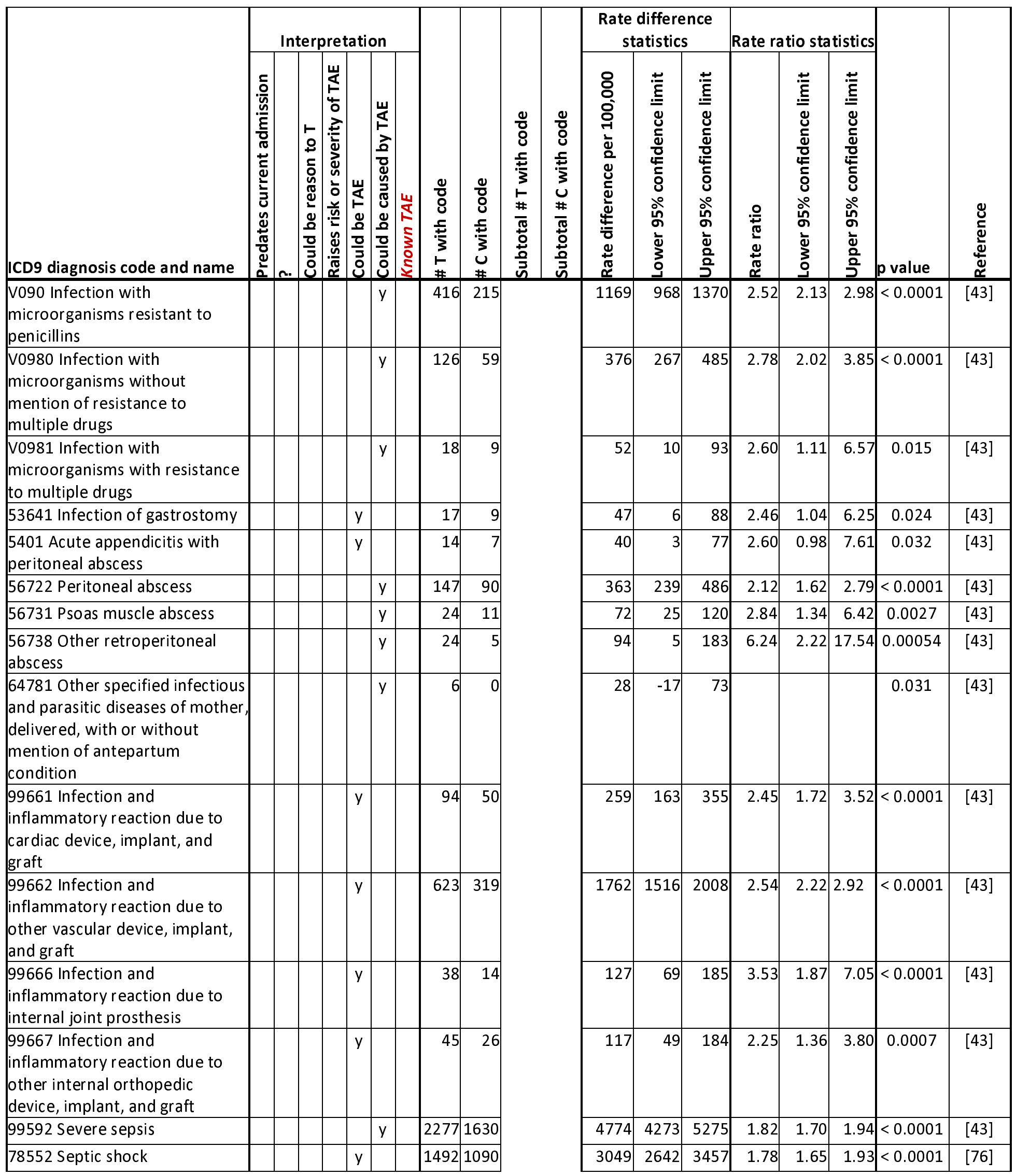


medRxiv preprint doi: https://doi.org/10.1101/2020.12.30.20218610; this version posted January 4, 2021. The copyright holder for this preprint (which was not certified by peer review) is the author/funder, who has granted medRxiv a license to display the preprint in perpetuity.

This article is a US Government work. It is not subject to copyright under 17 USC 105 and is also made available for use under a CCO license.

\begin{tabular}{|c|c|c|c|c|c|c|c|c|c|c|c|c|c|c|c|c|c|}
\hline \multirow[b]{2}{*}{ CD9 diagnosis code and name } & \multicolumn{5}{|c|}{ Interpretation } & \multirow[b]{2}{*}{ 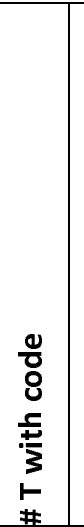 } & \multirow[b]{2}{*}{ 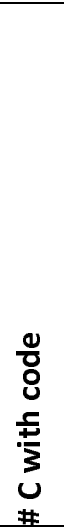 } & \multirow[b]{2}{*}{ 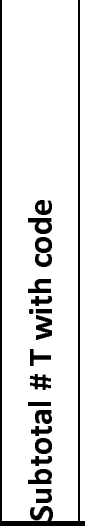 } & \multirow[b]{2}{*}{ 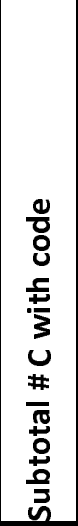 } & \multicolumn{3}{|c|}{$\begin{array}{c}\text { Rate difference } \\
\text { statistics }\end{array}$} & \multicolumn{3}{|c|}{ Rate ratio statistics } & \multirow[b]{2}{*}{ p value } & \multirow[b]{2}{*}{ 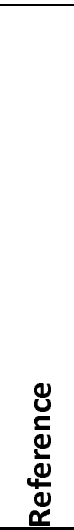 } \\
\hline & 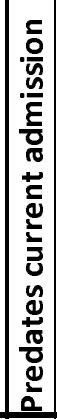 & 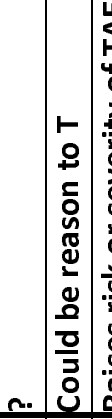 & 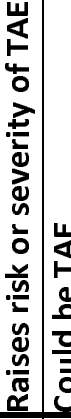 & 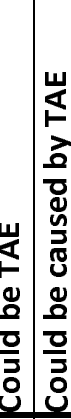 & \begin{tabular}{|l} 
\\
$\mathbf{w}$ \\
$\mathbf{z}$ \\
$\mathbf{5}$ \\
$\mathbf{3}$ \\
$\mathbf{0}$ \\
$\underline{\mathbf{s}}$ \\
\end{tabular} & & & & & 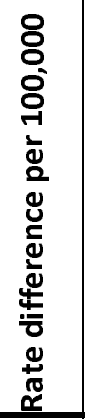 & 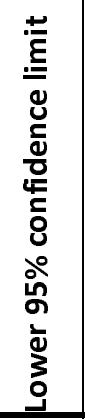 & 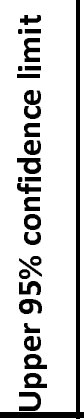 & 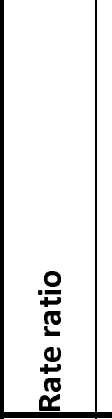 & 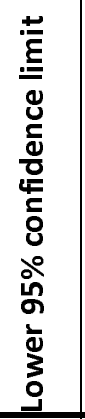 & 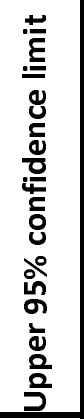 & & \\
\hline 72886 Necrotizing fasciitis & & & & $y$ & & 55 & 31 & & & 145 & 71 & 220 & 2.31 & 1.46 & 3.71 & 0.0001 & {$[82]$} \\
\hline
\end{tabular}


medRxiv preprint doi: https://doi.org/10.1101/2020.12.30.20218610; this version posted January 4, 2021. The copyright holder for this preprint (which was not certified by peer review) is the author/funder, who has granted medRxiv a license to display the preprint in perpetuity. This article is a US Government work. It is not subject to copyright under 17 USC 105 and is also made available for use under a CCO license.

Table 6. Analysis of $\mathrm{T}$ (transfusion) and C (comparison) groups for lungs and oral diagnosis codes. If all diagnoses in the table are dependent, alpha is 0.0034. Bracketed diagnosis code names were not in the MIMIC-III database, therefore were looked up [30] and confirmed in some notes.

\begin{tabular}{|c|c|c|c|c|c|c|c|c|c|c|c|c|c|c|c|c|}
\hline \multirow[b]{2}{*}{$\begin{array}{l} \\
\text { ICD9 diagnosis code and } \\
\text { name }\end{array}$} & \multicolumn{4}{|c|}{ Interpretation } & \multirow[b]{2}{*}{ 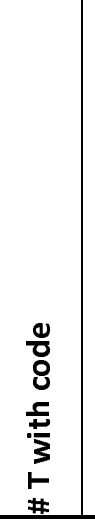 } & \multirow[b]{2}{*}{ 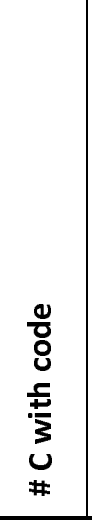 } & \multirow[b]{2}{*}{ 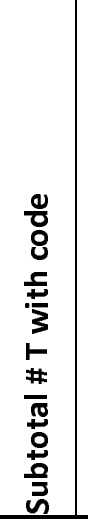 } & \multirow[b]{2}{*}{ 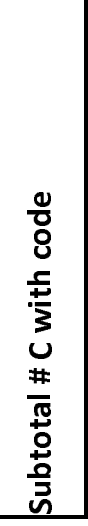 } & \multicolumn{3}{|c|}{$\begin{array}{l}\text { Rate difference } \\
\text { statistics }\end{array}$} & \multicolumn{3}{|c|}{$\begin{array}{l}\text { Rate ratio } \\
\text { statistics }\end{array}$} & \multirow[b]{2}{*}{$p$ value } & \multirow[b]{2}{*}{ 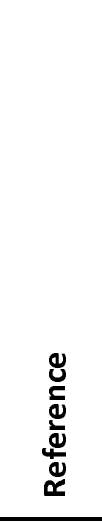 } \\
\hline & 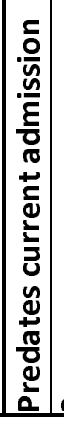 & 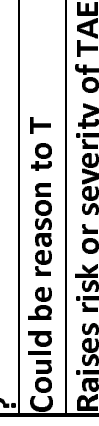 & 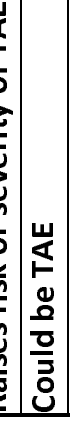 & 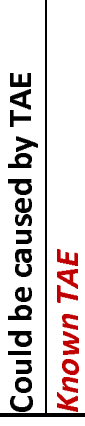 & & & & & 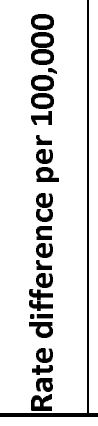 & 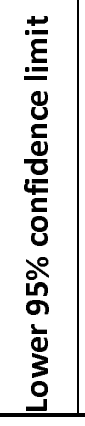 & 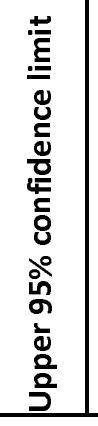 & 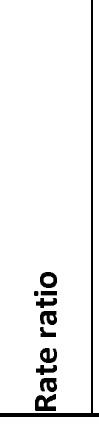 & 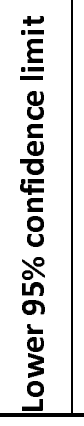 & 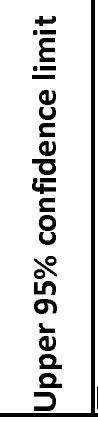 & & \\
\hline \multicolumn{7}{|l|}{ Pleural effusion (alpha $=0.025$ ) } & 1682 & 1177 & \multicolumn{2}{|c|}{36243195} & 4052 & 1.86 & 1.72 & 2.00 & $<0.0001$ & \\
\hline $\begin{array}{l}\text { 5118 [Other specified forms of } \\
\text { pleural effusion except } \\
\text { tuberculous.] }\end{array}$ & & & & $\mathrm{y}$ & 135 & 31 & & & 518 & 415 & 622 & 5.66 & 3.81 & 8.66 & $<0.0001$ & [80] \\
\hline \begin{tabular}{|l|}
5119 Unspecified pleural \\
effusion
\end{tabular} & & & & $\mathrm{y}$ & 1547 & 1146 & & & 3105 & 2689 & 3521 & 1.76 & 1.63 & 1.90 & $<0.0001$ & [80] \\
\hline \multicolumn{7}{|c|}{ Other diseases of respiratory system (alpha $=\mathbf{0 . 0 0 7 3}$ ) } & 2289 & 960 & \multicolumn{2}{|c|}{72326776} & 7689 & 3.10 & 2.87 & 3.35 & $<0.0001$ & \\
\hline \begin{tabular}{|l|}
5121 latrogenic \\
pneumothorax
\end{tabular} & & & & \begin{tabular}{|l|l|}
$\mathrm{y}$ & \\
\end{tabular} & 464 & 297 & & & 1099 & 878 & 1320 & 2.03 & 1.75 & 2.36 & $<0.0001$ & {$[80,81]$} \\
\hline $\begin{array}{l}5185 \text { [Pulmonary insufficiency } \\
\text { following trauma and } \\
\text { surgery.] }\end{array}$ & & & $\mathrm{y}$ & & 1359 & 436 & & & 4774 & 4435 & 5114 & 4.05 & 3.64 & 4.53 & $<0.0001$ & [72] \\
\hline $\begin{array}{l}51851 \text { Acute respiratory } \\
\text { failure following trauma and } \\
\text { surgery }\end{array}$ & & & $\mathrm{y}$ & & 116 & 55 & & & 344 & 239 & 449 & 2.74 & 1.97 & 3.85 & $<0.0001$ & [72] \\
\hline $\begin{array}{l}51852 \text { Other pulmonary } \\
\text { insufficiency, not elsewhere } \\
\text { classified, following trauma } \\
\text { and surgery }\end{array}$ & & & $y$ & & 48 & 27 & & & 127 & 58 & 196 & 2.31 & 1.41 & 3.85 & $<0.0001$ & {$[72]$} \\
\hline 5192 Mediastinitis & & & & $\mathrm{y}$ & 30 & 18 & & & 75 & 20 & 131 & 2.17 & 1.17 & 4.13 & 0.0078 & [83] \\
\hline 7864 Abnormal sputum & & 1 & & & 10 & 1 & & & 43 & -15 & 101 & 13.01 & 1.77 & 95.69 & 0.012 & \\
\hline $\begin{array}{l}9973 \text { [Respiratory } \\
\text { complications not elsewhere } \\
\text { classified.] }\end{array}$ & & & y & $\mathrm{y}$ & 262 & 126 & & & 770 & 612 & 928 & 2.70 & 2.18 & 3.37 & $<0.0001$ & {$[49,72]$} \\
\hline $\begin{array}{l}\text { Diseases of oral cavity, salivan } \\
0.0085 \text { ) }\end{array}$ & y g & nds, an & id jav & ws (a) & & & 165 & 76 & 497 & 373 & 621 & 2.82 & 2.14 & 3.76 & $<0.0001$ & \\
\hline $\begin{array}{l}52100 \text { Dental caries, } \\
\text { unspecified }\end{array}$ & $\mathrm{y}$ & & & & 65 & 28 & & & 203 & 125 & 280 & 3.02 & 1.91 & 4.89 & $<0.0001$ & \\
\hline 52109 Other dental caries & y & & & & 13 & 6 & & & 39 & 4 & 74 & 2.82 & 1.00 & 9.04 & 0.028 & \\
\hline
\end{tabular}


medRxiv preprint doi: https://doi.org/10.1101/2020.12.30.20218610; this version posted January 4, 2021. The copyright holder for this preprint (which was not certified by peer review) is the author/funder, who has granted medRxiv a license to display the preprint in perpetuity.

This article is a US Government work. It is not subject to copyright under 17 USC 105 and is also made available for use under a CCO license.

\begin{tabular}{|c|c|c|c|c|c|c|c|c|c|c|c|c|c|c|c|c|c|c|}
\hline \multirow[b]{2}{*}{$\begin{array}{l}\text { ICD9 diagnosis code and } \\
\text { name }\end{array}$} & \multicolumn{6}{|c|}{ Interpretation } & \multirow[b]{2}{*}{$\begin{array}{l}\frac{0}{8} \\
8 \\
5 \\
5 \\
5 \\
1 \\
=\end{array}$} & \multirow[b]{2}{*}{ 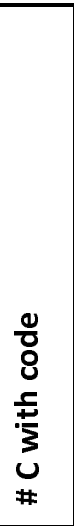 } & \multirow[b]{2}{*}{ 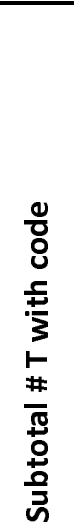 } & \multirow[b]{2}{*}{ 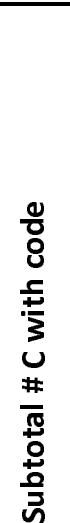 } & \multicolumn{3}{|c|}{$\begin{array}{l}\text { Rate difference } \\
\text { statistics }\end{array}$} & \multicolumn{3}{|c|}{$\begin{array}{l}\text { Rate ratio } \\
\text { statistics }\end{array}$} & \multirow[b]{2}{*}{$p$ value } & \multirow[b]{2}{*}{ 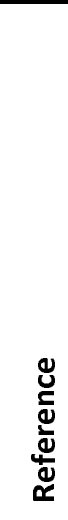 } \\
\hline & 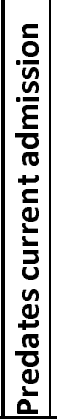 & I- & 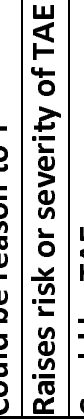 & 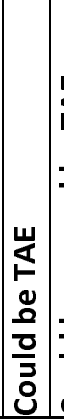 & 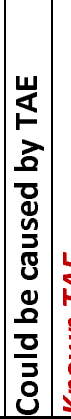 & 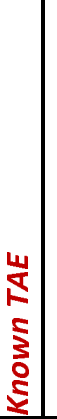 & & & & & 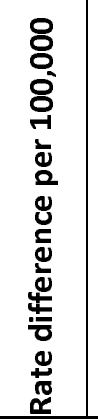 & 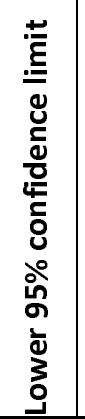 & 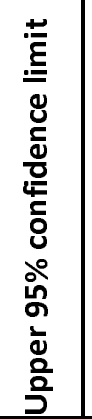 & 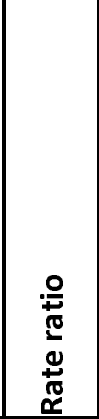 & 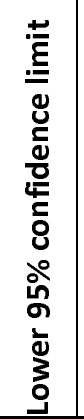 & 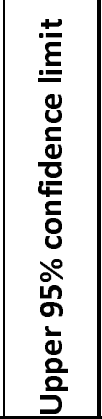 & & \\
\hline $\begin{array}{l}5224 \text { Acute apical } \\
\text { periodontitis of pulpal origin }\end{array}$ & & & & & $y$ & & 22 & 14 & & & 52 & 4 & 100 & 2.04 & 1.00 & 4.32 & 0.033 & [43] \\
\hline $\begin{array}{l}52510 \text { Acquired absence of } \\
\text { teeth, unspecified }\end{array}$ & & $y$ & & & & & 9 & 1 & & & 38 & -19 & 95 & $\mid 11.71$ & 1.43 & 95.53 & 0.021 & \\
\hline $\begin{array}{l}52800 \text { Stomatitis and } \\
\text { mucositis, unspecified }\end{array}$ & & & & & $y$ & & 24 & 10 & & & 76 & 29 & 123 & 3.12 & 1.44 & 7.31 & 0.0014 & [43] \\
\hline $\begin{array}{l}52801 \text { Mucositis (ulcerative) } \\
\text { due to antineoplastic therapy }\end{array}$ & & & & & $y$ & & 32 & 17 & & & 88 & 32 & 144 & 2.45 & 1.32 & 4.70 & 0.002 & [43] \\
\hline
\end{tabular}


medRxiv preprint doi: https://doi.org/10.1101/2020.12.30.20218610; this version posted January 4, 2021. The copyright holder for this preprint (which was not certified by peer review) is the author/funder, who has granted medRxiv a license to display the preprint in perpetuity.

This article is a US Government work. It is not subject to copyright under 17 USC 105 and is also made available for use under a CCO license.

Table 7. Analysis of $\mathrm{T}$ (transfusion) and $\mathrm{C}$ (comparison) groups for diagnosis codes that relate to fluids regulation. If all diagnoses in the table are dependent, alpha is 0.0032 . Bracketed diagnosis code names were not in the MIMIC-III database, therefore were looked up [30] and confirmed in some notes.

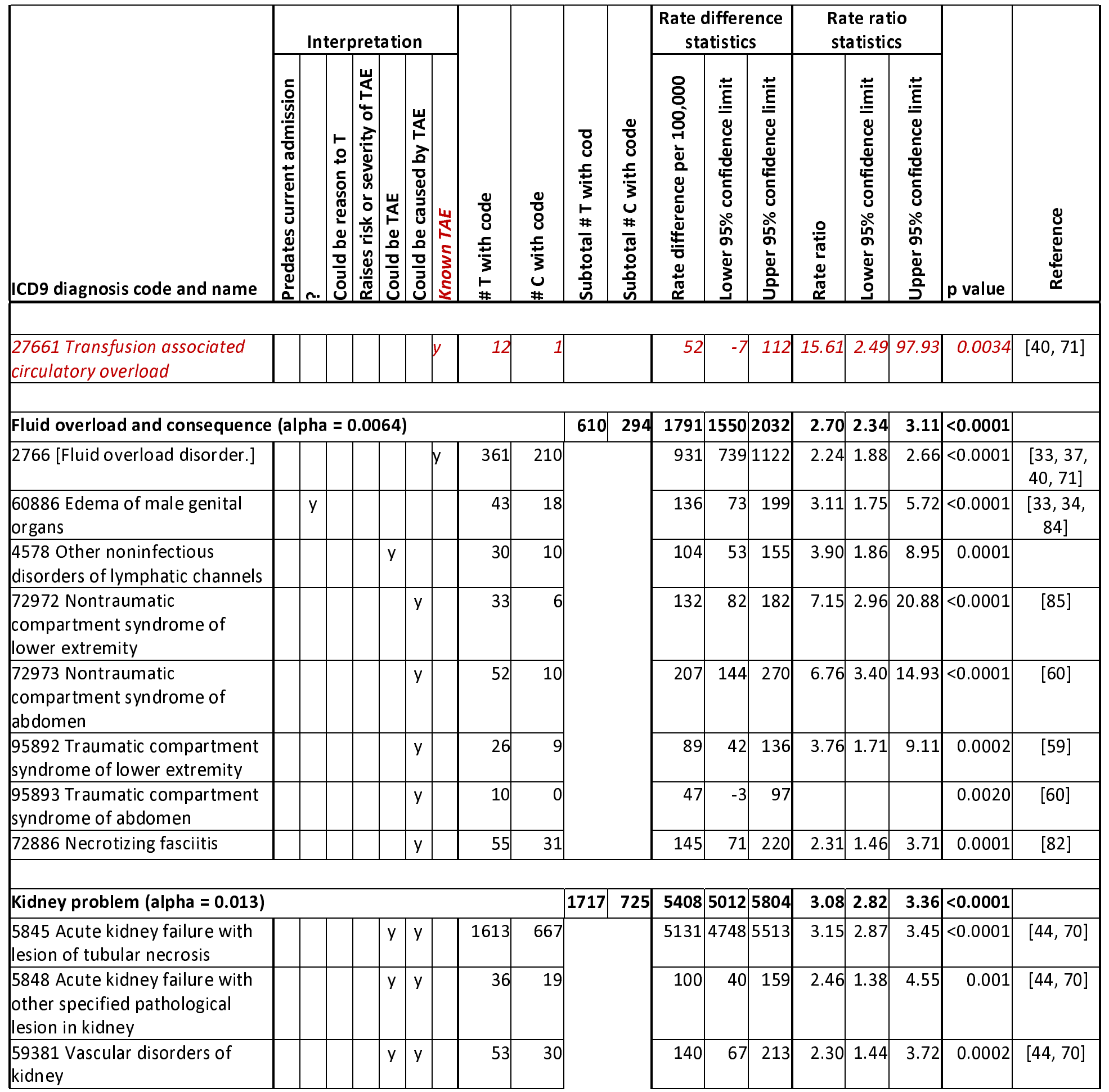


medRxiv preprint doi: https://doi.org/10.1101/2020.12.30.20218610; this version posted January 4, 2021. The copyright holder for this preprint (which was not certified by peer review) is the author/funder, who has granted medRxiv a license to display the preprint in perpetuity.

This article is a US Government work. It is not subject to copyright under 17 USC 105 and is also made available for use under a CCO license.

\begin{tabular}{|c|c|c|c|c|c|c|c|c|c|c|c|c|c|c|c|c|c|c|}
\hline \multirow[b]{2}{*}{ ICD9 diagnosis code and name } & \multicolumn{6}{|c|}{ Interpretation } & \multirow[b]{2}{*}{ 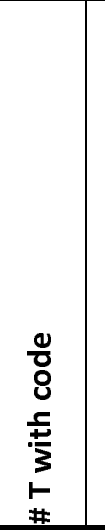 } & \multirow[b]{2}{*}{ 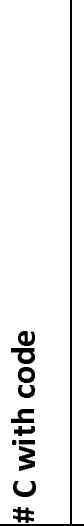 } & \multirow[b]{2}{*}{ 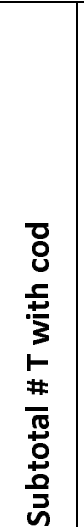 } & \multirow[b]{2}{*}{ 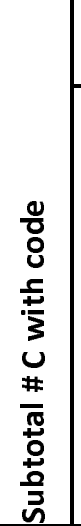 } & \multicolumn{3}{|c|}{$\begin{array}{c}\text { Rate difference } \\
\text { statistics }\end{array}$} & \multicolumn{3}{|c|}{$\begin{array}{c}\text { Rate ratio } \\
\text { statistics }\end{array}$} & \multirow[b]{2}{*}{$p$ value } & \multirow[b]{2}{*}{ 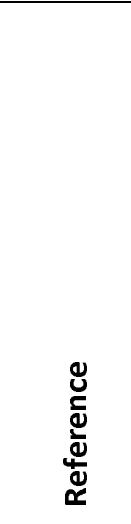 } \\
\hline & 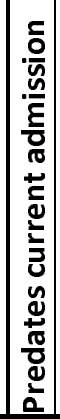 & & \begin{tabular}{l|l} 
& \\
\\
\\
\end{tabular} & 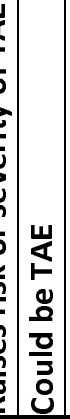 & 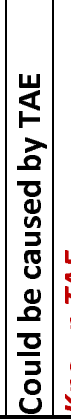 & $\begin{array}{l}\text { w } \\
\mathbf{5} \\
\mathbf{5} \\
\mathbf{5} \\
\text { s. }\end{array}$ & & & & & 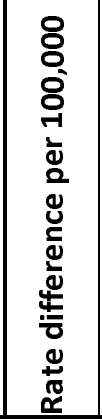 & 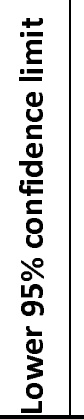 & 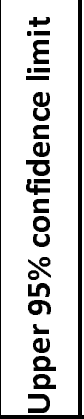 & 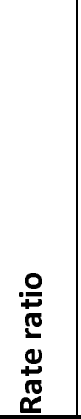 & 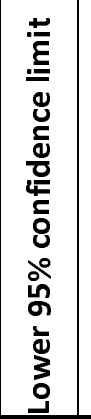 & 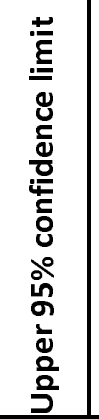 & & \\
\hline $\begin{array}{l}86601 \text { Injury to kidney without } \\
\text { mention of open wound into } \\
\text { cavity, hematoma without } \\
\text { rupture of capsule }\end{array}$ & & & & $y$ & $\mathrm{y}$ & & 15 & 9 & & & 38 & -2 & 77 & 2.17 & 0.89 & 5.60 & 0.06 & {$[44,70]$} \\
\hline \multicolumn{9}{|c|}{ Disorders of urinary system other than kidneys (alpha $=0.017$ ) } & 346 & 149 & 1079 & \multicolumn{2}{|c|}{9011258} & 3.02 & 2.49 & 3.68 & $<0.0001$ & \\
\hline $\begin{array}{l}5933 \text { Stricture or kinking of } \\
\text { ureter }\end{array}$ & & $\mathrm{y}$ & & & & & 23 & & & & 89 & 1 & 178 & 5.98 & 2.09 & 17.13 & 0.0009 & {$[33,34]$} \\
\hline 59582 Irradiation cystitis & & & & & $y$ & & 15 & 8 & & & 41 & 3 & 80 & 2.44 & 0.97 & 6.64 & 0.035 & [43] \\
\hline $\begin{array}{l}9975 \text { Urinary complications, not } \\
\text { elsewhere classified }\end{array}$ & & $y$ & & & & & 308 & 136 & & & 949 & 780 & 1118 & 2.95 & 2.40 & 3.63 & $<0.0001$ & \\
\hline
\end{tabular}


medRxiv preprint doi: https://doi.org/10.1101/2020.12.30.20218610; this version posted January 4, 2021. The copyright holder for this preprint (which was not certified by peer review) is the author/funder, who has granted medRxiv a license to display the preprint in perpetuity.

This article is a US Government work. It is not subject to copyright under 17 USC 105 and is also made available for use under a CCO license.

Table 8. Analysis of $\mathrm{T}$ (transfusion) and $\mathrm{C}$ (comparison) groups for digestion and hormones diagnosis codes. If all diagnoses in the table are dependent, alpha is 0.00071. Bracketed diagnosis code names were not in the MIMIC-III database, therefore were looked up [30] and confirmed in some notes.

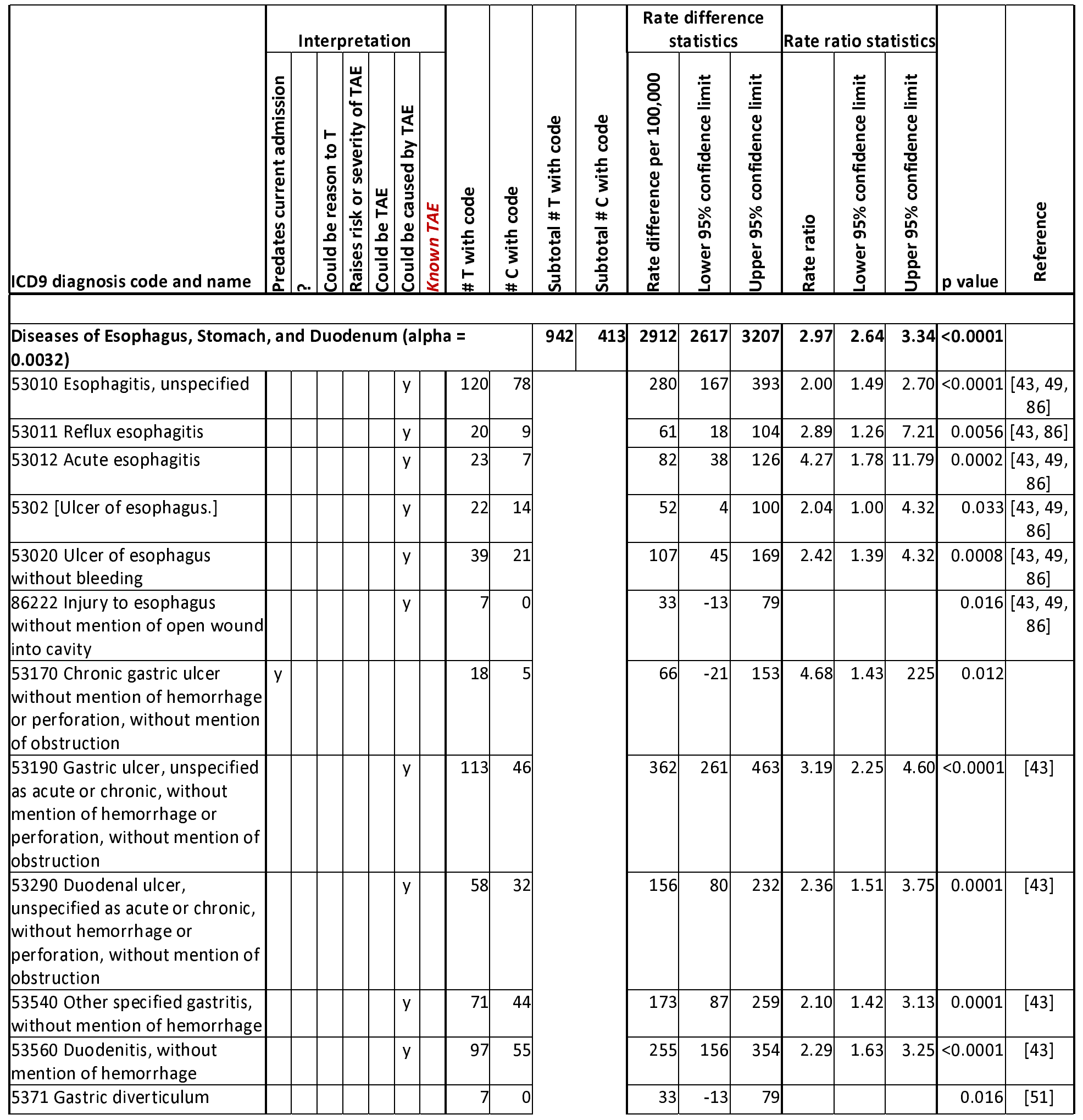


medRxiv preprint doi: https://doi.org/10.1101/2020.12.30.20218610; this version posted January 4, 2021. The copyright holder for this preprint (which was not certified by peer review) is the author/funder, who has granted medRxiv a license to display the preprint in perpetuity. This article is a US Government work. It is not subject to copyright under 17 USC 105 and is also made available for use under a CCO license.

\begin{tabular}{|c|c|c|c|c|c|c|c|c|c|c|c|c|c|c|c|c|c|}
\hline \multirow[b]{2}{*}{ ICD9 diagnosis code and name } & \multicolumn{5}{|c|}{ Interpretation } & \multirow[b]{2}{*}{ 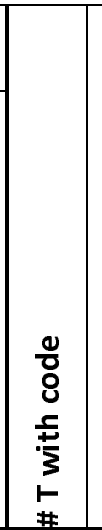 } & \multirow[b]{2}{*}{ 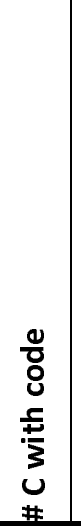 } & \multirow[b]{2}{*}{ 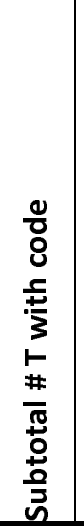 } & \multirow[b]{2}{*}{ 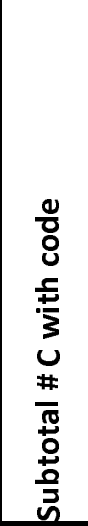 } & \multicolumn{3}{|c|}{$\begin{array}{l}\text { Rate difference } \\
\text { statistics }\end{array}$} & \multicolumn{3}{|c|}{ Rate ratio statistics } & \multirow[b]{2}{*}{$p$ value } & \multirow[b]{2}{*}{ 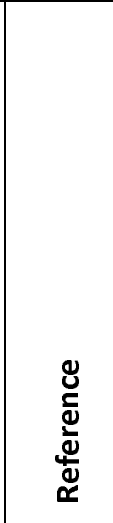 } \\
\hline & 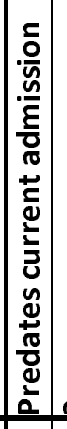 & 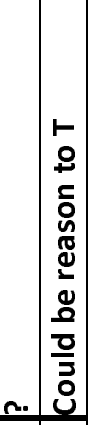 & 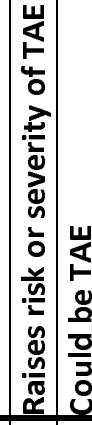 & 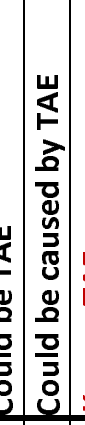 & 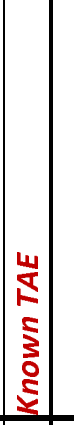 & & & & & 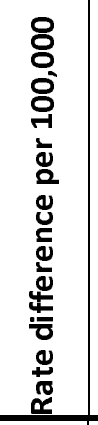 & 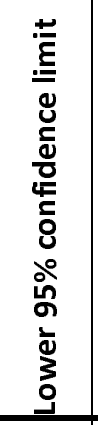 & 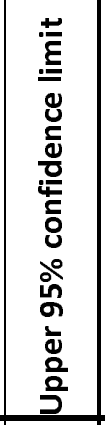 & 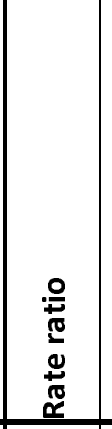 & 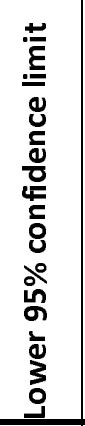 & 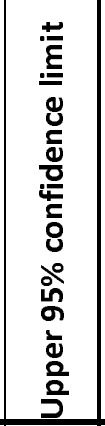 & & \\
\hline \begin{tabular}{|l|}
5374 Fistula of stomach or \\
duodenum
\end{tabular} & & $y$ & & & & 21 & 4 & & & 84 & 1 & 166 & 6.83 & 2.20 & 225 & 0.0009 & {$[33,34]$} \\
\hline $\begin{array}{l}53782 \text { Angiodysplasia of } \\
\text { stomach and duodenum } \\
\text { without mention of hemorrhage }\end{array}$ & & $y$ & & & & 42 & 11 & & & 156 & 98 & 215 & 4.97 & 2.51 & 10.70 & $<0.0001$ & {$[52]$} \\
\hline $\begin{array}{l}53789 \text { Other specified disorders } \\
\text { of stomach and duodenum }\end{array}$ & & & & $y$ & & 259 & 78 & & & 928 & 781 & 1075 & 4.32 & 3.34 & 5.64 & $<0.0001$ & [86] \\
\hline $\begin{array}{l}379 \text { Unspecified disorder of } \\
\text { stomach and duodenum }\end{array}$ & & & & $y$ & & 25 & 9 & & & 84 & 38 & 131 & 3.61 & 1.63 & 8.80 & \begin{tabular}{|l|}
0.0004 \\
\end{tabular} & [86] \\
\hline \multicolumn{8}{|c|}{$\begin{array}{l}\text { Small and large intestine, rectum, and anus disorders (alpha = } \\
0.0030)\end{array}$} & 2304 & 1228 & 6341 & 5865 & 6818 & 2.44 & 2.28 & 2.62 & $<0.0001$ & \\
\hline $\begin{array}{l}5552 \text { Regional enteritis of small } \\
\text { intestine with large intestine }\end{array}$ & & & & $y$ & & 21 & 11 & & & 58 & 13 & 104 & 2.48 & 1.14 & 5.70 & 0.012 & [43] \\
\hline $\begin{array}{l}56210 \text { Diverticulosis of colon } \\
\text { (without mention of } \\
\text { hemorrhage) }\end{array}$ & $y$ & & & & & 471 & 365 & & & 888 & 656 & 1120 & 1.68 & 1.46 & 1.93 & $<0.0001$ & \\
\hline \begin{tabular}{|l|}
5570 Acute vascular \\
insufficiency of intestine
\end{tabular} & & $y$ & & & & 371 & 123 & & & 1289 & 1111 & 1467 & 3.92 & 3.19 & 4.85 & $<0.0001$ & $\begin{array}{c}{[37,40,} \\
46]\end{array}$ \\
\hline $\begin{array}{l}5571 \text { Chronic vascular } \\
\text { insufficiency of intestine }\end{array}$ & $y$ & & & & & 96 & 29 & & & 344 & 254 & 433 & 4.31 & 2.82 & 6.77 & $<0.0001$ & $\begin{array}{c}37,40, \\
46]\end{array}$ \\
\hline $\begin{array}{l}5579 \text { Unspecified vascular } \\
\text { insufficiency of intestine }\end{array}$ & & $y$ & & & & 92 & 48 & & & 257 & 162 & 352 & 2.49 & 1.74 & 3.61 & $<0.0001$ & $\begin{array}{c}{[37,40,} \\
46]\end{array}$ \\
\hline 5601 Paralytic ileus & & & & $y$ & & 662 & 390 & & & 1689 & 1429 & 1949 & 2.21 & 1.95 & 2.51 & $<0.0001$ & {$[37,86]$} \\
\hline 5650 Anal fissure & & $\mathrm{y}$ & & & & 15 & 8 & & & 41 & 3 & 80 & 2.44 & 0.97 & 6.64 & 0.035 & {$[52]$} \\
\hline 5690 Anal and rectal polyp & & $y$ & & & & 13 & 2 & & & 53 & -14 & 121 & 8.45 & 1.77 & 225 & 0.0074 & $\begin{array}{l}{[33,34} \\
40,54] \\
\end{array}$ \\
\hline 56941 Ulcer of anus and rectum & & $y$ & & & & 39 & 11 & & & 142 & 86 & 199 & 4.61 & 2.32 & 9.98 & $<0.0001$ & {$[52]$} \\
\hline $\begin{array}{l}56949 \text { Other specified disorders } \\
\text { of rectum and anus }\end{array}$ & & $\mathrm{y}$ & & & & 39 & 17 & & & 121 & 61 & 181 & 2.98 & 1.65 & 5.62 & 0.0001 & \\
\hline $\begin{array}{l}56981 \text { Fistula of intestine, } \\
\text { excluding rectum and anus }\end{array}$ & & $y$ & & & & 119 & 52 & & & 368 & 264 & 473 & 2.98 & 2.13 & 4.21 & $<0.0001$ & {$[33,34]$} \\
\hline 56982 Ulceration of intestine & & $y$ & & & & 41 & 10 & & & 155 & 98 & 213 & 5.33 & 2.63 & 11.94 & $<0.0001$ & {$[33,34$} \\
\hline 56983 Perforation of intestine & & $y$ & & & & 158 & 72 & & & 479 & 357 & 600 & 2.85 & 2.15 & 3.83 & $<0.0001$ & $\begin{array}{l}{[33,34} \\
37,52]\end{array}$ \\
\hline $\begin{array}{l}56984 \text { Angiodysplasia of } \\
\text { intestine (without mention of } \\
\text { hemorrhage) }\end{array}$ & & $y$ & & & & 23 & 6 & & & 86 & 43 & 129 & 4.99 & 1.97 & 14.97 & $<0.0001$ & {$[52]$} \\
\hline
\end{tabular}


medRxiv preprint doi: https://doi.org/10.1101/2020.12.30.20218610; this version posted January 4, 2021. The copyright holder for this preprint (which was not certified by peer review) is the author/funder, who has granted medRxiv a license to display the preprint in perpetuity. This article is a US Government work. It is not subject to copyright under 17 USC 105 and is also made available for use under a CCO license.

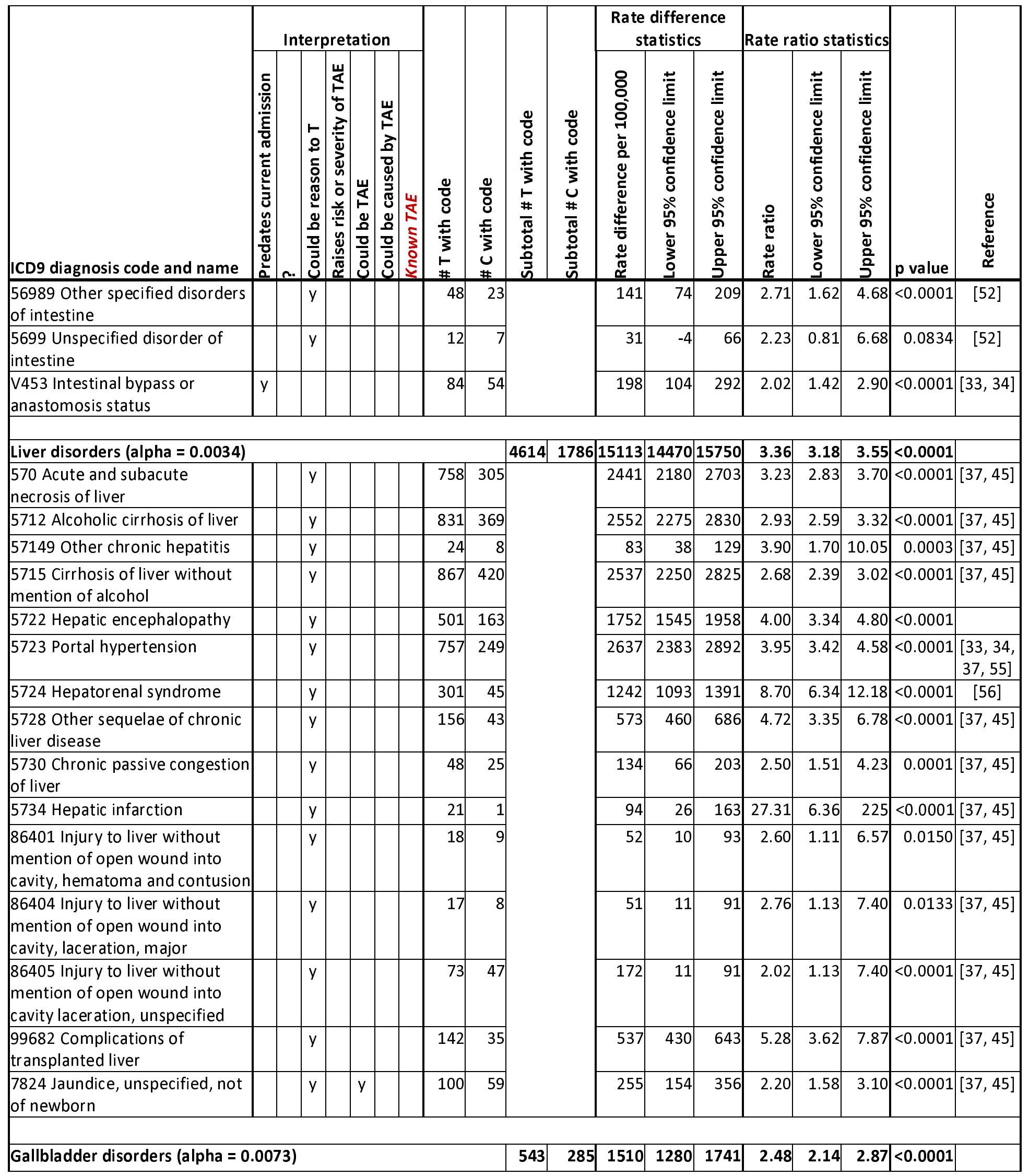


medRxiv preprint doi: https://doi.org/10.1101/2020.12.30.20218610; this version posted January 4, 2021. The copyright holder for this preprint (which was not certified by peer review) is the author/funder, who has granted medRxiv a license to display the preprint in perpetuity. This article is a US Government work. It is not subject to copyright under 17 USC 105 and is also made available for use under a CCO license.

\begin{tabular}{|c|c|c|c|c|c|c|c|c|c|c|c|c|c|c|c|c|c|}
\hline \multirow[b]{2}{*}{ ICD9 diagnosis code and name } & \multicolumn{5}{|c|}{ Interpretation } & \multirow[b]{2}{*}{ 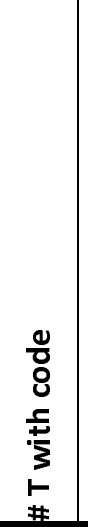 } & \multirow[b]{2}{*}{ 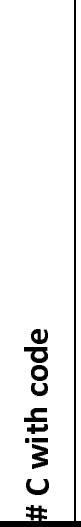 } & \multirow[b]{2}{*}{ 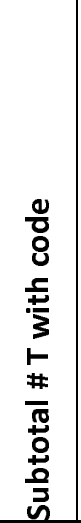 } & \multirow[b]{2}{*}{ 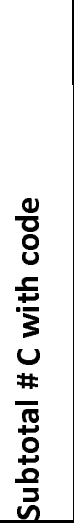 } & \multicolumn{3}{|c|}{$\begin{array}{l}\text { Rate difference } \\
\text { statistics }\end{array}$} & \multicolumn{3}{|c|}{ Rate ratio statistics } & \multirow[b]{2}{*}{$p$ value } & \multirow[b]{2}{*}{ 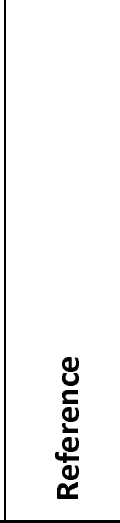 } \\
\hline & 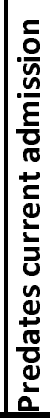 & م. & 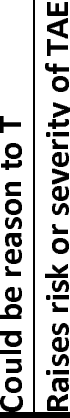 & 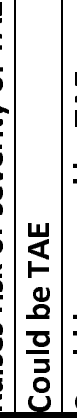 & 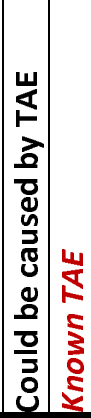 & & & & & 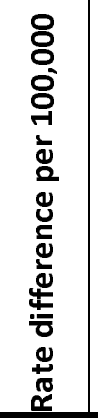 & 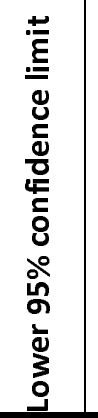 & 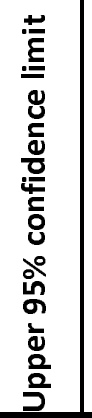 & 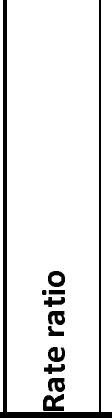 & 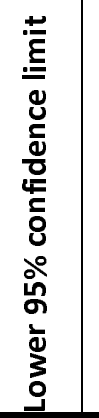 & 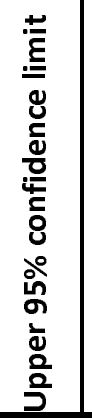 & & \\
\hline $\begin{array}{l}57410 \text { Calculus of gallbladder } \\
\text { with other cholecystitis, without } \\
\text { mention of obstruction }\end{array}$ & $y$ & & & & & 107 & 60 & & & 284 & 180 & 387 & 2.32 & 1.68 & 3.24 & $+<0.0001$ & \\
\hline 5750 Acute cholecystitis & & & & & $y$ & 115 & 61 & & & 318 & 211 & 424 & 2.45 & 1.78 & 3.40 & $<0.0001$ & {$[43,86]$} \\
\hline 57510 Cholecystitis, unspecified & & & & & $y$ & 24 & 13 & & & 65 & 17 & 114 & 2.40 & 1.18 & 5.14 & 0.0086 & {$[43,86]$} \\
\hline 57511 Chronic cholecystitis & $y$ & & & & & 80 & 36 & & & 244 & 158 & 330 & 2.89 & 1.93 & 4.41 & $<0.0001$ & {$[43,86]$} \\
\hline $\begin{array}{l}57512 \text { Acute and chronic } \\
\text { cholecystitis }\end{array}$ & $y$ & & & & $y$ & 22 & 13 & & & 56 & 9 & 103 & 2.20 & 1.06 & 4.76 & 0.021 & {$[43,86]$} \\
\hline $\begin{array}{l}5768 \text { Other specified disorders } \\
\text { of biliary tract }\end{array}$ & & & y & & & 181 & 95 & & & 503 & 370 & 637 & 2.48 & 1.92 & 3.21 & $<0.0001$ & \\
\hline $\begin{array}{l}57490 \text { Calculus of gallbladder } \\
\text { and bile duct without } \\
\text { cholecystitis, without mention } \\
\text { of obstruction }\end{array}$ & $y$ & & & & & 14 & 7 & & & 40 & 3 & 77 & 2.60 & 0.98 & 7.62 & 0.032 & \\
\hline \multicolumn{8}{|c|}{ Nonspecific digestive disorders (alpha $=0.025$ ) } & 587 & 272 & 1762 & 1527 & 1997 & 2.81 & 2.43 & 3.25 & $<0.0001$ & \\
\hline $\begin{array}{l}9974 \text { [Digestive system } \\
\text { complications not elsewhere } \\
\text { classified.] }\end{array}$ & & $\mathrm{y}$ & & & & 513 & 235 & & & 1550 & 1331 & 1769 & 2.84 & 1.78 & 2.37 & $<0.0001$ & \\
\hline $\begin{array}{l}99749 \text { Other digestive system } \\
\text { complications }\end{array}$ & & $\mathrm{y}$ & & & & 74 & 37 & & & 212 & 128 & 297 & 2.60 & 1.73 & 3.97 & $<0.0001$ & \\
\hline \multicolumn{8}{|c|}{ Abdominal non-organ disorders (alpha $=0.0051$ ) } & 1814 & 713 & 5903 & 5500 & 6306 & 3.31 & 3.03 & 3.61 & $<0.0001$ & \\
\hline $\begin{array}{l}5672 \text { [Other suppurative } \\
\text { peritonitis.] }\end{array}$ & & & & & $y$ & 181 & 36 & & & 715 & 597 & 833 & 6.54 & 4.55 & 9.63 & $<0.0001$ & [43] \\
\hline $\begin{array}{l}56721 \text { Peritonitis (acute) } \\
\text { generalized }\end{array}$ & & & & & y & 60 & 27 & & & 183 & 108 & 258 & 2.89 & 1.81 & 4.74 & $<0.0001$ & [43] \\
\hline $\begin{array}{l}56729 \text { Other suppurative } \\
\text { peritonitis }\end{array}$ & & & & & y & 90 & 38 & & & 283 & 193 & 374 & 3.08 & 2.09 & 4.63 & $<0.0001$ & [43] \\
\hline $\begin{array}{l}5678 \text { [Other specified } \\
\text { peritonitis.] }\end{array}$ & & & & & $y$ & 27 & 5 & & & 108 & 17 & 199 & 7.02 & 2.63 & 225 & 0.0001 & [43] \\
\hline 56781 Choleperitonitis & & & & & $y$ & 16 & 4 & & & 60 & -21 & 141 & 5.20 & 1.44 & 225 & 0.0118 & [43] \\
\hline $\begin{array}{l}56789 \text { Other specified } \\
\text { peritonitis }\end{array}$ & & & & & $y$ & 25 & 9 & & & 84 & 38 & 131 & 3.61 & 1.63 & 8.80 & $<0.0001$ & [43] \\
\hline 5679 Unspecified peritonitis & & & & & $y$ & 62 & 31 & & & 178 & 101 & 255 & 2.60 & 1.66 & 4.14 & $<0.0001$ & [43] \\
\hline $\begin{array}{l}5680 \text { Peritoneal adhesions } \\
\text { (postoperative) (postinfection) }\end{array}$ & $y$ & & & & & 275 & 129 & & & 820 & 659 & 981 & 2.77 & 2.24 & 3.44 & $<0.0001$ & \\
\hline
\end{tabular}




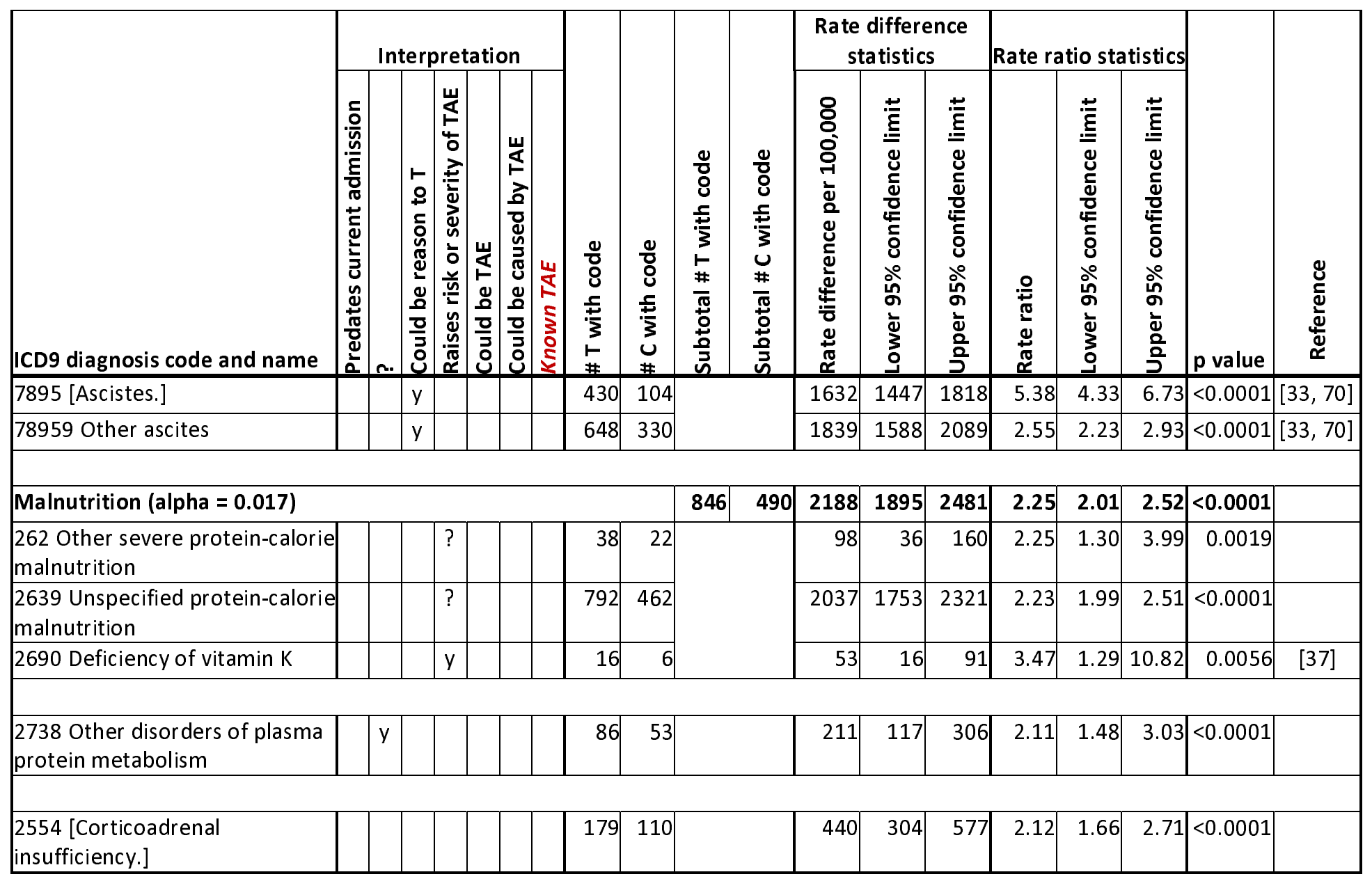


medRxiv preprint doi: https://doi.org/10.1101/2020.12.30.20218610; this version posted January 4, 2021. The copyright holder for this preprint (which was not certified by peer review) is the author/funder, who has granted medRxiv a license to display the preprint in perpetuity.

This article is a US Government work. It is not subject to copyright under 17 USC 105 and is also made available for use under a CCO license.

Table 9. Analysis of $\mathrm{T}$ (transfusion) and C (comparison) groups for connective, nervous, and reproductive diagnosis codes. If all diagnoses in the table are dependent, alpha is 0.0023. TAE: transfusion adverse event. Bracketed diagnosis code names were not in the MIMIC-III database, therefore were looked up [30] and confirmed in some notes.

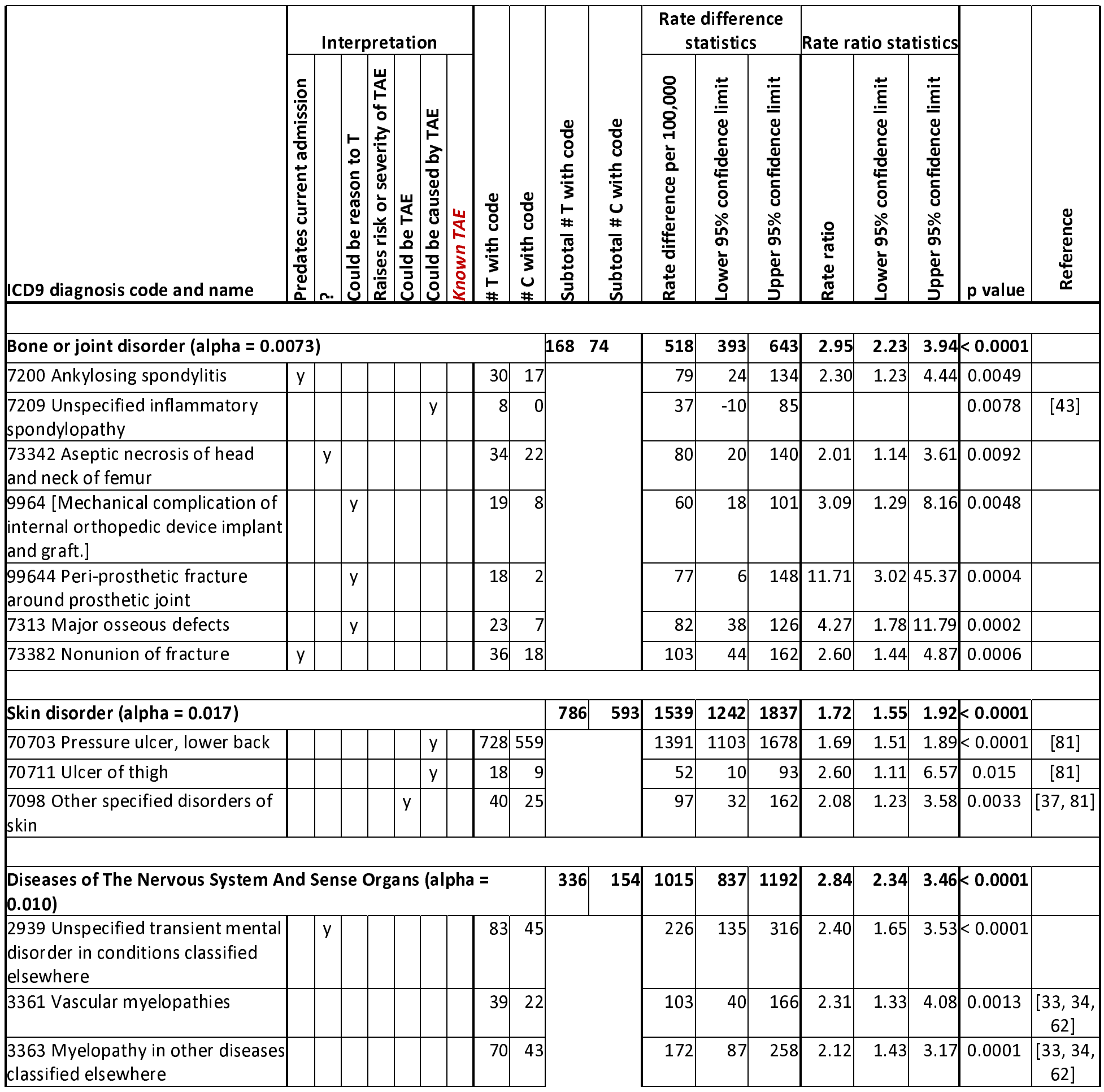


medRxiv preprint doi: https://doi.org/10.1101/2020.12.30.20218610; this version posted January 4, 2021. The copyright holder for this preprint (which was not certified by peer review) is the author/funder, who has granted medRxiv a license to display the preprint in perpetuity.

This article is a US Government work. It is not subject to copyright under 17 USC 105 and is also made available for use under a CCO license.

\begin{tabular}{|c|c|c|c|c|c|c|c|c|c|c|c|c|c|c|c|c|c|c|}
\hline \multirow[b]{2}{*}{ ICD9 diagnosis code and name } & \multicolumn{6}{|c|}{ Interpretation } & & \multirow[b]{2}{*}{ 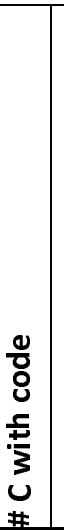 } & \multirow[b]{2}{*}{ 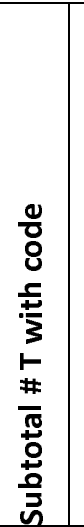 } & \multirow[b]{2}{*}{ 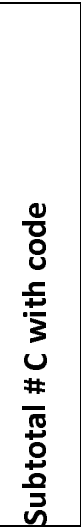 } & \multicolumn{3}{|c|}{$\begin{array}{l}\text { Rate difference } \\
\text { statistics }\end{array}$} & \multicolumn{3}{|c|}{ Rate ratio statistics } & \multirow[b]{2}{*}{$p$ value } & \multirow[b]{2}{*}{ 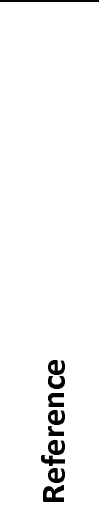 } \\
\hline & 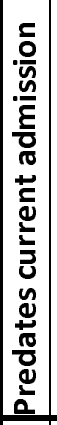 & م. & 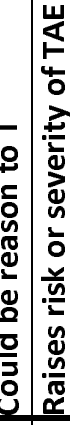 & 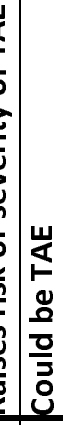 & 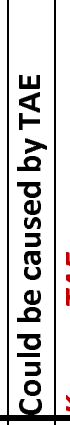 & & & & & & 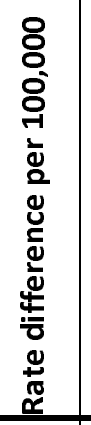 & 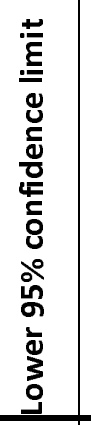 & 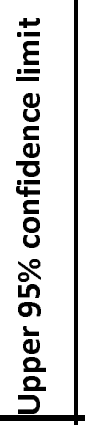 & 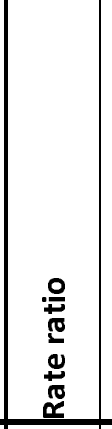 & 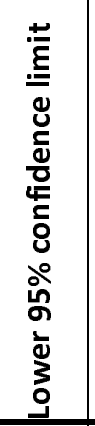 & 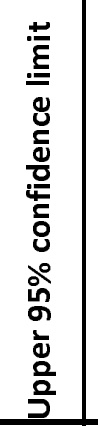 & & \\
\hline $\begin{array}{l}\text { E9359 Unspecified analgesic and } \\
\text { antipyretic causing adverse effects } \\
\text { in therapeutic use }\end{array}$ & & & & & & & 108 & 33 & & & 385 & 290 & 481 & 4.26 & 2.86 & 6.49 & $<0.0001$ & \\
\hline 35981 Critical illness myopathy & & & & $\mathrm{y}$ & $\mathrm{y}$ & & 36 & 11 & & & 128 & 74 & 183 & 4.26 & 2.12 & 9.27 & $<0.0001$ & {$[36,43]$} \\
\hline \multicolumn{9}{|c|}{ Diseases of The Genitourinary System (alpha $=0.017$ ) } & 68 & 36 & 188 & 106 & 270 & 2.46 & 1.62 & $3.79 k$ & $<0.0001$ & \\
\hline $\begin{array}{l}605 \text { Redundant prepuce and } \\
\text { phimosis }\end{array}$ & & & & & & & 17 & 11 & & & 40 & -3 & 82 & 2.01 & 0.89 & 4.75 & 0.0656 & \\
\hline $\begin{array}{l}6146 \text { Pelvic peritoneal adhesions, } \\
\text { female (postoperative) } \\
\text { (postinfection) }\end{array}$ & & & & & $y$ & & 22 & 10 & & & 67 & 21 & 112 & 2.86 & 1.30 & 6.77 & 0.0039 & [43] \\
\hline $\begin{array}{l}6238 \text { Other specified } \\
\text { noninflammatory disorders of } \\
\text { vagina }\end{array}$ & & $y$ & & & & & 29 & 15 & & & 81 & 28 & 135 & 2.51 & 1.30 & 5.05 & 0.0027 & \\
\hline \multicolumn{9}{|c|}{$\begin{array}{l}\text { Complications of Pregnancy, Childbirth, and the Puerperium } \\
\text { (alpha }=0.013 \text { ) }\end{array}$} & 62 & 15 & 235 & 165 & 306 & 5.38 & 3.02 & 10.18 & $<0.0001$ & \\
\hline $\begin{array}{l}64891 \text { Other current conditions } \\
\text { classifiable elsewhere of mother, } \\
\text { delivered, with or without } \\
\text { mention of antepartum condition }\end{array}$ & & & & & & & 17 & 5 & & & 61 & -26 & 149 & 4.42 & 1.30 & 14.99 & 0.0169 & \\
\hline $\begin{array}{l}65421 \text { Previous cesarean delivery, } \\
\text { delivered, with or without } \\
\text { mention of antepartum condition }\end{array}$ & y & & & & & & 10 & 2 & & & 39 & -26 & 105 & 6.50 & 1.10 & 38.43 & 0.0385 & \\
\hline $\begin{array}{l}67432 \text { Other complications of } \\
\text { obstetrical surgical wounds, } \\
\text { delivered, with mention of } \\
\text { postpartum complication }\end{array}$ & & & & $y$ & & & 6 & 0 & & & 28 & -17 & 73 & & & & 0.0312 & [48] \\
\hline $\begin{array}{l}\text { V270 Outcome of delivery, single } \\
\text { liveborn }\end{array}$ & & & y & & & & 29 & 8 & & & 107 & 58 & 155 & 4.71 & 2.10 & $11.94 \mathrm{~K}$ & $<0.0001$ & \\
\hline
\end{tabular}


medRxiv preprint doi: https://doi.org/10.1101/2020.12.30.20218610; this version posted January 4, 2021. The copyright holder for this preprint (which was not certified by peer review) is the author/funder, who has granted medRxiv a license to display the preprint in perpetuity.

This article is a US Government work. It is not subject to copyright under 17 USC 105 and is also made available for use under a CCO license.

Table 10. Comparison of MIMIC-III diagnoses of TAEs (transfusion adverse events) with published Medicare data from varying time periods 2007-2012. The expected number applies the rate found in Medicare data to the study $T$ (transfusion) group.

\begin{tabular}{|c|c|c|c|c|c|c|}
\hline \multirow[b]{2}{*}{$\begin{array}{l}\text { Transfusion adverse } \\
\text { event (TAE) }\end{array}$} & \multirow[b]{2}{*}{$\begin{array}{l}\text { \# TAE } \\
\text { in T }\end{array}$} & \multicolumn{3}{|c|}{ Medicare data } & \multirow[b]{2}{*}{$\begin{array}{l}\text { Expected } \\
\quad \# \text { in } \mathrm{T}\end{array}$} & \multirow{2}{*}{$\begin{array}{c}\text { Fisher's } \\
\text { exact test } \\
\text { (FET) p value }\end{array}$} \\
\hline & & $\begin{array}{c}\text { \# TAE/ } \\
\text { \# transfused }\end{array}$ & $\begin{array}{c}\text { Calendar } \\
\text { years }\end{array}$ & Reference & & \\
\hline $\begin{array}{l}\text { Tranfusion related } \\
\text { acute lung injury } \\
\text { (TRALI) }\end{array}$ & 0 & $\begin{array}{c}2556 / \\
11,378,264\end{array}$ & $2007-2011$ & [20] & 4.8 & 0.019 \\
\hline $\begin{array}{l}\text { Transfusion } \\
\text { associated circulatory } \\
\text { overload (TACO) }\end{array}$ & 12 & $\begin{array}{c}1340 / \\
2,147,038\end{array}$ & 2011 & [19] & 13.4 & 0.089 \\
\hline $\begin{array}{l}\text { Posttransfusion } \\
\text { purpura }\end{array}$ & 0 & $\begin{array}{c}78 / \\
4,336,338\end{array}$ & $2011-2012$ & [89] & 0.39 & 1 \\
\hline $\begin{array}{l}\text { Febrile non- } \\
\text { haemolytic } \\
\text { transfusion reaction }\end{array}$ & 3 & $\begin{array}{c}2517 / \\
4,336,338\end{array}$ & 2011-2012 & [90] & 12.5 & 0.004 \\
\hline
\end{tabular}


medRxiv preprint doi: https://doi.org/10.1101/2020.12.30.20218610; this version posted January 4, 2021. The copyright holder for this preprint (which was not certified by peer review) is the author/funder, who has granted medRxiv a license to display the preprint in perpetuity. This article is a US Government work. It is not subject to copyright under 17 USC 105 and is also made available for use under a CCO license.

\section{REFERENCES}

1. Brewer T, Colditz GA. Postmarketing surveillance and adverse drug reactions: current perspectives and future needs. JAMA. 1999 Mar 3;281(9):824-9. PMID:10071004. DOI: 10.1001/jama.281.9.824.

2. Scott HD, Thacher-Renshaw A, Rosenbaum SE, et al. Physician reporting of adverse drug reactions: Results of the Rhode Island Adverse Drug Reaction Reporting Project. JAMA 1990;263:1785-1788. PMID:2313850.

3. Hoang T, Liu J, Pratt N, et al. Authenticity and credibility aware detection of adverse drug events from social media. Int J Med Inform. 2018Dec;120:101-115. PMID:30409335.

DOI:10.1016/j.jjmedinf.2018.09.002.

4. Bright RA, Nelson RC. Automated support for pharmacovigilance: a proposed system.

Pharmacoepidemiol and Drug Safety. 2002;11(2):121-125. PMID: 11998536. DOI:10.1002/pds.684.

5. Samore MH, Evans RS, Lassen A, et al. Surveillance of medical device-related hazards and adverse events in hospitalized patients. JAMA 2004;291:325-34. PMID: 14734595.

DOI:10.1001/jama.291.3.325.

6. Bright RA. Strategy for surveillance of adverse drug events. Food Drug Law J 2007;62(3):605-615. PMID:17915403.

7. Classen D, Li M, Miller S, Ladner D. An electronic health record-based real-time analytics program for patient safety surveillance and improvement. Health Aff (Millwood). 2018Nov;37(11):1805-1812. PMID: 30395491. DOI:10.1377/hlthaff.2018.0728.

8. Wang L, Rastegar-Mojarad M, Ji Z, et al. Detecting pharmacovigilance signals combining electronic medical records with spontaneous reports: a case study of conventional disease-modifying antirheumatic drugs for rheumatoid arthritis. Front Pharmacol. 2018Aug7;9:875. PMID:30131701. DOI:10.3389/fphar.2018.00875.

9. Alghamdi AA, Keers RN, Sutherland A, Ashcroft DM. Prevalence and nature of medication errors and preventable adverse drug events in paediatric and neonatal intensive care settings: a systematic review. Drug Saf. 2019Dec;42(12):1423-1436. PMID:31410745. DOI:10.1007/s40264-019-00856-9.

10. Molina FJ, Rivera PT, Cardona A, et al. Adverse events in critical care: Search and active detection through the trigger tool. World J Crit Care Med. 2018Feb4;7(1):9-15. PMID:29430403.

DOI:10.5492/wjccm.v7.i1.9. 
medRxiv preprint doi: https://doi.org/10.1101/2020.12.30.20218610; this version posted January 4, 2021. The copyright holder for this preprint

(which was not certified by peer review) is the author/funder, who has granted medRxiv a license to display the preprint in perpetuity.

This article is a US Government work. It is not subject to copyright under 17 USC 105 and is also made available for use under a CCO license.

11. Report to Congress: Update on the adoption of health information technology and related efforts to facilitate the electronic use and exchange of health information. Office of the National Coordinator for Health Information Technology, US Department of Health and Human Services. 2016 Feb.

https://www.healthit.gov/sites/default/files/Attachment_1_-_2-26-

16_RTC_Health_IT_Progress.pdf.

12. Melton GB, Hripcsak G. Automated detection of adverse events using natural language processing of discharge summaries. J Am Med Inform Assoc. 2005;12:448-457. PMID:15802475.

DOI:10.1197/jamia.M1794.

13. Classen D, Li M, Miller S, Ladner D. An electronic health record-based real-time analytics program for patient safety surveillance and improvement. Health Aff (Millwood). 2018Nov;37(11):1805-1812. PMID:30395491. DOI:10.1377/hlthaff.2018.0728.

14. Patadia VK, Schuemie MJ, Coloma PM, et al. Can electronic health records databases complement spontaneous reporting system databases? A historical-reconstruction of the association of rofecoxib and acute myocardial infarction. Front Pharmacol. 2018Jun 6;9:594. PMID:29928230.

DOI:10.3389/fphar.2018.00594.

15. Zhou L, Siddiqui T, Seliger SL, et al. Text preprocessing for improving hypoglycemia detection from clinical notes - A case study of patients with diabetes. Int J Med Inform. 2019Sep;129:374-380. PMID:31445280. DOI:10.1016/j.ijmedinf.2019.06.020.

16. Dejam A, Malley BE, Feng M, et al. The effect of age and clinical circumstances on the outcome of red blood cell transfusion in critically ill patients. Crit Care 2014;18(4):487. PMID:25175389. DOI:10.1186/s13054-014-0487-z.

17. Carson JL, Grossman BJ, Kleinman, S, et al. Red blood cell transfusion: a clinical practice guideline from the AABB. Ann Intern Med. 2012; 57:49-58. PMID:22751760. DOI:10.7326/0003-4819-157-1201206190-00429.

18. Holness L, Knippen MA, Simmons L, Lachenbruch PA. Fatalities caused by TRALI. Transfus Med Rev. 2004;18(3):184-188. PMID:15248168. DOI:10.1016/j.tmrv.2004.03.004.

19. Menis M, Anderson SA, Forshee RA, et al. Transfusion-associated circulatory overload (TACO) and potential risk factors among the inpatient US elderly as recorded in Medicare administrative databases during 2011. Vox Sang. 2014Feb;106(2):144-52. PMID:23848234. DOI:10.1111/vox.12070. 
medRxiv preprint doi: https://doi.org/10.1101/2020.12.30.20218610; this version posted January 4, 2021. The copyright holder for this preprint

(which was not certified by peer review) is the author/funder, who has granted medRxiv a license to display the preprint in perpetuity.

This article is a US Government work. It is not subject to copyright under 17 USC 105 and is also made available for use under a CCO license.

20. Menis M, Anderson SA, Forshee RA, et al. Transfusion-related acute lung injury and potential risk factors among the inpatient US elderly as recorded in Medicare claims data, during 2007 through 2011. Transfusion. 2014;54:2182-2193. PMID:24673344 DOI:10.1111/trf.12626.

21. Reardon JM, Harmon KJ, Schult GC, Staton CA, Waller AE. Use of diagnosis codes for detection of clinically significant opioid poisoning in the emergency department: A retrospective analysis of a surveillance case definition. BMC Emerg Med. 2016Feb8;16:11. PMID:26856978.

DOI:10.1186/s12873-016-0075-4.

22. Hargrove J, Waller A. Motor vehicle crash case definitions and how they impact injury surveillance. $N$ C Med J. 2018Nov-Dec;79(6):351-357. PMID: 30397080. DOI:10.18043/ncm.79.6.351.

23. Wiese AD, Griffin MR, Stein CM, et al. Validation of discharge diagnosis codes to identify serious infections among middle age and older adults. BMJ Open. 2018Jun19;8(6):e020857. PMID:29921683. DOI:10.1136/bmjopen-2017-020857.

24. Johnson AEW, Pollard TJ, Shen L, et al. MIMIC-III, a freely accessible critical care database. Sci Data. 2016;3:160035. PMID: 27219127. DOI:10.1038/sdata.2016.35.

25. MIMIC-III Critical Care Database. https://mimic.physionet.org/about/mimic/.

26. Code of Federal Regulations Title 45 Part 46 Protection of Human Subjects, Subpart A-Basic HHS Policy for Protection of Human Research Subjects, §46.101 (b) (4). 2000 Oct 1. https://www.govinfo.gov/content/pkg/CFR-2000-title45-vol1/pdf/CFR-2000-title45-vol1-part46.pdf.

27. Slee VN. The International Classification of Diseases: Ninth Revision (ICD-9). Ann Intern Med. 1978;88(3):424-426. PMID:629506. DOI:10.7326/0003-4819-88-3-424.

28. Statistical functions (scipy.stats). The SciPy Community. 2019. https://docs.scipy.org/doc/scipy/reference/stats.html.

29. Pandas. Python Software Foundation. https://pypi.org/project/pandas/.

30. The Web's Free ICD-9-CM Medical Coding Reference. ICD9Data.com. http://www.icd9data.com/.

31. Comparison of two rates. MedCalc Software Ltd. 2020.

https://www.scistat.com/statisticaltests/rate comparison.php.

32. Altman DG, Bland JM. How to obtain the confidence interval from a P value. BMJ 2011;343-344. PMID:21824904. DOI:10.1136/bmj.d2090. 
medRxiv preprint doi: https://doi.org/10.1101/2020.12.30.20218610; this version posted January 4, 2021. The copyright holder for this preprint (which was not certified by peer review) is the author/funder, who has granted medRxiv a license to display the preprint in perpetuity. This article is a US Government work. It is not subject to copyright under 17 USC 105 and is also made available for use under a CCO license.

33. Stanworth SJ, Tinmouth AT. Plasma transfusion and use of albumin. IN: Simon TL, Snyder EL, Solheim BG, et al, eds. Rossi's Principles of Transfusion Medicine, $4^{\text {th }}$ ed. Blackwell Publishing Ltd. 2009;287297. ISBN:978-1-444-35886-5.

34. Omi EC, Gamelli RL. Transfusion therapy in the care of trauma and burn patients. IN: Simon TL, Snyder EL, Solheim BG, et al, eds. Rossi's Principles of Transfusion Medicine, 4th ed. Blackwell Publishing Ltd. 2009;589-603. ISBN:978-1-444-35886-5.

35. Arnold DM, Smith JW, Warkentin TE. Management of immune thrombocytopenia. IN: Simon TL, Snyder EL, Solheim BG, et al, eds. Rossi's Principles of Transfusion Medicine, 4th ed. Blackwell Publishing Ltd. 2009;344-375. ISBN:978-1-444-35886-5.

36. Juffermans NP, Walsh TS. Introduction. IN: Juffermans NP, Walsh TS, eds. Transfusion in the Intensive Care Unit. Springer, NY, 2015;1. DOI:10.1007/978-3-319-08735-1_1.

37. Kennedy MS, Wu HM. Transfusion therapy and transfusion in transplantation. IN: Harmening D, ed. Modern Blood Banking and Transfusion Practices, 5th ed. F.A. Davis Company, Philadelphia, 2005;303-321. ISBN:9780803612488.

38. Carvalho B, Quiney NF. 'Near-miss' hyperkalaemic cardiac arrest associated with rapid blood transfusion. Anaesthesia. 1999Nov;54(11):1094-6. PMID:10540099. DOI:10.1046/j.13652044.1999.01109.x.

39. Heafner T, Bews K, Kalra M, et al. Transfusion timing and postoperative myocardial infarction and death in patients undergoing common vascular procedures. Ann Vasc Surg. 2019. PMID:31626929. DOI:10.1016/j.avsg.2019.08.090.

40. Schmidt AE, Refaai MA, Blumberg N. Platelet transfusion and thrombosis: More questions than answers. Semin Thromb Hemost. 2016 Mar;42(2):118-24. PMID:26716501. DOI:10.1055/s-00351564833.

41. Chang S-L, Huang Y-L, Lee M-C, et al. Association of varicose veins with incident venous thromboembolism and peripheral artery disease. JAMA. 2018; 319(8):807-817. PMID:29486040. DOI:10.1001/jama.2018.0246.

42. Rossetti A, Buchs NC, Breguet R, et al. Transarterial embolization in acute colonic bleeding: review of 11 years of experience and long-term results. Int J Colorectal Dis. 2013Jun;28(6):777-82. PMID:23208010. DOI:10.1007/s00384-012-1621-5. 
medRxiv preprint doi: https://doi.org/10.1101/2020.12.30.20218610; this version posted January 4, 2021. The copyright holder for this preprint

(which was not certified by peer review) is the author/funder, who has granted medRxiv a license to display the preprint in perpetuity.

This article is a US Government work. It is not subject to copyright under 17 USC 105 and is also made available for use under a CCO license.

43. Vamvakas EC, Bordin JO, Blajchman MA. Immunomodularity and proinflammatory effects of allogeneic blood transfusion. IN: Simon TL, Snyder EL, Solheim BG, et al, eds. Rossi's Principles of Transfusion Medicine, 4th ed. Blackwell Publishing Ltd. 2009;699-717. ISBN:978-1-444-35886-5.

44. Davenport RD. Hemolytic transfusion reactions. IN: Simon TL, Snyder EL, Solheim BG, et al, eds. Rossi's Principles of Transfusion Medicine, 4th ed. Blackwell Publishing Ltd. 2009;811- 825. ISBN:9781-444-35886-5.

45. Raife TJ, Rose JS, Lentz SR. Bleeding from acquired coagulation defects and antithrombotic therapy. IN: Simon TL, Snyder EL, Solheim BG, et al, eds. Rossi's Principles of Transfusion Medicine, 4th ed. Blackwell Publishing Ltd. 2009;376-390. ISBN:978-1-444-35886-5.

46. Debus ES, Mueller-Huelsbeck S, Koelbel T, Larena-Avellaneda A. Intestinal ischemia. Int J Colorectal Dis. 2011 Sep;26(9):1087-97. PMID: 21541663 DOI:10.1007/s00384-011-1196-6.

47. Marks PW. Thrombocytopenia and platelet transfusion. IN: Simon TL, Snyder EL, Solheim BG, et al, eds. Rossi's Principles of Transfusion Medicine, 4th ed. Blackwell Publishing Ltd. 2009;199-210. ISBN:978-1-444-35886-5.

48. Carson JL, Hébert P. Anemia and red blood cell transfusion. IN: Simon TL, Snyder EL, Solheim BG, et al, eds. Rossi's Principles of Transfusion Medicine, $4^{\text {th }}$ ed. Blackwell Publishing Ltd. 2009;131-148. ISBN:978-1-444-35886-5.

49. Halaweh O, Usmani SZ, Abouasaleh R. Barrett's esophagitis related bronchoesophageal fistula - the diagnostic value of persistent air leak in the ventilated setting. Mcgill J Med 2007; 10(2):96-98. PMID: 18523545. https://www.ncbi.nlm.nih.gov/pmc/articles/PMC2323478/.

50. Shears M, Alhazzani W, Marshall JC, et al. Stress ulcer prophylaxis in critical illness: a Canadian survey. Can J Anaesth. 2016Jun; 63(6):718-724. PMID:26911559. DOI:10.1007/s12630-016-0612-3.

51. Rashid F, Aber A, Iftikhar SY. A review on gastric diverticulum. World J Emerg Surg. 2012;7:1. PMID: 22257431. DOI:10.1186/1749-7922-7-1.

52. Warkentin TE, Moore JC, Anand SS, et al. Gastrointestinal bleeding, angiodysplasia, cardiovascular disease, and acquired von Willebrand syndrome. Transfus Med Rev. 2003;17(4):272-286. PMID:14571395. DOI: 10.1016/S0887-7963(03)00037-3.

53. Ivascu FA, Janczyk RJ, Bair HA, Bendick PJ, Howells GA. Spontaneous retroperitoneal hemorrhage. Am J Surg. 2005;189(3):345-347. PMID:15792766. DOI:10.1016/j.amjsurg.2004.11.020. 
medRxiv preprint doi: https://doi.org/10.1101/2020.12.30.20218610; this version posted January 4, 2021. The copyright holder for this preprint (which was not certified by peer review) is the author/funder, who has granted medRxiv a license to display the preprint in perpetuity. This article is a US Government work. It is not subject to copyright under 17 USC 105 and is also made available for use under a CCO license.

54. Wang CY, Won CW, Shieh MJ. Aggressive colonoscopic approaches to lower intestinal bleeding. Gastroenterol Jpn. 1991;26:125-128. PMID:1884944. DOI:10.1007/BF02779280.

55. Bacon BR. Cirrhosis and its complications. In: Jameson JL, Fauci AS, Kasper DL, et al, eds. Harrison's Principles of Internal Medicine, 20th ed. McGraw-Hill Medical. ISBN:978-1-259-64404-7. Accessed 2019. https://accessmedicine. mhmedical.com/content.aspx?bookid=2129\&sectionid=192283819.

56. Briglia AE, Anania FA. Hepatorenal syndrome: Definition, pathophysiology, and intervention. Crit Care Clin. 2002 Apr;18(2):345-73. PMID:12053838. DOI:10.1016/s0749-0704(01)00003-3.

57. Morgan DJ, Kellerman R. Epistaxis: evaluation and treatment. Prim Care. 2014 Mar;41(1):63-73. PMID:24439881. DOI: 10.1016/j.pop.2013.10.007.

58. Ittrich H, Bockhorn M, Klose H, Simon M. The diagnosis and treatment of hemoptysis. Dtsch Arzteb/ Int. 2017Jun; 114(21):371-381. PMID:28625277. DOI: 10.3238/arztebl.2017.0371.

59. Gourgiotis S, Villias C, Germanos S, et al. Acute limb compartment syndrome: A review. J Surg Education. 2007; 64(3):178-186. PMID:17574182. DOI:10.1016/j.jsurg.2007.03.006.

60. Sosa G, Gandham N, Landeras V, et al. Abdominal compartment syndrome. Dis Mon. 2019 Jan;65(1):5-19. PMID:30454823. DOI:10.1016/j.disamonth.2018.04.003.

61. Selvan K, Edriss H, Sigler M, Nugent KM. Complications and resource utilization associated with mechanical ventilation in a medical intensive care unit in 2013. J Intensive Care Med. 2017 Feb; 32(2):146-150. PMID:26474803. DOI: 10.1177/0885066615612413.

62. Rabinstein AA. Vascular myelopathies. Continuum (Minneap Minn). 2015 Feb;21(1 Spinal Cord Disorders):67-83. PMID:25651218. DOI:10.1212/01.CON.0000461085.79241.e0.

63. Radford MJ, Johnson RA, Daggett WM Jr, et al. Ventricular septal rupture: a review of clinical and physiologic features and an analysis of survival. Circulation. 1981;64(3):545-53. PMID: 7020978. DOI: 10.1161/01.cir.64.3.545.

64. Sheth S. Transfusional iron overload. IN: Simon TL, Snyder EL, Solheim BG, et al, eds. Rossi's Principles of Transfusion Medicine, 4th ed. Blackwell Publishing Ltd. 2009;858-869. ISBN:978-1-44435886-5.

65. Sharma S, Sharma P, Tyler LN. Transfusion of blood and blood products: indications and complications. Am Fam Physician. 2011 Mar 15;83(6):719-24. PMID: 21404983. https://www.aafp.org/afp/2011/0315/p719.html. 
medRxiv preprint doi: https://doi.org/10.1101/2020.12.30.20218610; this version posted January 4, 2021. The copyright holder for this preprint

(which was not certified by peer review) is the author/funder, who has granted medRxiv a license to display the preprint in perpetuity.

This article is a US Government work. It is not subject to copyright under 17 USC 105 and is also made available for use under a CCO license.

66. Harmening DM, Steffey NB, Prihoda LA, Green REB. Autoimmune hemolytic anemias. IN: Harmening D, ed. Modern Blood Banking and Transfusion Practices, 5th ed. F.A. Davis Company, Philadelphia, 2005;396-430. ISBN:9780803612488.

67. Duffy TP. Autoimmune hemolytic anemia and paroxysmal nocturnal hemoglobinuria. IN: Simon TL, Snyder EL, Solheim BG, et al, eds. Rossi's Principles of Transfusion Medicine, 4th ed. Blackwell Publishing Ltd. 2009;321-343. ISBN:978-1-444-35886-5.

68. Gibson C, Berliner N. How we evaluate and treat neutropenia in adults. Blood. 2014Aug;124(8):12518. PMID:24869938. DOI:10.1182/blood-2014-02-482612.

69. Hellstern P. Composition and mechanisms of blood coagulation and fibrinolysis. IN: Simon TL, Snyder EL, Solheim BG, et al, eds. Rossi's Principles of Transfusion Medicine, 4th ed. Blackwell Publishing Ltd. 2009;247-259. ISBN:978-1-444-35886-5.

70. Tormey CA, Edward L. Snyder EL. Transfusion support for the oncology patient. IN: Simon TL, Snyder EL, Solheim BG, et al, eds. Rossi's Principles of Transfusion Medicine, 4th ed. Blackwell Publishing Ltd. 2009;482-497. ISBN:978-1-444-35886-5.

71. Pomper GJ. Febrile, allergic, and nonimmune transfusion reactions. IN: Simon TL, Snyder EL, Solheim BG, et al, eds. Rossi's Principles of Transfusion Medicine, 4th ed. Blackwell Publishing Ltd. 2009;826846. ISBN:978-1-444-35886-5.

72. Wallis JP, Sachs UJH. Transfusion-related acute lung injury. IN: Simon TL, Snyder EL, Solheim BG, et al, eds. Rossi's Principles of Transfusion Medicine, 4th ed. Blackwell Publishing Ltd. 2009;870-884. ISBN:978-1-444-35886-5.

73. Vianna NJ. Lymphoreticular Malignancies: Epidemiologic and Related Aspects. Medical \& Technical Publishing Co. Ltd, Lancaster, UK, 1975; ISBN:839108133.

74. Muslimani A, Chisti MM, Nadeau L, et al. How we treat tumor lysis syndrome. Oncology J 2011;25(4):369-75. PMID:21618960. https://www.cancernetwork.com/view/how-we-treat-tumorlysis-syndrome.

75. Park YA, Brecher ME. Bacterial contamination of blood products. IN: Simon TL, Snyder EL, Solheim BG, et al, eds. Rossi's Principles of Transfusion Medicine, 4th ed. Blackwell Publishing Ltd. 2009;771790. ISBN:978-1-444-35886-5. 
medRxiv preprint doi: https://doi.org/10.1101/2020.12.30.20218610; this version posted January 4, 2021. The copyright holder for this preprint

(which was not certified by peer review) is the author/funder, who has granted medRxiv a license to display the preprint in perpetuity.

This article is a US Government work. It is not subject to copyright under 17 USC 105 and is also made available for use under a CCO license.

76. Cook LO, Wise SC, Larison PJ. Adverse effects of blood transfusion. IN: Harmening D, ed. Modern Blood Banking and Transfusion Practices, 5th ed. F.A. Davis Company, Philadelphia, 2005;336-358. ISBN:9780803612488.

77. Alter HJ, Esteban-Mur JI. Transfusion-transmitted hepatitis. IN: Simon TL, Snyder EL, Solheim BG, et al, eds. Rossi's Principles of Transfusion Medicine, 4th ed. Blackwell Publishing Ltd. 2009;718-745. ISBN:978-1-444-35886-5.

78. Barbara JAJ, Dow BC. Retroviruses and other viruses. IN: Simon TL, Snyder EL, Solheim BG, et al, eds. Rossi's Principles of Transfusion Medicine, 4th ed. Blackwell Publishing Ltd. 2009;746-759. ISBN:9781-444-35886-5.

79. Williams EF, Jarreau PC, Zitzmann MP. Transfusion-transmitted disease. IN: Harmening D, ed. Modern Blood Banking and Transfusion Practices, 5th ed. F.A. Davis Company, Philadelphia, 2005;359-382. ISBN:9780803612488.

80. Finley C, Clifton J, FitzGerald JM, Yee J. Empyema: An increasing concern in Canada. Can Respir J. 2008 Mar; 15(2): 85-89. PMID:18354748. DOI:10.1155/2008/975312.

81. Kalanuria AA, Ziai W, Mirski M. Ventilator-associated pneumonia in the ICU. Crit Care. 2014; 18(2): 208. PMID:25029020. DOI:10.1186/cc13775.

82. Wang J-M, Lim H_K. Necrotizing fasciitis: eight-year experience and literature review. Braz J Infect Dis. 2014;18 (2):137-143. PMID:24275377. DOI:10.1016/j.bjid.2013.08.003.

83. Cross MR, Greenwald MF, Dahhan A. Esophageal perforation and acute bacterial mediastinitis: Other causes of chest pain that can be easily missed. Medicine (Baltimore). 2015 Aug; 94(32): e1232. PMID: 26266352. DOI:10.1097/MD.0000000000001232.

84. Cheville AL, McGarvey CL, et al. Lymphedema management. Semin Radiat Oncol. 2003 Jul;13(3):290301. PMID:12903017. DOI:10.1016/S1053-4296(03)00035-3.

85. Karaoren G, Bakan N, Tomruk SG, et al. Bilaterally symmetrical lower extremity compartment syndrome following massive transfusion. Case Rep Orthop. 2016;2016:2718421. PMID:26885421. DOI: $10.1155 / 2016 / 2718421$.

86. Mutlu GM, Mutlu EA, Factor P. GI complications in patients receiving mechanical ventilation. Chest. 2001 Apr;119(4):1222-41. PMID:11296191. DOI:10.1378/chest.119.4.1222. 
medRxiv preprint doi: https://doi.org/10.1101/2020.12.30.20218610; this version posted January 4, 2021. The copyright holder for this preprint

(which was not certified by peer review) is the author/funder, who has granted medRxiv a license to display the preprint in perpetuity.

This article is a US Government work. It is not subject to copyright under 17 USC 105 and is also made available for use under a CCO license.

87. Stangroom J. Easy Fisher exact test calculator. Social Science Statistics. 2020.

https://www.socscistatistics.com/tests/fisher/default2.aspx.

88. Dunn 0J. Confidence intervals for the means of dependent, normally distributed variables. J Am Stat Assoc. 1959;54:613-21. https://www.jstor.org/stable/pdf/2282541.pdf.

89. Menis M, Forshee RA, Anderson SA, et al. Posttransfusion purpura occurrence and potential risk factors among the inpatient US elderly, as recorded in large Medicare databases during 2011 through 2012. Transfusion 2015:55:284-295. PMID:25065878. DOI:10.1111/trf.12782.

90. Menis M, Forshee RA, Anderson SA, et al. Febrile non-haemolytic transfusion reaction occurrence and potential risk factors among the U.S. elderly transfused in the inpatient setting, as recorded in Medicare databases during 2011-2012. Vox Sang. 2015;108:251-261. PMID: 25470076.

DOI:10.1111/vox.12215.

91. Bates DW, Cullen DJ, Laird N. et al. Incidence of adverse drug events and potential adverse drug events: implications for prevention. JAMA.1995;274:29-34. PMID:7791255.

DOI:10.1001/jama.1995.03530010043033.

92. Kane-Gill SL, Kirisci L, Verrico MM, Rothschild JM. Analysis of risk factors for adverse drug events in critically ill patients. Crit Care Med. 2012;40(3):823-828. PMID:22036859.

DOI:10.1097/CCM.0b013e318236f473.

93. Rivkees SA, Szarfman A. Dissimilar hepatotoxicity profiles of propylthiouracil and methimazole in children. JClin Endocrinol Metab. 2010Jul;95(7):3260-3267. PMID:20427502. DOI:10.1210/jc.20092546. 


\section{Appendix to \\ Bright et al, "Use of Diagnosis Codes for Blood Transfusion Adverse Events in Electronic Health Records"}

Table A1. Codes for definitions of T (transfused) and Excluded groups. See main paper for methods.

\begin{tabular}{|c|c|c|c|}
\hline Group & ICD9 code & Item code & Long name \\
\hline $\mathrm{T}$ & 9901 & & Exchange transfusion \\
\hline $\mathrm{T}$ & 9903 & & Other transfusion of whole blood \\
\hline $\mathrm{T}$ & 9904 & & Transfusion of packed cells \\
\hline $\mathrm{T}$ & 9905 & & Transfusion of platelets \\
\hline $\mathrm{T}$ & 9907 & & Transfusion of other serum \\
\hline $\mathrm{T}$ & & 783 & Blood Products \\
\hline $\mathrm{T}$ & & 5649 & PRBCS \\
\hline $\mathrm{T}$ & & 5661 & PLTS \\
\hline $\mathrm{T}$ & & 5751 & PRBCS \\
\hline $\mathrm{T}$ & & 6174 & PLT transfusion \\
\hline $\mathrm{T}$ & & 7597 & PRBC \\
\hline $\mathrm{T}$ & & 30001 & Packed 'BC's \\
\hline $\mathrm{T}$ & & 30002 & Whole Blood \\
\hline $\mathrm{T}$ & & 30004 & Washed P'BC's \\
\hline $\mathrm{T}$ & & 30005 & Fresh Frozen Plasma \\
\hline $\mathrm{T}$ & & 30006 & Platelets \\
\hline $\mathrm{T}$ & & 30103 & OR FFP \\
\hline $\mathrm{T}$ & & 30104 & OR Packed 'BC's \\
\hline$T$ & & 30105 & OR Platelets \\
\hline $\mathrm{T}$ & & 30179 & $\mathrm{P}^{\prime} \mathrm{BC} C^{\prime} \mathrm{s}$ \\
\hline $\mathrm{T}$ & & 30180 & Fresh Froz Plasma \\
\hline $\mathrm{T}$ & & 42239 & CC7 PRBC \\
\hline$T$ & & 42323 & er ffp \\
\hline $\mathrm{T}$ & & 42324 & er prbc \\
\hline $\mathrm{T}$ & & 42588 & VICU PRBC \\
\hline$T$ & & 42740 & prbc in er \\
\hline $\mathrm{T}$ & & 43009 & ffp pacu \\
\hline $\mathrm{T}$ & & 43010 & Packed cells pacu \\
\hline$T$ & & 44044 & FFP Drip \\
\hline
\end{tabular}


medRxiv preprint doi: https://doi.org/10.1101/2020.12.30.20218610; this version posted January 4, 2021. The copyright holder for this preprint (which was not certified by peer review) is the author/funder, who has granted medRxiv a license to display the preprint in perpetuity.

This article is a US Government work. It is not subject to copyright under 17 USC 105 and is also made available for use under a CCO license.

\begin{tabular}{|c|c|c|c|}
\hline Group & ICD9 code & Item code & Long name \\
\hline $\mathrm{T}$ & & 44172 & FFP GTT \\
\hline $\mathrm{T}$ & & 44236 & E.R. FFP \\
\hline $\mathrm{T}$ & & 44560 & blood \\
\hline $\mathrm{T}$ & & 44819 & FFP ON FARR 2 \\
\hline $\mathrm{T}$ & & 44905 & ed blood products \\
\hline $\mathrm{T}$ & & 45669 & ED FFP \\
\hline$T$ & & 46122 & ER in FFP \\
\hline$T$ & & 46124 & er in prbc \\
\hline $\mathrm{T}$ & & 46407 & ED PRBC \\
\hline$T$ & & 46410 & angio FFP \\
\hline $\mathrm{T}$ & & 46418 & ER ffp \\
\hline $\mathrm{T}$ & & 46530 & Floor FFP \\
\hline$T$ & & 46612 & E.R. prbc \\
\hline $\mathrm{T}$ & & 46684 & ER FFP \\
\hline$T$ & & 220969 & Filterrythrocytestes \\
\hline$T$ & & 220970 & Fresh Frozen Plasma \\
\hline $\mathrm{T}$ & & 220971 & ESDEP (Solvent / Detergent Virus-Inactivated Plasma) \\
\hline $\mathrm{T}$ & & 220972 & Octopals \\
\hline $\mathrm{T}$ & & 220996 & Packed Red Cells \\
\hline $\mathrm{T}$ & & 221004 & Thrombocyte suspension \\
\hline $\mathrm{T}$ & & 221013 & Whole Blood \\
\hline $\mathrm{T}$ & & 225168 & Packed Red Blood Cells \\
\hline $\mathrm{T}$ & & 225170 & Platelets \\
\hline$T$ & & 226367 & OR FFP Intake \\
\hline $\mathrm{T}$ & & 226368 & OR Packed RBC Intake \\
\hline $\mathrm{T}$ & & 226369 & OR Platelet Intake \\
\hline$T$ & & 227070 & PACU Packed RBC Intake \\
\hline $\mathrm{T}$ & & 227071 & PACU Platelet Intake \\
\hline$T$ & & 227072 & PACU FFP Intake \\
\hline Excluded & 9900 & & Perioperative autologous transfusion of whole blood or blood components \\
\hline Excluded & 9902 & & Transfusion of previously collected autologous blood \\
\hline Excluded & & 30053 & Cell Saver \\
\hline Excluded & & 30092 & Autotransfusion \\
\hline Excluded & & 30094 & Other Blood Products \\
\hline Excluded & & 30106 & OR Autologous Blood \\
\hline Excluded & & 40801 & plasma pheresis \\
\hline
\end{tabular}


medRxiv preprint doi: https://doi.org/10.1101/2020.12.30.20218610; this version posted January 4, 2021. The copyright holder for this preprint (which was not certified by peer review) is the author/funder, who has granted medRxiv a license to display the preprint in perpetuity.

This article is a US Government work. It is not subject to copyright under 17 USC 105 and is also made available for use under a CCO license.

\begin{tabular}{|c|c|c|c|}
\hline Group & ICD9 code & Item code & Long name \\
\hline Excluded & & 41381 & PLASMAPHERESIS \\
\hline Excluded & & 41383 & PLASMAPHORESIS \\
\hline Excluded & & 41810 & plasmaphoresis \\
\hline Excluded & & 42538 & cell saver/or \\
\hline Excluded & & 42629 & CELL SAVER IN OR \\
\hline Excluded & & 42784 & cell saver OR \\
\hline Excluded & & 42801 & cell saver in or \\
\hline Excluded & & 42830 & OR CELL SAVER \\
\hline Excluded & & 42866 & cell saver in OR \\
\hline Excluded & & 44064 & plasma phoresis \\
\hline Excluded & & 44511 & Plasmapheresis \\
\hline Excluded & & 44515 & PLASMAPHERESIS IN \\
\hline Excluded & & 44517 & pheresis ivf \\
\hline Excluded & & 44528 & plasmapheresis \\
\hline Excluded & & 44856 & plasmaphersis \\
\hline Excluded & & 44861 & Pheresis \\
\hline Excluded & & 44873 & plasmapharesis \\
\hline Excluded & & 44878 & Pheresis Intake \\
\hline Excluded & & 44912 & pheresis. \\
\hline Excluded & & 44919 & Plasmaphoresis \\
\hline Excluded & & 45214 & OR cellsaver \\
\hline Excluded & & 45379 & OR CELL Saver \\
\hline Excluded & & 45839 & partial exchange \\
\hline Excluded & & 45878 & cellsaver \\
\hline Excluded & & 46078 & OR cell saver \\
\hline Excluded & & 46222 & Plasma pheresis \\
\hline Excluded & & 46384 & plasma pheresis in \\
\hline Excluded & & 46599 & OR Cell Saver \\
\hline Excluded & & 221193 & Auto transfusion \\
\hline Excluded & & 225173 & Cell Saver \\
\hline Excluded & & 226370 & OR Autologous Blood Intake \\
\hline Excluded & & 226372 & OR Cell Saver Intake \\
\hline Excluded & & 227532 & Plasma Pheresis \\
\hline Excluded & & 227551 & Plasma Pheresis. \\
\hline
\end{tabular}

